UNIVERSIDADE DE SÃO PAULO

FFCLRP - DEPARTAMENTO DE FÍSICA

PROGRAMA DE PÓS-GRADUAÇÃO EM FÍSICA APLICADA A MEDICINA E BIOLOGIA

Simulação Monte Carlo e avaliação das distribuições de dose de radioterapia intraoperatória para tumores mamários

Camila Eduarda Polegato Baltazar

Dissertação apresentada à Faculdade de Filosofia, Ciências e Letras de Ribeirão Preto da USP, como parte das exigências para a obtenção do título de Mestre em Ciências, Área: Radioterapia.

Ribeirão Preto - SP 
Camila Eduarda Polegato Baltazar

\title{
Simulação Monte Carlo e avaliação das distribuições de dose de radioterapia intraoperatória para tumores mamários
}

\author{
Versão corrigida \\ (Versão original encontra-se na unidade que aloja \\ o Programa de Pós-graduação)
}

Dissertação apresentada à Faculdade de Filosofia, Ciências e Letras de Ribeirão Preto da USP, como parte das exigências para a obtenção do título de Mestre em Ciências.

Área de Concentração: Radioterapia.

Orientadora: Profa Dra Patrícia Nicolucci 
Autorizo a reprodução e divulgação total ou parcial deste trabalho, por qualquer meio convencional ou eletrônico, para fins de estudo e pesquisa, desde que citada à fonte.

Catalogação da publicação

Departamento de Física

Faculdade de Filosofia, Ciências e Letras de Ribeirão Preto da

Universidade de São Paulo

Baltazar, Camila Eduarda Polegato

Simulação Monte Carlo e avaliação das distribuições de dose de radioterapia intraoperatória para tumores mamários Ribeirão Preto, 2018.

105 p.: il.; $30 \mathrm{~cm}$

Dissertação de Mestrado, apresentada ao Departamento de Física da Faculdade de Filosofia, Ciências e Letras de Ribeirão Preto/USP - Área de concentração: Física Aplicada à Medicina e Biologia.

Orientadora: Nicolucci, Patrícia.

1. Radioterapia intra-operatória. 2. Câncer de mama. 3. Simulação Monte Carlo. 4. PENELOPE. 
Nome: BALTAZAR, Camila Eduarda Polegato

Título: Simulação Monte Carlo e avaliação das distribuições de dose de radioterapia intraoperatória para tumores mamários.

Dissertação apresentada à Faculdade de Filosofia, Ciências e Letras de Ribeirão Preto da USP, como parte das exigências para a obtenção do título de Mestre em Ciências.

Aprovado em:

Banca Examinadora

Prof. Dr.

Instituição:

Julgamento:

Prof. Dr.

Instituição:

Julgamento:

Prof. Dr.

Instituiç̧ão:

Julgamento:

Prof. Dr.

Instituição:

Julgamento: 
Dedico aos meus pais e irmã, vocês merecem mais que eu. 


\section{Agradecimentos}

Agradeço a Deus, por sempre guiar meus passos.

À Profa. Drá. Patrícia Nicolucci. Obrigada pelos ensinamentos, por sua paciência e seu tempo. Obrigada por estar sempre disposta a sentar ao meu lado e me mostrar, passo por passo, qual o melhor caminho. Obrigada por ser um exemplo a ser seguido.

Aos meus pais, Luís e Shirley. Não sou nada sem vocês, e agradeço todo o investimento que puseram em mim e, principalmente, toda a paciência e carinho em meus momentos de ansiedade.

À minha irmã, obrigada por ser minha alma gêmea, e me mostrar a realidade quando estou sendo boba.

À Dra Cassiana, pelas conversas esclarecedoras, não apenas sobre física, mas sobre a vida. Obrigada por ser nossa mãe fora de casa.

A todos meus colegas de laboratório: Carol, Fernanda, Ana Luíza, Laís, Vinícius, Fernanda Ribeiro, Jaqueline, Franciely, Matheus e Miriã. Obrigada pelas opiniões durante as reuniões de grupo e por estarem lá, passando por todas as mesmas coisas, e oferecendo apoio. Sem vocês não teria sido o mesmo.

Aos professores e funcionários do Departamento de Física dessa universidade, que trabalham pela qualidade desse Programa.

E a todos que, mesmo não citados, participaram, direta ou indiretamente, do desenvolvimento desse trabalho: obrigada. 


\section{Resumo}

Baltazar, Camila Eduarda Polegato. Simulação Monte Carlo e avaliação das distribuições de dose de radioterapia intraoperatória para tumores mamários. 2018. 105f Dissertação (Mestrado em Ciências) - Departamento de Física, Faculdade de Filosofia, Ciências e Letras de Ribeirão Preto, Universidade de São Paulo, Ribeirão Preto, 2018.

Cirurgia conservadora de mama seguida de radioterapia é considerada como tratamento padrão para câncer de mama. A radioterapia intraoperatória (IORT) pode ser vantajosa, pois diminui o tempo de tratamento, geralmente de 4 a 6 semanas, para uma única fração, aplicada durante o procedimento cirúrgico. As distribuições de doses para tratamento por IORT não são bem conhecidas, pois o volume a ser irradiado é definido no momento da aplicação e não existe uma rotina de otimização do plano. Dessa forma as distribuições de dose não foram foco de estudos até o momento, de forma que torna-se interessante conhece-las. O objetivo do presente trabalho é simular e comparar as distribuições de doses para IORT com diferentes feixes e geometrias mamárias e compará-las com as distribuições obtidas para radioterapia 3D (3DR). Através do pacote de simulação Monte Carlo PENELOPE foram obtidas as distribuições de doses em técnicas radioterápicas 3DR e IORT por feixe de elétrons, gerados pelo acelerador NOVAC7, e por raios-X de baixa energia, gerado pelo acelerador Intrabeam. A validação dos feixes estudados, realizada através de comparação com dados da literatura, mostrou, para o feixe de 3DR, o perfil de dose esperado para os feixes com os filtros simulados. As maiores diferenças ocorreram nas regiões de horns, que aparecem subestimados na simulação. Para os feixes de IORT, as maiores diferenças entre simulação e literatura, de 7,79 e 8,6 pontos percentuais, respectivamente para NOVAC7 e Intrabeam, ocorrem em baixas profundidades. A simulação do tratamento para três diferentes volumes mamários gerou distribuições de doses que puderam ser usadas para comparação qualitativa entre as técnicas de tratamento. Para 3DR, as distribuições de doses mostram que parte considerável da dose é depositada no tórax. Embora as maiores doses sejam entregues dentro do volume da mama, ocorrem regiões frias dentro desse volume. As distribuições de dose obtidas para o Intrabeam mostraram que parte da dose pode ser entregue no tórax, dependendo do volume mamário e da posição do aplicador. 0 tratamento com NOVAC7 apresentou distribuições mais homogêneas dentro do volume alvo, em relação às outras técnicas. De forma geral, os resultados indicam que os tratamentos podem ser largamente influenciados pelo tamanho e posicionamento do campo para 3DR e posicionamento do aplicador para ambas as técnicas de IORT. O tratamento através do Intrabeam é comparável à 3DR. Segundo os parâmetros de avaliação do plano, IORT por feixe de elétrons proporcionaria o melhor tratamento, independentemente do volume mamário.

Palavras-chave: Radioterapia intraoperatória, câncer de mama, Simulação Monte Carlo, PENELOPE. 


\begin{abstract}
Baltazar, Camila Eduarda Polegato. Monte Carlo Simulation and dose distribution evaluation for intraoperative radiation therapy in breast cancer. 2018. 105f Dissertation (Master's) - Departamento de Física, Faculdade de Filosofia, Ciências e Letras de Ribeirão Preto, Universidade de São Paulo, Ribeirão Preto, 2018.
\end{abstract}

Conservative breast surgery followed by radiation therapy is considered the standart treatment for breast cancer. Intraoperative radiation therapy (IORT) has the advantage of decreasing the treatment duration, from the usual 4 to 6 weeks, to a single fraction, delivered during the surgical procedure. The dose distribution for treatment given through IORT are not well known, as the volume to be irradiated is defined at the moment of treatment deliver and there is not a plan optimization routine. Therefore the dose distributions were not, to the moment, the goal of any study, what makes interesting to know them. The goal of the present work is to simulate and compare the IORT dose distribution for different beams and breast geometries, and to compare to the 3D radiation therapy (3DR) dose distribution. The dose distributions for 3DR and for electron beam IORT, generated by the NOVAC7 dedicated accelerator, and for low energy x-ray IORT, generated by Intrabeam dedicated accelerator, were obtained using the Monte Carlo simulation package PENELOPE. The beams validation, performed through comparison with literature data, showed, for the 3DR beam, the dose profile expected for the simulated filters. The greatest differences occurred at the horns region, that appear sub estimated in the simulation. For IORT beams the greatest difference between simulation and literature, of 7.79 and 8.6 percentage points, respectively for the NOVAC7 and Intrabeam, occurred at low depths. The treatment simulation, with three different breast volumes, generated dose distributions that were used for a qualitative comparison of the techniques. 3DR dose distribution showed that a considerable fraction of the dose was delivered to the thorax. Although the highest doses were delivered inside the breast volume, cold regions occurred inside this volume also. Intrabeam dose distributions showed that part of the dose may be delivered to the thorax, given the breast volume and applicator position. The treatment through NOVAC7 presented more homogeneous dose distribution in relation to the other techniques. In general the results indicated that the treatment may be greatly affected by field size and position in 3DR and by the applicator position for both of the IORT techniques. Treatment through low energy $x$-ray IORT is comparable to 3DR treatment. According to the plan evaluation parameters electron beam IORT could give the best treatment for all the breast volumes evaluated.

Key words: Intraoperative radiation therapy, breast cancer, Monte Carlo simulation, PENELOPE. 


\section{Lista de Figuras}

Figura 1: Acelerador linear dedicado a IORT por feixe de elétrons NOVAC7 ..................................... 9

Figura 2: Acelerador linear dedicado a IORT por feixe de raios-X de baixa energia Intrabeam............ 10

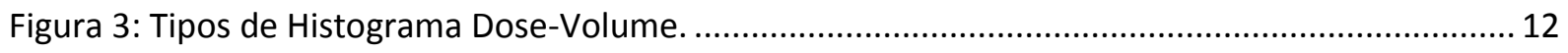

Figura 4: Comportamento ideal de histogramas dose-volume para volume alvo e órgão de risco..... 12

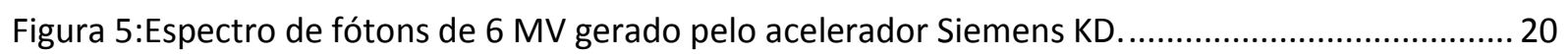

Figura 6: Geometria utilizada para simulação do filtro físico de 30 graus.......................................... 21

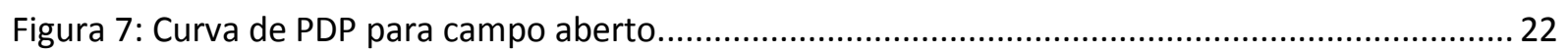

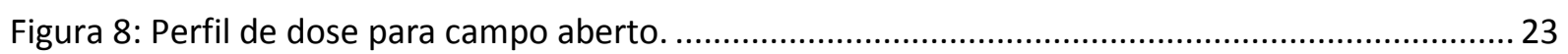

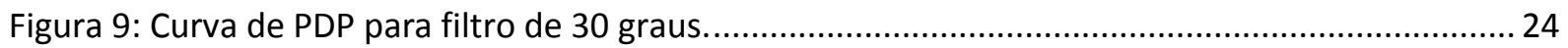

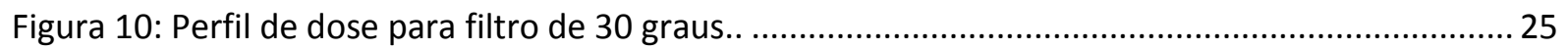

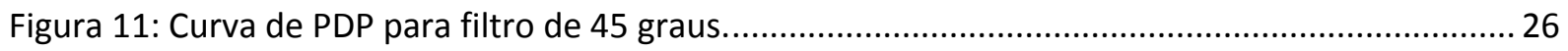

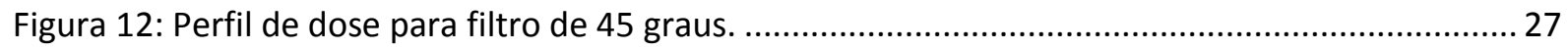

Figura 13: geometria utilizada para avaliação do espectro pós filtro. ................................................. 28

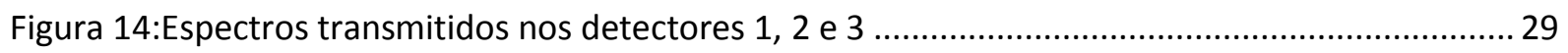

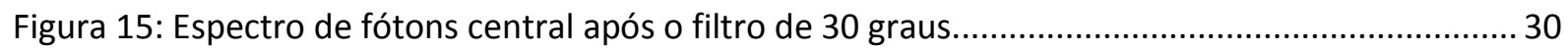

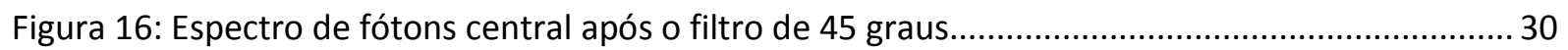

Figura 17: geometria utilizada para validação da modelagem do acelerador NOVAC7. ....................... 31

Figura 18: Espectro de elétrons gerado pelo acelerador NOVAC7 para as energias de 5, 7 e 9 MeV. 31

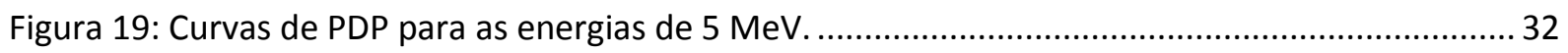

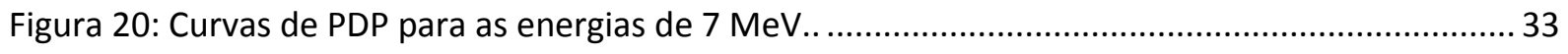

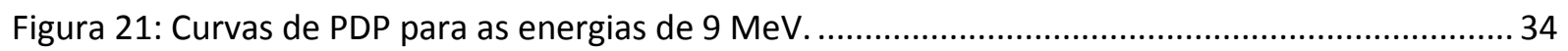

Figura 22: geometria utilizada para validação da modelagem do feixe produzido pelo acelerador

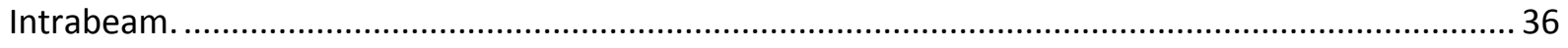

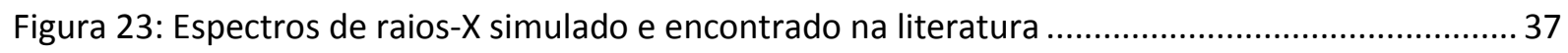

Figura 24:Curvas de PDP simulada e encontrada na literatura.......................................................... 38

Figura 25: Curva de PDP simulada com espectro onde as linhas de menor energia foram retiradas

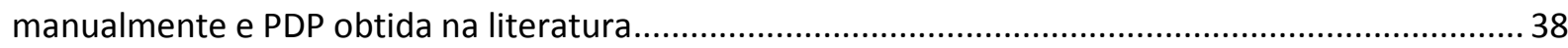

Figura 26: geometria de tórax feminino utilizada para simulação do tratamento de volume mamário

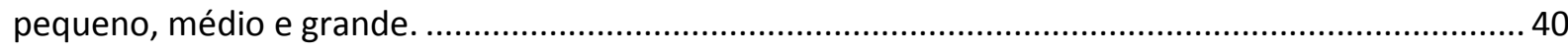

Figura 27: Distribuições de dose obtidas ao simular-se o tratamento com radioterapia 3D. .............. 42

Figura 28: geometria utilizada para simulação do tratamento com radioterapia intra-operatória por

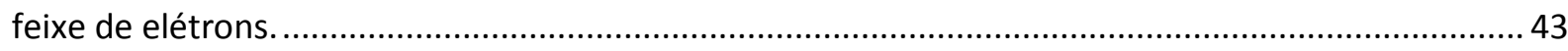

Figura 29: distribuições de dose simulação do tratamento radioterapia intra-operatória por feixe de

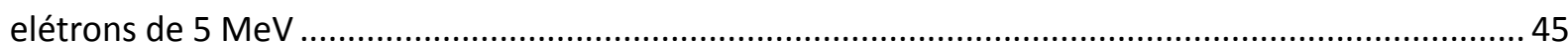

Figura 30: distribuições de dose simulação do tratamento no plano central sem angulação do aplicador - radioterapia intra-operatória por feixe de elétrons de $5 \mathrm{MeV}$......................................46 Figura 31: distribuições de dose simulação do tratamento radioterapia intra-operatória por feixe de elétrons de $7 \mathrm{MeV}$.

Figura 32: distribuições de dose simulação do tratamento no plano central sem angulação do aplicador - radioterapia intra-operatória por feixe de elétrons de $7 \mathrm{MeV}$

Figura 33: distribuições de dose simulação do tratamento radioterapia intra-operatória por feixe de elétrons de $9 \mathrm{MeV}$. 
Figura 34: distribuições de dose simulação do tratamento no plano central sem angulação do aplicador - radioterapia intra-operatória por feixe de elétrons de $9 \mathrm{MeV}$......

Figura 35: geometria utilizada para simulação do tratamento com radioterapia intra-operatória com feixe de raios- $X$ de baixa energia.

Figura 36: distribuições de dose simulação do tratamento radioterapia intra-operatória por raios-x de

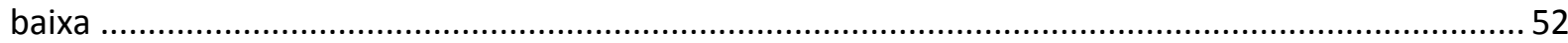

Figura 37: Distribuição de dose e curvas de isodoses no volume alvo para 3DR ................................. 54

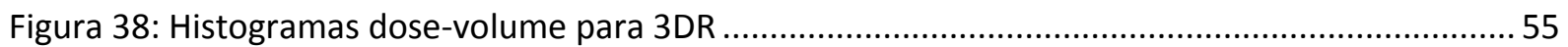

Figura 39: Distribuição de dose e curvas de isodose no volume alvo para IORT por feixe de elétrons

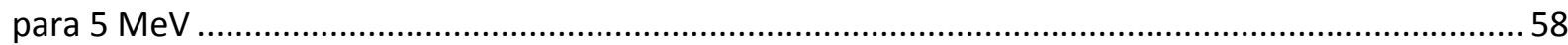

Figura 40: Histogramas dose-volume para IORT por elétrons de $5 \mathrm{MeV}$............................................ 59

Figura 41: Histogramas dose-volume completo para IORT por elétrons de $5 \mathrm{MeV}$............................. 61

Figura 42: Distribuições de dose e curvas de isodose no volume alvo para IORT por feixe de elétrons

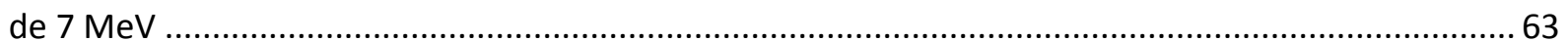

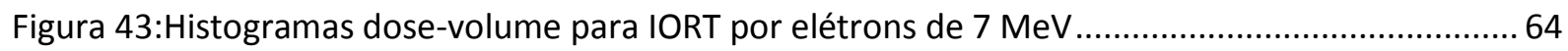

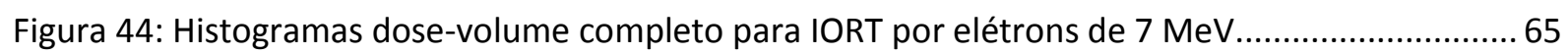

Figura 45: Distribuições de dose e curvas de isodose no volume alvo para IORT por feixe elétrons de

$9 \mathrm{MeV}$

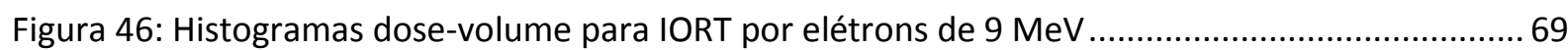

Figura 47: Histogramas dose-volume completo para IORT por elétrons de $9 \mathrm{MeV}$.............................. 70

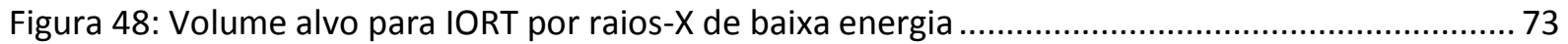

Figura 49: Histograma dose-volume para IORT por raios-X de baixa energia....................................... 74

Figura 50: Histograma dose-volume completo para IORT por raios-X de baixa energia ...................... 76

Figura 51: Histograma dose-volume para geometria de volume mamário pequeno............................ 79

Figura 52: Histograma dose-volume para geometria de volume mamário médio. ............................... 81

Figura 53: Histograma dose-volume para geometria de volume mamário grande............................... 83 


\section{Lista de Tabelas}

Tabela 1: Profundidades nas quais ocorrem doses de interesse para feixe de teleterapia convencional para campo aberto.

Tabela 2: Profundidades nas quais ocorrem doses de interesse para feixe de teleterapia convencional com filtro de 30 graus.

Tabela 3: Profundidades nas quais ocorrem doses de interesse para feixe de teleterapia convencional com filtro de 45 graus. 26

Tabela 4: Profundidades nas quais ocorrem doses de interesse para feixe de elétrons intra-operatório de $5 \mathrm{MeV}$

Tabela 5: Profundidades nas quais ocorrem doses de interesse para feixe de elétrons intra-operatório de $7 \mathrm{MeV}$

Tabela 6: Profundidades nas quais ocorrem doses de interesse para feixe de elétrons intra-operatório de $9 \mathrm{MeV}$ 35

Tabela 7: Profundidades nas quais ocorrem doses de interesse para raios- $X$ de baixa energia intraoperatório. 39

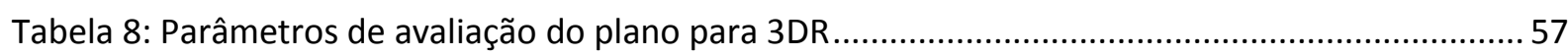

Tabela 9: Parâmetros de avaliação do plano para IORT por elétrons de $5 \mathrm{MeV}$...................................62

Tabela 10: parâmetros de avaliação da qualidade do plano para IORT por elétrons de $7 \mathrm{MeV}$...........67

Tabela 11: parâmetros de avaliação da qualidade do plano para IORT por elétrons de $9 \mathrm{MeV}$............ 72

Tabela 12: parâmetros de avaliação da qualidade do plano para IORT por raios-X de baixa energia.. 77

Tabela 13: Parâmetro de avaliação da qualidade do plano para geometria de mama pequena. ......... 79

Tabela 14: parâmetros de avaliação da qualidade do plano para geometria de mama média............ 81

Tabela 15: parâmetros de avaliação da qualidade do plano para geometria de mama grande............ 83 


\section{Lista de Siglas}

Radioterapia 3D

APBI Irradiação Parcial Acelerada De Mama

HI Índice De Homogeneidade

IC Índice De Conformidade

IORT Radioterapia Intra-Operatória

PDP Porcentagem De Dose Profunda

PENELOPE Penetration And Energy Loss Of Positrons And Electrons

$\mathrm{pp}$

Pontos Percentuais

PTV Volume Alvo Planejado

TCl Índice De Cobertura Do PTV 


\section{Sumário}

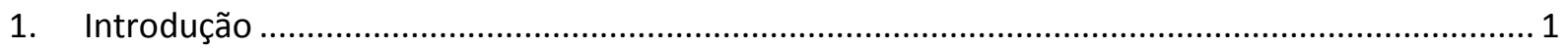

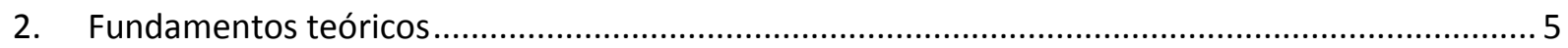

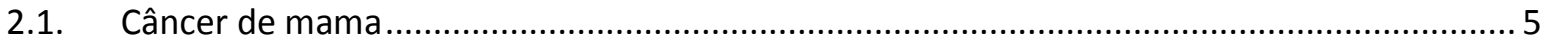

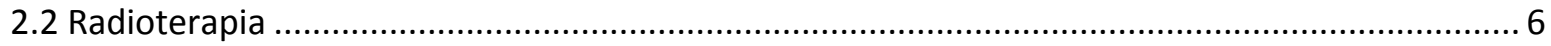

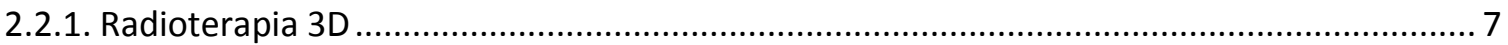

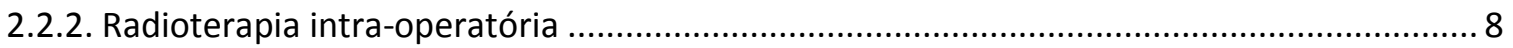

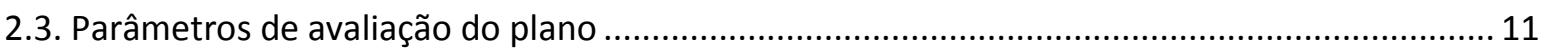

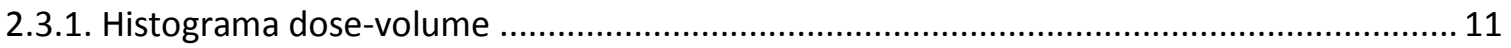

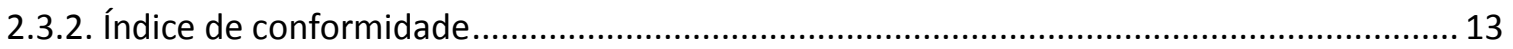

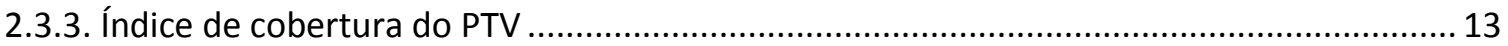

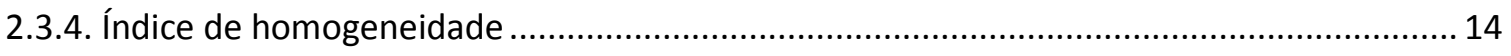

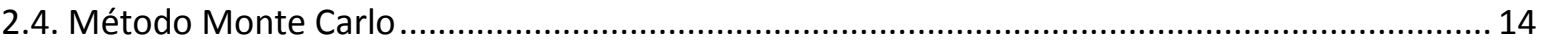

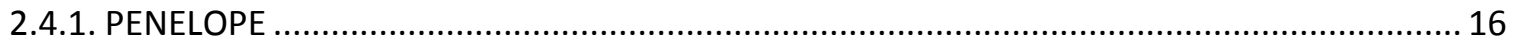

3. Modelagem dos feixes de radioterapia .................................................................................. 19

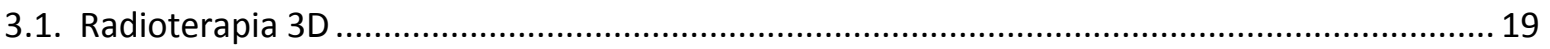

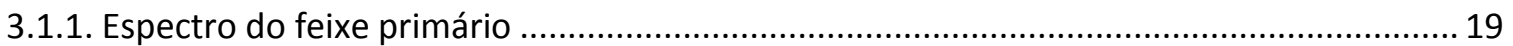

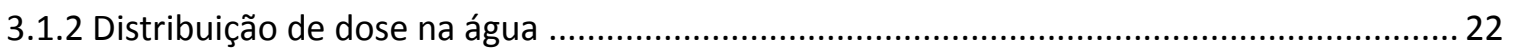

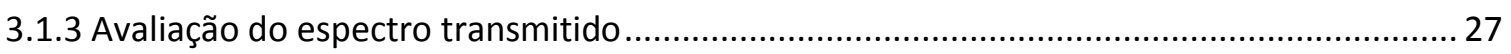

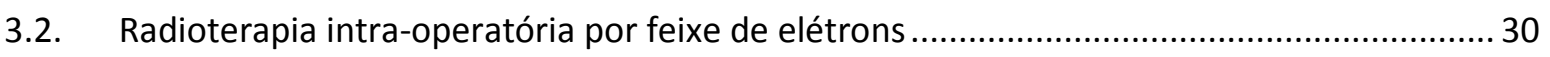

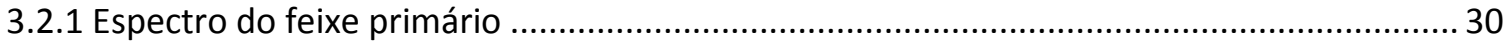

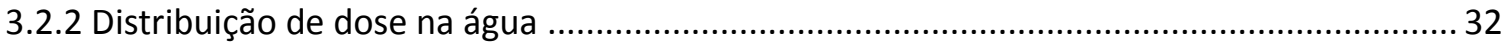

3.3 Radioterapia intra-operatória por raios-X de baixa energia ..................................................... 35

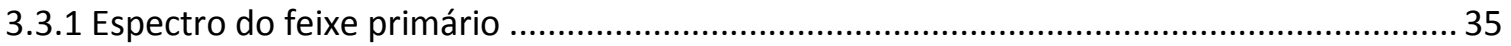

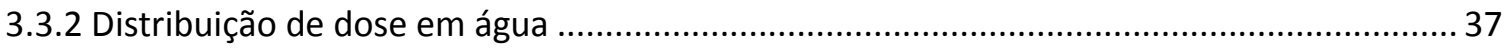

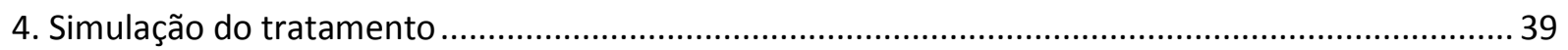

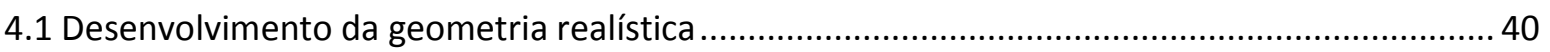

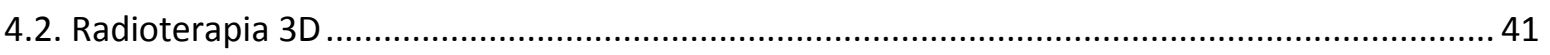

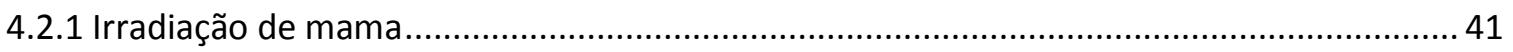

4.2.2 Distribuição de dose de tratamento................................................................................... 41

4.3 Radioterapia intra-operatória por feixe de elétrons .................................................................. 43

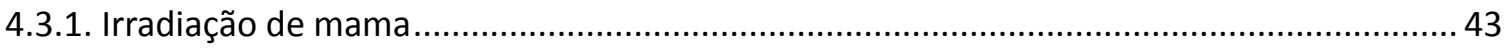

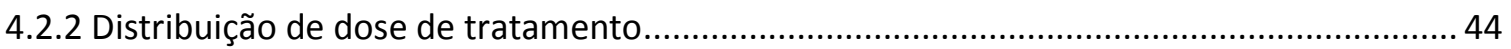

4.4 Radioterapia intra-operatória por raios-X de baixa energia ................................................... 51 


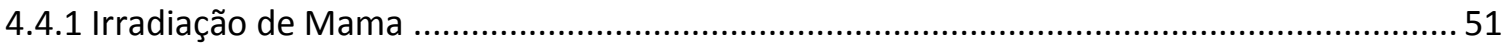

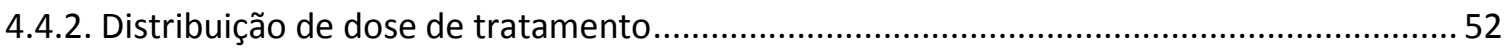

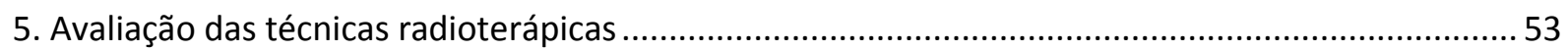

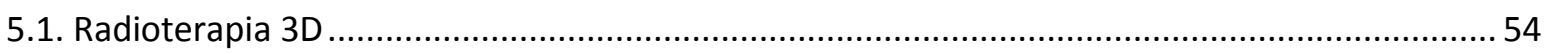

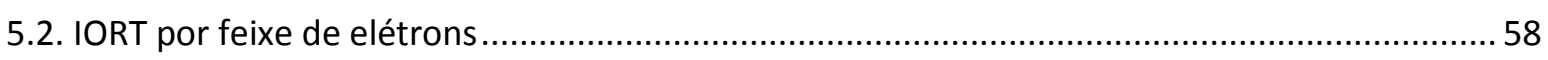

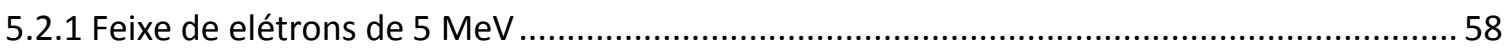

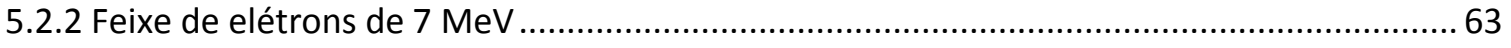

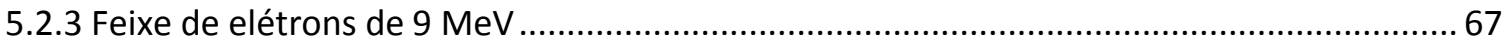

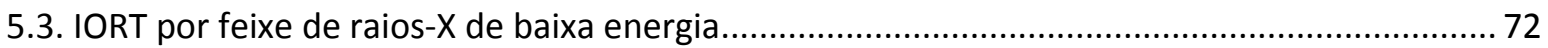

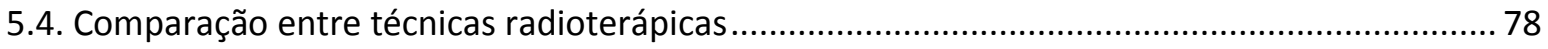

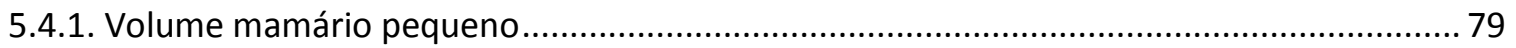

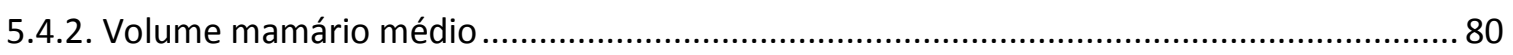

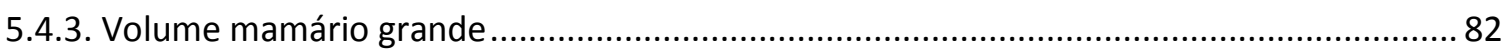

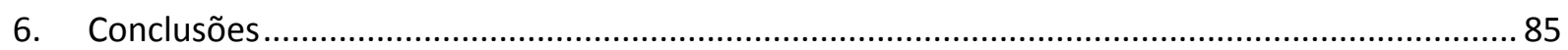

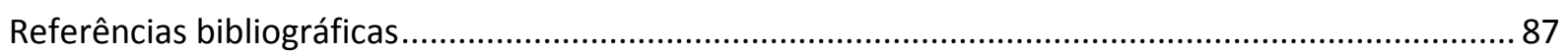




\section{Introdução}

A replicação celular é um processo composto pela replicação do DNA e pela divisão do citoplasma em duas novas células. Essa sequência de eventos é chamada de ciclo celular. $\mathrm{O}$ ciclo celular é um processo altamente ordenado e regulado, que conta com mecanismos de controle cuja função é avaliar sinais de crescimento extracelular, tamanho da célula e integridade do DNA, e definir se a célula deve se renovar, diferenciar ou morrer. Quando os mecanismos de controle falham podem ocorrer mutações que permitem que a célula permaneça em estado constante de divisão, e previna sua diferenciação ou morte, propagando a mutação (Park e Lee, 2003; Massagué, 2004).

Células com essas características constituem o câncer. Podem ocorrer mutações adicionais que conferem ao câncer capacidade de invadir tecidos adjacentes ou de espalharse para órgãos e tecidos distantes. As mutações podem ocorrem em qualquer tecido, gerando diferentes tipos de tumores, com diferentes comportamentos. Enquanto alguns tumores apresentam comportamento altamente agressivo, por exemplo, outros se limitam ao órgão primariamente afetado. (Pedraza-Fariña, 2006).

No caso do câncer de mama as mutações ocorrem especificamente nas células mamárias, ductos e lobos, sendo que a maior parte dos tumores de mama inicia-se nos ductos (INCA, 2016).

Diversas modalidades podem ser adotadas para o tratamento do câncer de mama. Podese tomar uma abordagem loco-regional, com cirurgia e radioterapia, ou sistêmica, com quimioterapia e hormônio terapia. A melhor abordagem é definida com base no estadiamento da doença, em suas características histológicas e nas condições clínicas do paciente (Marta et al, 2011).

Para câncer de mama em estágios iniciais a cirurgia conservadora de mama tem substituído a mastectomia com taxas de sobrevivência equivalente, como descrito na literatura (Marta et al, 2011;). A irradiação total de mama após cirurgia conservadora tornou-se tratamento padrão para câncer de mama em estágios iniciais, pois diminui as chances de recidiva local quando comparada com a cirurgia sem irradiação posterior (EBCTCG, 2005). Entretanto essa abordagem é prejudicada por alguns fatores, em especial o longo tempo de tratamento e a irradiação de estruturas e órgãos saudáveis adjacentes à área tratada (Zhang et al, 2015).

Assim iniciaram-se estudos de técnicas alternativas que alcançassem efeitos comparáveis de controle tumoral em menor tempo e com menor morbidade (White, 2016). Sabe-se, ainda, que, após a cirurgia conservadora de mama, as recidivas locais ocorrem principalmente próximo ou no leito tumoral (Zhang et al, 2015). Aliando esses conhecimentos foi desenvolvida a radioterapia intra-operatória (do inglês, Intraoperative 
Radiation Therapy (ORT), que consiste na irradiação direta da cavidade e leito tumoral em uma única fração, aplicada durante o procedimento cirúrgico (Johnstone, Sindelar e Kinsella, 1994).

Raios-X de baixa energia, feixes de elétrons, implantes de alta taxa de dose e outras fontes híbridas são utilizadas para entrega de IORT. Diversas instituições publicaram estudos individuais sobre IORT, sendo dois dos mais relevantes os chamados TARGIT-A e ELIOT (Esposito et al, 2015b). Esses ensaios compararam radioterapia intra-operatória por raios-X de baixa energia e por feixes de elétrons à radioterapia 3D, respectivamente. Ambos os testes mostraram que, apesar da taxa de recorrência local ser maior para pacientes tratadas com IORT, os efeitos colaterais são pouco observados nesse grupo (Veronesi et al, 2013; Vaidya et al, 2014). Os resultados dos testes clínicos indicam, entretanto, que a IORT pode ser uma alternativa aplicável em certos casos. Recomenda-se que a IORT seja utilizada em pacientes com baixo risco de recidiva local. São consideradas pacientes de baixo risco mulheres acima de 50 anos, tumores menores que $3 \mathrm{~cm}$, margens cirúrgicas, de pelo menos $2 \mathrm{~cm}$, limpas e linfonodos axilares não afetados (Polgár et al, 2010).

Por ser realizada através de unidades de terapia dedicadas, as características dosimétricas dos feixes de IORT diferem daquelas de um feixe de teleterapia (Mihailescu e Borcia, 2014). Foram realizados estudos como os de Ebert e Carruthers (2003), Pimpinella et al (2004) e de Mihailescu e Borcia (2014) que se utilizam de medidas experimentais e de método Monte Carlo para avaliar as características dosimétricas dos feixes de IORT. As características mais marcantes observadas experimentalmente para feixes de raios- $X$ de baixa energia foram uma maior influência de raios- $X$ espalhados em profundidades maiores para o feixe de 50 $\mathrm{keV}$, quando comparado aos feixes de 30 e $40 \mathrm{keV}$ do mesmo acelerador, e uma alteração na profundidade da distribuição de dose causada pela utilização dos aplicadores típicos do acelerador dedicado estudado (Ebert e Carruthers, 2003).

Quanto aos feixes de elétrons, estes apresentam boa uniformidade espacial, obtida através da soma das componentes direta e espalhada da fluência. A fluência espalhada aumenta próximo à borda do aplicador, devido à interação dos elétrons com suas paredes, enquanto a fluência direta do feixe diminui nessas regiões, de forma a se compensarem. Além disso, a distribuição angular dos elétrons depende da energia do feixe e do tamanho do aplicador, e mostrou-se mais larga do que a distribuição comumente vista para feixes convencionais de teleterapia (Mihaislescu e Borcia, 2014). Uma distribuição angular mais larga que a apresentada em feixes convencionais, pode indicar que o feixe de IORT deposita maiores doses na superfície e apresenta um menor gradiente de dose, quando comparado ao convencional (Björk, Knöös e Nilsson, 2002)

Feixes gerados por aceleradores dedicados a IORT apresentam alta taxa de dose por pulso e alto gradiente de dose, variando rapidamente em profundidade. A alta taxa de dose dos feixes de IORT leva a incertezas nas medidas realizadas através de câmaras de ionização, instrumento padrão nos protocolos definidos para feixes convencionais de teleterapia 
(Baghani et al 2015; Bouzid et al, 2015). A impropriedade de dosímetros e protocolos utilizados em técnicas convencionais em de feixes de IORT, faz com que a dosimetria experimental não esteja bem estabelecida para a técnica (Lamanna, 2012). As medidas realizadas através do método Monte Carlo e apresentadas nos trabalhos citados acima apresentam boa concordância com os dados experimentais, possibilitando o estudo de características dosimétricas dos feixes de IORT através de simulação Monte Carlo (Mihaislescu e Borcia, 2014).

A utilização do Método Monte Carlo não está limitada apenas a avaliação de características dosimétricas ou simulação do feixe inicial, outros trabalhos foram realizados utilizando simulação Monte Carlo, como de Bouzid et al (2015) e de Valdivieso-Casique et al (2015), para desenvolvimento de plataformas de planejamento para IORT. O objetivo de ambos os estudos foi possibilitar um tratamento otimizado e uma análise de riscos mais criteriosa para IORT. No estudo de Bouzid et al (2015), a plataforma desenvolvida apresentou boa concordância com valores experimentais. Entretanto, a abordagem adotada nesse trabalho ainda requer muito tempo de cálculo, o que a torna incompatível com o uso clínico. Por outro lado, o trabalho de Valdivieso-Casique et al (2015) apresenta um sistema de planejamento para IORT mais desenvolvido e automatizado, chamado RADIANCE-A. Essa plataforma está em uso em diferentes centros cujos relatos indicam que o sistema de planejamento é bastante promissor (Valdivieso-Casique et al, 2015).

Apesar da existência de sistemas de planejamento como o RADIANCE-A, o planejamento prévio do tratamento através de IORT não está bem estabelecido. A remoção do tecido modifica a área de aplicação do tratamento, em relação ao visto em imagens préoperatórias, de forma que as dimensões do volume alvo são definidas durante o procedimento cirúrgico, e, portanto, poucos momentos antes da irradiação. Somente nesse momento é possível definir o tipo, tamanho e posicionamento do aplicador, além da energia do feixe para tratamentos com elétrons (Lamanna, 2012).

As dificuldades na medida das características dosimétricas dos feixes e no planejamento do tratamento faz com que pouco seja conhecido sobre a distribuição de dose de tratamento gerada pelas unidades de terapia dedicadas a IORT, não existe na literatura, até o momento, estudo que tenha distribuições de dose como foco. Dessa forma, conhece-las torna-se um aspecto de grande interesse para entendimento da técnica. O método Monte Carlo pode ser utilizado para cálculos de distribuição de dose, gerando resultados precisos e detalhados, comparáveis àqueles gerados por sistemas de planejamento convencionais (Faddegon, 2005 e Lamanna, 2012).

O método Monte Carlo é uma ferramenta utilizada em diversas áreas da radioterapia e, conforme os trabalhos citados acima, pode ser utilizado em estudos sobre IORT. O método Monte Carlo está baseado na física do transporte de partículas, simulando uma a uma, sua interação com a matéria, sendo considerado o método mais exato para cálculos de deposição de dose em um tecido (Nwankwo et al 2013; Chen, Xiao e Li, 2014). 
Existem diversos códigos para implementação do método Monte Carlo. Em radioterapia são comumente utilizados os códigos EGSnrc (Kawrakow 2000a, 2000b), Geant4 (Agostinelli et al 2003, Allison et al 2006) e PENELOPE (Salvat et al 2008, Sempau et al 2003). Diversos trabalhos compararam o código PENELOPE com dados experimentais e com outros códigos Monte Carlo. Em simulação de feixe de elétrons o PENELOPE simula o espalhamento das partículas com exatidão comparável a de medidas experimentais e de outros códigos de simulação Monte Carlo; o ajuste das condições de modelagem, como fonte de radiação e geometria a ser simulada (em especial a geometria do cabeçote do acelerador) proporcionam resultados melhores da simulação, segundo descrito em Faddegon et al (2009). Para simulação de raios-X de baixa energia o código PENELOPE mostrou-se uma ferramenta satisfatória para cálculos de características dosimétricas e espectro de raios-X e para estudos de radiobiologia, conforme descrito na revisão realizada por Hill et al (2014).

O presente estudo tem por objetivo comparar, através de parâmetros de qualidade do planejamento, as distribuições de dose geradas por simulação Monte Carlo, para teleterapia e IORT com raios-X e com elétrons. Para isso o estudo foi dividido em três partes principais: modelagem da fonte de radiação, simulação do tratamento em objeto simulador de mama e análise dos parâmetros de qualidade do planejamento.

No capítulo dois é apresentada uma revisão sobre os aspectos teóricos que fundamentam esse estudo, tais como câncer, radioterapia de mama e método Monte Carlo com o pacote de simulação PENELOPE.

No terceiro capítulo está descrita a metodologia utilizada para modelagem dos feixes de radiação estudados, assim como os resultados obtidos e discussões, além de testes adicionais realizados com o objetivo de validar determinada simulação ou otimizar simulações futuras.

A metodologia utilizada para simular as situações reais de tratamento de cada uma das técnicas estudadas está apresentada no capítulo 4, juntamente com as distribuições de dose geradas para todas as técnicas. Para as diferentes modalidades de IORT foi também realizada a comparação das distribuições de dose para diferentes tamanhos de objeto simulador de mama.

No capítulo 5 tem-se a comparação entre técnicas, realizada através dos parâmetros de avaliação da qualidade do plano.

Finalmente, no sexto capítulo estão apresentadas as conclusões do estudo. 


\section{Fundamentos teóricos}

\subsection{Câncer de mama}

O ciclo celular é um processo altamente ordenado e regulado, composto pela replicação do DNA e pela divisão do citoplasma em duas novas células. Estão presentes no ciclo celular os chamados pontos de verificação, onde mecanismos de controle avaliam sinais de crescimento extracelular, tamanho da célula e integridade do DNA. A avaliação desses sinais define se a célula deve se replicar, diferenciar ou morrer.

Frequentemente, em tumores humanos, os mecanismos de controle do ciclo celular apresentam disfunções. Mutações podem manter a célula em constante estado de divisão, e previnem sua diferenciação em tecidos normais ou morte. Podem ocorrer mutações adicionais que conferem ao câncer capacidade de invadir tecidos adjacentes ou de espalharse para órgãos e tecidos distantes (Park e Lee, 2003; Massagué, 2004).

O câncer é considerado uma doença altamente complexa e heterogênea uma vez que pode afetar diversos tecidos, gerando distintas patologias, e apresentar diferentes comportamentos, como por exemplo, manifestação de diferentes sintomas clínicos e diferentes graus de agressividade e de resistência ao tratamento (Urbach, 2012, PedrazaFariña, 2006).

Entre a população feminina de todo o mundo, o câncer de mama apresenta a maior incidência e a maior taxa de mortalidade, tanto para países desenvolvidos quanto em desenvolvimento. As taxas de mortalidade, para esse tipo de câncer, são mais elevadas para regiões desenvolvidas socioeconomicamente, quando comparadas às taxas de mortalidade para regiões em desenvolvimento. É a segunda principal causa de morte em regiões desenvolvidas, perdendo para o câncer de pulmão, enquanto permanece em primeiro em regiões mais pobres. Para o ano de 2018 são esperados 59.700 novos casos de câncer de mama, no Brasil (INCA, 2018).

O câncer de mama pode afetar todos os diferentes tipos de células mamárias, desde lóbulos e túbulos mamários, a ductos e papilas, caracterizando-se como uma patologia heterogênea. Entretanto, cerca de $80 \%$ dos carcinomas de mama originam-se nos ductos (INCA, 2016).

Vários fatores podem aumentar o risco do desenvolvimento do câncer de mama: fatores biológicos, como envelhecimento, densidade mamária e, histórico familiar; e fatores ligados ao estilo de vida, como sedentarismo, excesso de peso e consumo de álcool. É importante ressaltar, ainda, que existem casos de câncer de mama em mulheres que não pertencem ao grupo de risco. Desta forma, a prevenção primária a doença conta com a mudança dos hábitos. A prática de atividades físicas e a manutemção do peso corporal são exemplos de 
hábitos que podem levar a uma diminuição de até 30\% no risco de desenvolver câncer de mama (INCA, 2016).

Diversas modalidades podem ser adotadas para o tratamento do câncer de mama. A melhor abordagem para cada paciente é definida com base no estadiamento da doença, em suas características histológicas e nas condições clínicas do paciente (Marta, 2011). Pode-se tomar uma abordagem loco-regional, como cirurgia e radioterapia, ou sistêmica, como quimioterapia e hormônio terapia. A combinação de técnicas loco-regionais com abordagens sistêmicas também pode ser aplicada para tratamento (Salvajoli, Souhami e Faria, 2013).

\subsection{Radioterapia}

A retirada total da mama, chamada de mastectomia radical, proposta pelo cirurgião americano William Halsted, foi, por muito tempo, o tratamento padrão adotado para câncer de mama. Entretanto, no final da década de 70 e início dos anos 80 , o médico brasileiro Fernando Gentil desenvolveu a cirurgia conservadora de mama, procedimento no qual se retira somente o tumor e o tecido adjacente a ele, poupando pele, auréola e mamilo (Mendes e Casarin, 2016).

A cirurgia conservadora seguida de radioterapia é, hoje, considerada padrão para o tratamento de tumores de mama em estágio inicial (Marta, 2011). A combinação das duas técnicas é utilizada, pois aplicação de radioterapia após a retirada do tumor demonstrou reduzir significativamente a recidiva local (EBCTCG, 2005).

A radioterapia é uma técnica onde se visa o controle da massa tumoral através da utilização de radiação ionizante. A radiação deposita energia nos tecidos, causando danos ao DNA e subsequente morte das células. Apesar de afetar também as células normais próximas ao tumor, a radioterapia busca causar o maior dano possível às células tumorais enquanto poupa tecidos saudáveis (Baskar et al, 2012).

A radioterapia pode ter finalidade curativa ou paliativa. A radioterapia curativa visa o controle tumoral. Para isso, é utilizada uma alta dose total, normalmente dividida em um longo período, onde cada fração entrega uma dose pequena. A forma como a dose é entregue leva a uma toxicidade associada à radioterapia curativa, considerada efeito colateral esperado da técnica. Por outro lado, a radioterapia paliativa é adotada quando as chances de cura são pequenas. Tem o objetivo de melhorar a qualidade de vida do paciente, aliviando os sintomas da doença, como dor. A radioterapia paliativa é entregue em um esquema de hipofracionamento: o tratamento dura menos tempo, contando com uma quantidade menor de frações, porém cada fração entrega uma dose maior do que a dose por fração em radioterapia curativa. Entretanto, a dose total da radioterapia paliativa é menor do que a dose total da radioterapia curativa. O tratamento com finalidade paliativa é planejado de forma a causar a menor toxicidade possível (Rastogi et al, 2012). 
Existem duas principais formas de entrega de radioterapia: braquiterapia e teleterapia. Na braquiterapia, a dose é entregue através de fontes seladas de radiação posicionadas nas proximidades do tumor. É utilizada para tratamento ginecológico e de próstata, entre outros (Blake, 2007). A teleterapia é a forma mais frequentemente usada na clínica. Nesta, a fonte de radiação é posicionada à distância do tumor. Geralmente, são utilizados feixes de alta energia, como fótons e elétrons, gerados por equipamentos como ${ }^{60} \mathrm{Co}$ ou aceleradores lineares. Dados os diferentes tipos de feixes, de geradores e os avanços tecnológicos em técnicas de imagem e em sistemas de planejamento, a teleterapia tem se desenvolvido em diversas modalidades, dentre elas, a terapia 3D, terapia de intensidade modulada, radioterapia guiada por imagem e arcoterapia volumétrica modulada (Baskar et al, 2012, Halperin et al, 2004).

\subsubsection{Radioterapia 3D}

A radioterapia 3D (do inglês, 3D radiation therapy, 3DR) substituiu a radioterapia 2D à medida que as técnicas de imagem tridimensionais foram se desenvolvendo. Uma vez que técnicas como tomografia computadorizada e ressonância magnética oferecem representações anatômicas volumétricas, a delimitação do volume tumoral e dos órgãos de risco torna-se mais precisa. A 3DR tem como base a utilização dessas técnicas para otimizar a entrega de dose no tumor e proteger estruturas de risco adjacentes (Schleger, 2006). A otimização da deposição de dose também pode ser alcançada através da conformação do feixe. Essa conformação consiste na modificação do feixe feita de tal forma que a isodose de planejamento tenha a forma aproximada do tumor. Isso é alcançado através da modificação dos campos e do uso de colimadores multifolhas ou de blocos de blindagem (Fraass, 1995).

O planejamento do tratamento para 3DR é chamado de planejamento direto, onde a distribuição de dose é calculada com base na dose prescrita, uma vez que a orientação do feixe e o formato da abertura dos campos já tenham sido determinados. A conformação é definida durante o planejamento através de ferramentas como "ponto de vista do feixe" (do inglês, beam's-eye view) e radiografias reconstruídas digitalmente (Purdy, Pootmans e Perez, 2012).

O protocolo padrão, adotado para irradiação de mama, consiste na irradiação de todo o volume mamário, normalmente com fótons de $6 \mathrm{MV}$, utilizando dois campos de mesmo tamanho, paralelos, isocêntricos, opostos entre si e tangenciais à parede do tórax (Borges, Cunha e Teixeira, 2013).

A 3DR apresenta algumas desvantagens, em especial, a longa duração do tratamento, entre 4 a 6 semanas, nas quais o paciente deve se apresentar diariamente ao centro terapêutico. Outros fatores que dificultam o tratamento são: a distância entre a residência do paciente e o hospital, dificuldade de locomoção, a escassez de recursos voltados à 
radioterapia, o que leva a longas esperas para o início do tratamento, prejudicando sua eficiência, e falta de recursos econômicos do paciente (Zhang et al, 2015).

\subsubsection{Radioterapia intra-operatória}

Buscando contornar os fatores que dificultam a utilização da teleterapia, iniciaram-se estudos de técnicas alternativas que alcançassem efeitos comparáveis de controle tumoral em menor tempo (White, 2016).

Considerando tais fatores, e sabendo que após a cirurgia conservadora de mama as recidivas locais ocorrem principalmente próximas ou no leito tumoral, foram desenvolvidas técnicas de irradiação parcial acelerada de mama (do inglês, accelerated partial-breast irradiation APBI). São consideradas APBI técnicas onde a irradiação é aplicada na região do tumor, geralmente em frações maiores que $2 \mathrm{~Gy}$. Dessa forma, ao diminuir o volume de tratamento e aumentar a dose, a APBI proporciona um tratamento mais curto (Njeh, Saunders e Langton, 2010).

Existem diversas abordagens que podem ser classificadas como ABPI, dentre elas está a radioterapia intra-operatória (do inglês, intraoperative radiation therapy IORT), que consiste na irradiação direta da cavidade e leito tumoral em uma única fração, aplicada durante o procedimento cirúrgico (Johnstone, Sindelar e Kinsella, 1994; Zhang et al, 2015; Esposito et al, 2015a).

A IORT não apenas resolve os problemas práticos existentes na aplicação de teleterapia, mas também apresenta diversas vantagens clínicas, como a visualização direta do volume a ser irradiado e possibilidade de afastamento dos tecidos sadios próximos, levando a uma maior entrega de dose no tumor e maior proteção de regiões saudáveis; efeito biológico aumentado, uma vez que a entrega de uma alta dose em uma única fração impede o reparo e proliferação das células tumorais; redução do risco de desenvolvimento de tumores radioinduzidos, pois os tecidos normais recebem dose reduzida; e redução de efeitos colaterais e melhor resultado cosmético, visto que a pele pode ser afastada recebendo menos dose (Njeh, Saunders e Langton, 2010; Wang, 2015).

Raios-X de baixa energia, feixes de elétrons, implantes de alta taxa de dose e outros aparelhos híbridos são técnicas utilizadas para entrega de IORT.

\subsubsection{Radioterapia intra-operatória por feixe de elétrons}

Os primeiros tratamentos com IORT, realizados na década de 70, no Japão e Estados Unidos, utilizaram unidades convencionais de radioterapia (Beddar et al, 2006). Embora bem-sucedida, a aplicação de IORT através de LINACs requer que o paciente seja transportado do centro cirúrgico ao setor de radioterapia. O transporte do paciente é um procedimento difícil e dispendioso para os dois setores, adicionando a sua rotina tempo 
ocioso. A instalação de uma unidade de terapia dedicada ao centro cirúrgico deixa de ser uma opção devido aos custos da própria máquina e da blindagem da sala, necessária para proteção radiológica. Esses aspectos impulsionaram o desenvolvimento de aceleradores dedicados à técnica. Esses aceleradores têm por caraterística serem móveis e apresentarem sistemas de colimação diferenciados, de forma a gerarem feixes diferentes dos feixes convencionais (Pimpinella et al, 2007).

O NOVAC7 (Hitesys, Itália) é um modelo de acelerador dedicado a IORT por feixe de elétrons, sendo mostrado na Figura 1(a). O NOVAC7 tem a capacidade de gerar feixes pulsados de elétrons com quatro diferentes energias nominais: 3, 5, 7 e $9 \mathrm{MeV}$, além de contar com um braço móvel que facilita o posicionamento do feixe para o tratamento.

O sistema de colimação do NOVAC7 é realizado através do acoplamento de um aplicador à saída do feixe, mostrado na Figura 1(b). O aplicador é um cilindro de acrílico (PMMA) e está disponível em quatro diferentes diâmetros, indo de 4 a $10 \mathrm{~cm}$, com parede de $0,5 \mathrm{~cm}$ de espessura. O tamanho do campo é definido pelo diâmetro do aplicador, sendo o aplicador de $10 \mathrm{~cm}$, considerado de referência. Para esse aplicador, a distância fonte-superfície é de $100 \mathrm{~cm}$, enquanto que para os outros é de $80 \mathrm{~cm}$. A uniformidade espacial do feixe é produto do espalhamento dos elétrons nas paredes do aplicador, de forma que não são necessários filtros ou lâminas de espalhamento (Mihailescu e Borcia, 2013; Pimpinella et al, 2007; Njeh, Saunders e Langton, 2010).

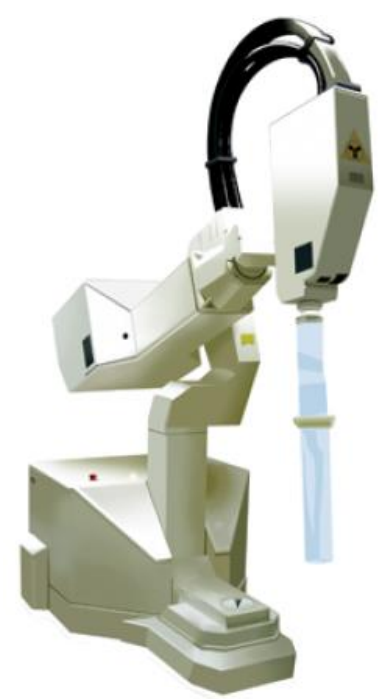

a

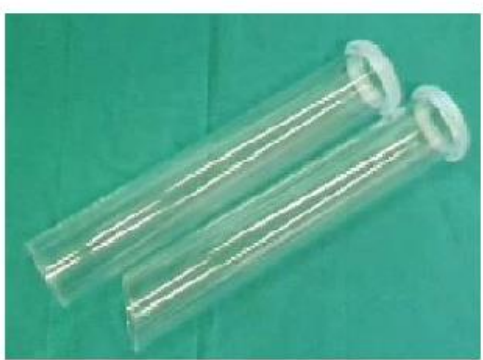

b

Figura 1: Acelerador linear dedicado a IORT por feixe de elétrons NOVAC7 (a) e seus aplicadores (b). Fonte: Mihailescu e Borcia, 2014

O teste clínico ELIOT mostrou que a IORT com feixe de elétrons apresenta uma taxa de recorrência local maior do que a apresentada para pacientes tratados com teleterapia, sendo que $2,5 \%$ dos pacientes tratados com IORT apresentaram novos tumores no quadrante irradiado, contra apenas $0,4 \%$ dos pacientes tratados com teleterapia convencional (Veronesi et al, 2013). A taxa de recorrência local em 5 anos encontrada, para IORT, foi menor do que o previsto para a técnica. Esta taxa também é menor do que o 
descrito na literatura, para acompanhamento em 5 anos, para pacientes tratados com irradiação total de mama. A taxa de metástases distantes e a sobrevivência geral são iguais para ambas as técnicas, segundo esse estudo clínico. Também foram observados poucos efeitos colaterais no grupo tratado com IORT. As análises devem ser continuadas, avaliandose mais pacientes por maior tempo, para gerar conclusões mais robustas de longo prazo. 0 estudo indica que a IORT é uma alternativa válida, desde que as pacientes sejam selecionadas, sobretudo levando-se em consideração o risco de recidiva local. Para pacientes com alto risco de recidiva, o estudo sugere o uso de irradiação total de mama após a aplicação de IORT.

\subsubsection{Radioterapia intra-operatória por raios- $X$ de baixa energia}

Assim como no caso do NOVAC7, também foi desenvolvido, para a aplicação de IORT com feixes de raios- $X$ de baixa energia, um acelerador linear dedicado. $O$ Intrabeam (Carl Zeiss, Alemanha), apresentado na Figura 2(a) conta com um braço móvel em cuja extremidade está posicionada a chamada sonda, onde é produzido o feixe de radiação. O sistema Intrabeam acelera elétrons a uma energia máxima de $50 \mathrm{keV}$. Ao colidirem com o alvo de ouro posicionado ao final da sonda é produzido um feixe de raios- $X$ de distribuição aproximadamente isotrópica (Yanch e Harte, 1996; Eaton e Duck, 2010).

Foram desenvolvidos diversos aplicadores passíveis de utilização com o sistema Intrabeam, cada um específico para uma aplicação. Para tratamento de câncer de mama é acoplado à sonda um aplicador esférico, mostrado na Figura 2(b). Esse aplicador está disponível em diferentes tamanhos, com raios variando desde 1,5 a $5 \mathrm{~cm}$, e é constituído por uma esfera maciça de resina (polieterimida). O tamanho do aplicador a ser utilizado deve ser selecionado de forma que preencha a cavidade tumoral (Eaton e Duck, 2010).

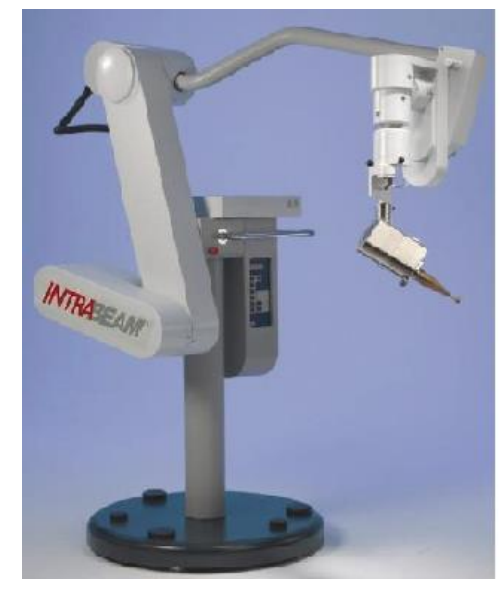

a

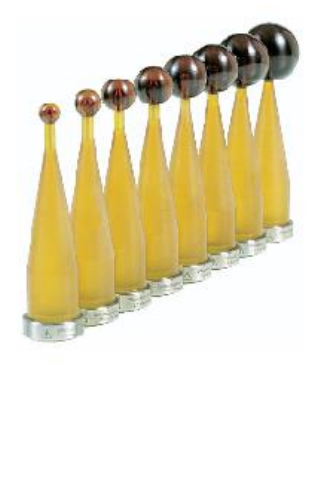

b

Figura 2: Acelerador linear dedicado a IORT por feixe de raios-X de baixa energia Intrabeam e seus aplicadores esféricos. Fonte: Njeh, Saunders e Langton, 2010 
Resultados semelhantes àqueles descritos no teste clínico ELIOT, para IORT por feixe de elétrons, foram relatados para o TARGIT-A, para feixes de raios- $X$ de baixa energia (Vaidya et al, 2014). O risco de recorrência local foi maior para pacientes tratados com IORT quando comparado com aquele para pacientes tratados com teleterapia. A quantidade de mortes relacionadas a câncer de mama foi semelhante para as duas técnicas. Entretanto, as mortes não causadas diretamente pelo câncer de mama, atribuídas a doenças cardiovasculares e outros tumores, aconteceram em menor número no grupo tratado com IORT. Os resultados estéticos foram melhores com IORT, uma vez que as complicações relacionadas a ferida cirúrgica foram menos severas nesse grupo. Nesse teste foi ressaltado que, em casos de alto risco, deve-se adicionar ao tratamento irradiação com feixe externo, de forma que seja alcançada uma taxa de controle local satisfatória.

\subsection{Parâmetros de avaliação do plano}

Apesar do desenvolvimento das técnicas de radioterapia permitir uma entrega de dose mais complexa, o objetivo do tratamento permanece sendo o máximo controle tumoral com mínimo prejuízo de tecidos sadios. Portanto, é importante conhecer qual o tipo de tratamento que melhor realiza tal objetivo para cada caso em particular. Para isso são utilizados os chamados parâmetros de avaliação da qualidade do plano. Existem diversos parâmetros desenvolvidos para avaliar o plano de tratamento radioterápico, tanto qualitativos quanto quantitativos.

\subsubsection{Histograma dose-volume}

O histograma dose-volume é uma ferramenta de avaliação do plano que busca resumir a grande quantidade de dados gerada pelos cálculos de volume característicos do planejamento 3D, apresentando em um gráfico as informações de distribuição de dose em um volume ou estrutura específico. O histograma dose-volume facilita a avaliação do plano que seria dificultada se fosse realizada apenas através das curvas de isodose, uma vez que estas são apresentadas em diversos planos.

De acordo com a definição matemática, o histograma é obtido através da soma do volume dos elementos que recebem dose dentro de um intervalo específico, dentre o conjunto de intervalos considerado. Esse modelo de histograma é chamado de diferencial, sendo mostrado na Figura 3(a).

Existe, entretanto, a opção de apresentar o histograma do volume que recebe doses maiores ou iguais a um valor determinado em função do intervalo de dose esperado. Esse tipo de histograma é o mais utilizado na clínica e caracteriza a distribuição em frequência da dose-volume, sendo um histograma cumulativo, ou simplesmente histograma dose-volume, apresentado na Figura 3(b) (Drzymala et al, 1991). 


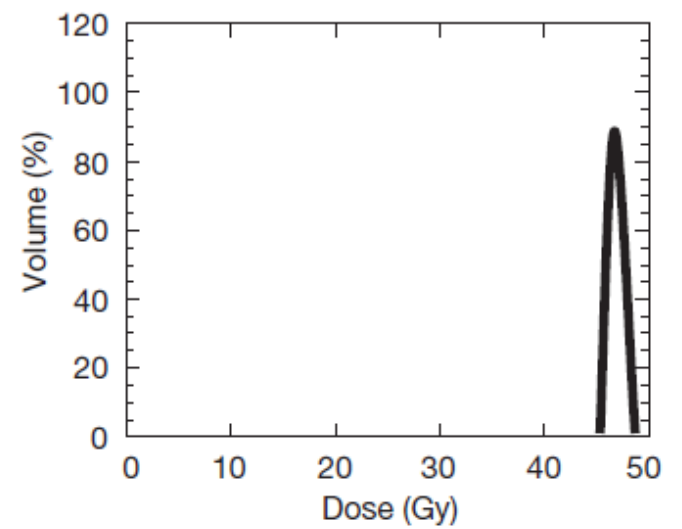

a

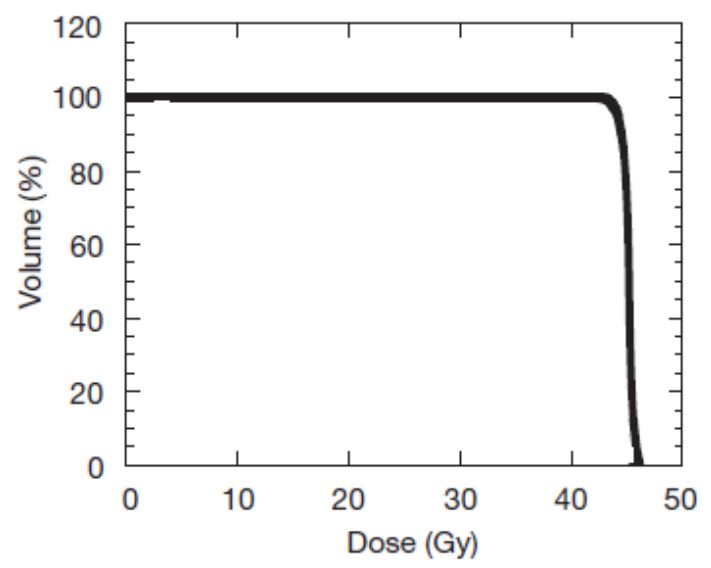

b

Figura 3: Tipos de Histograma Dose-Volume. Histograma diferencial (a) e histograma cumulativo (b). Adaptado de Parker e Patrocinio.

O histograma dose-volume pode ser utilizado para avaliar a entrega de dose no volume alvo e em órgão adjacentes. Para o volume alvo, o histograma deve ter comportamento semelhante ao de uma função degrau, caracterizando uma dose alta uniformemente distribuída em todo o volume, conforme apresentado na Figura 4. Em contrapartida, para tecidos adjacentes e estruturas de risco, o histograma dose-volume deve apresentar uma relação inversamente proporcional entre dose e volume: uma alta dose pode ser entrega para um pequeno volume ou uma baixa dose pode ser entregue em um grande volume; sua aparência ideal está representada na Figura 4. Além disso, o histograma dose-volume pode ser utilizado para comparar diversos planejamentos diferentes (Bidmead e Rosenwald, 2007).

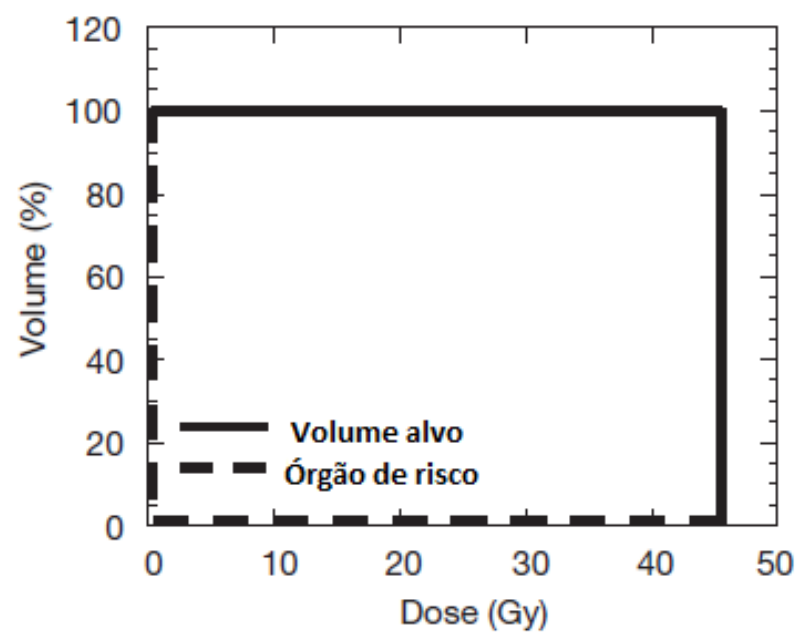

Figura 4: Comportamento ideal de histogramas dose-volume para volume alvo e órgão de risco. Adaptado de Parker e Patrocinio.

A avaliação de um histograma dose-volume está baseada nos critérios de restrição da prescrição radioterápica. Um órgão pode apresentar diferentes reações à irradiação de acordo com a fração de seu volume que recebeu a dose. Alguns órgãos podem perder toda a 
sua função após irradiação de apenas uma porção de seu volume, enquanto outros podem manter-se funcionais após a mesma irradiação. A tolerância à dose para irradição total ou parcial foi estudada para diversos órgãos, e níveis de tolerância de dose-volume foram estabelecidos (Halperin et al, 2004). Esses níveis são tomados como critérios de restrição para o histograma dose-volume de órgãos sadios adjacentes ao tumor. Um plano só será aprovado se a avaliação do histograma dose-volume indicar que os níveis de tolerância de dose foram respeitados.

\subsection{2. Índice de conformidade}

O índice de conformidade (IC) busca avaliar quão bem a isodose de planejamento se adequa ao volume alvo. A conformidade do plano é essencial para o tratamento e deveria ser expressa em uma forma de fácil entendimento e gerada por parâmetros obtidos através do histograma dose-volume.

O índice de conformidade compara o volume na isodose de planejamento com o volume alvo. Essa fração é dada, simplesmente, pela intersecção dos dois volumes: de isodose de planejamento e do alvo, conforme a equação 2.1 :

$$
I C=V_{P I V} / V_{\alpha}
$$

onde $V_{P I V}$ é a fração do volume alvo coberta pela isodose prescrita e $V_{\alpha}$ é o volume alvo.

Deveria ser considerada, entretanto, a fração do volume alvo coberto pela isodose prescrita. Essa definição está proposta nas diretrizes do Grupo de Radioterapia Oncológica (do inglês Radiation Therapy Oncology Group) desde 1993.

Essa abordagem deve ser cuidadosa, pois o índice de conformidade ótimo, IC $=1$, sempre pode ser alcançado com uma isodose prescrita baixa, o que levaria a irradiação de tecidos saudáveis ao redor do tumor (Paddick, 2000; Feuvret et al, 2005 ).

\subsection{3. Índice de cobertura do PTV}

Conceito semelhante ao índice de conformidade, o índice de cobertura do volume alvo planejado (do inglês, target coverage index, $\mathrm{TCl}$ ) compara a proporção do volume alvo coberto pela isodose de planejamento à proporção do volume alvo coberto por uma isodose de porcentagem específica, geralmente $95 \%$, conforme a equação 1.2:

$$
T C I=V_{\text {iso }} / V_{95 \%}
$$

onde $V_{\text {iso }}$ é a fração do volume alvo coberta pela isodose prescrita e $V_{95 \%}$ é o volume coberto pela isodose de $95 \%$.

Deseja-se que $95 \%$ do volume alvo receba pelo menos $95 \%$ da dose prescrita, portanto menores valores de índice de cobertura do PTV indicam melhor qualidade do tratamento. 
Valores menores que 1 indicam que a isodose planejada está mais interna à isodose de 95\%, e portanto, a totalidade do tumor recebe uma dose aceitável. O maior valor aceitável para o $\mathrm{TCl}$ é 1, que ocorre quando a isodose de planejamento cobre igual proporção do volume àquela coberta pela isodose de $95 \%$. Valores maiores que 1 indicam regiões de altas doses no volume tumoral, bem como alta heterogeneidade de doses.

\subsection{4. Índice de homogeneidade}

$O$ índice de homogeneidade (do inglês, homogeneity index, HI) analisa quão bem distribuída a dose está dentro do volume alvo, e se existe, dentro do volume considerado, áreas de dose muito altas, chamadas de "quentes" e/ou áreas de dose muito baixa, "frias".

Existem diferentes formas de se obter o índice de homogeneidade de um plano. Entretanto, este consiste, basicamente, em avaliar a dose em proporções diferentes do volume, como por exemplo, realizar a razão entre as doses recebidas por $2 \%$ do volume e $98 \%$ do volume (ou entre 5 e 95\%). A dose na menor porcentagem do volume seria a dose máxima e a dose na maior parcela do volume seria a dose mínima. Portanto, o índice de homogeneidade indica, basicamente, a razão entre a dose máxima e mínima dentro do volume alvo. Dessa forma, um índice de homogeneidade pequeno indica um plano aceitável.

Para avaliação do plano de tratamento para tumores de mama, é mais frequentemente usada na clínica a equação 1.3 para avaliação do HI:

$$
H I=\frac{D_{2}-D_{98}}{D_{\mathrm{p}}} \times 100 \%
$$

onde $D_{2 \%}$ é a dose em $2 \%$ do volume, $D_{98 \%}$ é a dose em $98 \%$ do volume e $D_{p}$ é a dose prescrita (Yoon et al, 2017).

\subsection{Método Monte Carlo}

A avaliação do plano através dos parâmetros citados anteriormente é bastante difundida na radioterapia clínica. Entretanto, para sua utilização é necessário planejamento antecipado do tratamento e conhecer sua distribuição de dose, fatores que, dada a técnica, podem não ser facilmente obtidos experimentalmente.

Uma alternativa à medidas experimentais de distribuições de doses de um plano radioterápico é o Método Monte Carlo, utilizado desde seu desenvolvimento em transporte de elétrons, na década de 50, para gerar informações relevantes na área de radioterapia (Bielajew, 2013; Fippel, 2013 ). 
Em sua definição mais básica, o Método Monte Carlo é descrito como um método numérico, baseado em números aleatórios, cuja finalidade é resolver equações e integrais complexas. O Método Monte Carlo busca modelar situações reais a partir das interações de suas partes. Em transporte de partículas, busca-se simular toda a trajetória da partícula estudada, sendo essa composta por vários deslocamentos, cada um culminando em uma interação que altera o estado da partícula, isto é, muda sua direção e/ou energia (Bielajew, 2013).

Diversos mecanismos podem reger as interações das partículas com o meio, como efeito fotoelétrico, Compton ou produção de pares. Esses mecanismos são descritos e caracterizados por suas seções de choque. O conjunto de seções de choque que descrevem cada mecanismo de interação é chamado de "modelo de interação" e é a base da determinação da trajetória das partículas em simulação Monte Carlo. A trajetória da partícula é descrita por variáveis como livre caminho entre interações, tipo de interação e perda de energia e ângulo de espalhamento decorrentes da interação. As seções de choque determinam a distribuição de probabilidade dessas variáveis, e essa probabilidade permite produzir trajetórias probabilísticas, através de métodos de amostragem adequados. Com um número de trajetórias suficientemente grande o transporte de partículas está representado conforme o real e, informações quantitativas podem ser obtidas sobre as distribuições das partículas (Salvat et al, 2008).

O transporte de partículas por Método Monte Carlo é, portanto, baseado na física dos mecanismos de interação, sendo considerado o método mais preciso para estudos em radioterapia. Os resultados simulados reproduzam resultados experimentais, comprovandose um método eficiente (Nwankwo et al, 2013; Oprea et al, 2012).O Método Monte Carlo pode ser usado em diversas aplicações e com diversos objetivos, indo desde o estudo do feixe, com a simulação do cabeçote do acelerador e ajuste de suas características dosimétricas, chegando até ao desenvolvimento de plataformas de planejamento do tratamento baseadas em Monte Carlo (Mihailescu e Borcia, 2014; Bouzid et al, 2015; Valdivieso-Casique et al, 2015).

Entretanto, o método ainda está sujeito a incertezas. Incertezas do tipo estatísticas são inerentes do método e sua influência pode ser minimizada com a simulação de um número grande de partículas. Existem, porém, outras fontes de incerteza, como as aproximações adotadas nos modelos de interação e a representação geométrica da situação a ser simulada. Uma vez que a simulação é inerentemente baseada na modelagem de um sistema real essas fontes de incertezas sempre estarão presentes, e dificilmente seus efeitos podem ser previstos.

A comparação dos resultados simulados a resultados de referência é uma abordagem necessária para averiguar os efeitos gerados por diferentes modelagens, assim como a validade destas. Realizar a validação da modelagem é, portanto, necessário para se conhecer o grau de confiabilidade de seus resultados. 
A comparação com resultados experimentais é bastante utilizada para validação do método Monte Carlo. Entretanto, pode ser inconclusiva: dentre outros motivos, pelo fato dos resultados experimentais serem, muitas vezes, corrigidos por parâmetros desconhecidos, ou obtidos através do próprio método Monte Carlo.

A comparação com resultados obtidos através da utilização de distintos códigos Monte Carlo não apenas constitui uma alternativa para a impossibilidade de comparação com resultados experimentais, mas também é uma abordagem desejável. Resultados gerados por diferentes códigos Monte Carlo estão igualmente sujeitos a erros na descrição geométrica e sua comparação indica, no mínimo, quão sensível a simulação é à diferentes modelos de interação (Sempau et al, 2001).

Existem diversos códigos desenvolvidos para implementação do Método Monte Carlo, dentre eles o código PENELOPE, utilizado nesse trabalho.

\subsubsection{PENELOPE}

O pacote PENELOPE foi inicialmente desenvolvido para simular a penetração e perda de energia de pósitrons e elétrons na matéria (do inglês, PENetration and Energy LOss of Positrons and Electrons). Mais tarde foram introduzidos fótons ao pacote, sendo utilizado atualmente para simular o transporte de elétrons e fótons acoplados em sistemas compostos por corpos preenchidos por quaisquer materiais arbitrariamente determinados. Graças aos modelos de interação adotas no código podem ser simuladas partículas com energias indo de $50 \mathrm{keV}$ a $1 \mathrm{GeV}$ (Salvat et al, 2008).

PENELOPE é composto por quatro arquivos fonte, responsáveis por controlar a simulação em diversos aspectos, desde tempo a modelos de interação, passando por geometria e material a serem simulados. São eles: timer.f, penvared.f, material.f, pengeom.f e penelope.f 0 arquivo fonte penelope.f é o principal, responsável por toda a parte de transporte da simulação e está dividido em quatro blocos de sub-programas: cálculos preparatórios e rotinas de entrada/saída, procedimentos de simulação de interações, rotinas numéricas e rotinas de transporte.

A forma como o código foi estruturado e a existência do arquivo fonte penelope.f, permite ao usuário criar simulações específicas sem a necessidade de lidar com aspectos mais complexos do trabalho de simulação. A simulação é definida segundo os interesses do usuário através de arquivos simples que descrevam geometria, material, características da fonte de radiação.

A geometria da simulação, para o pengeom.f, é definida como um sistema de corpos homogêneos delimitados por superfícies quadráticas. Pengeom.f tem a função de guiar a simulação das partículas e determinar em qual corpo acontece uma específica interação. Para que o arquivo fonte pengeom.f possa aplicar a rotina geométrica da simulação as geometrias devem ser escritas através de equações quadráticas, como a equação (1.4), em 
arquivo tabulado, sendo descritos os corpos mais internos inicialmente. Podem ser definidas nesse arquivo qualquer posição, tamanho e orientação para os corpos, individual ou coletivamente.

$$
F_{\mathrm{r}}(x, y, z)=I_{1} x^{2}+I_{2} y^{2}+I_{3} z^{2}+I_{4} z+I_{5}=0
$$

$\mathrm{O}$ arquivo fonte material.f permite que os corpos determinados no arquivo de geometria sejam preenchidos por qualquer material, uma vez que suas características, relevantes para a simulação, estejam descritas em um arquivo específico. A criação desse arquivo é possível através do código material.f, disponível no pacote PENELOPE. A esse código devem ser fornecidas, pelo usuário, informações básicas sobre o material que se quer simular, como composição química e densidade. O pacote conta com uma base de dados onde estão incluídos todos os elementos químicos da tabela periódica, utilizados para a composição de misturas, e alguns compostos mais utilizados em estudos de radiações, como tecidos biológicos e materiais dosimétricos.

Além da descrição do meio, cabe ao usuário a determinação da fonte de radiação a ser simulada. Informações como o tipo de partícula, sua energia ou espectro de energia, sua localização, tipo e tamanho de campo a ser utilizado são necessárias para descrever a fonte de radiação. Esses aspectos são especificados no arquivo de entrada da simulação. Os parâmetros de simulação, que controlam a energia de corte das partículas e o grau de detalhamento da simulação, também são definidos no arquivo de entrada.

O pacote de simulação tem disponível um código principal, chamado penmain.f. Esse código realiza toda simulação do transporte de elétrons-fóton em sistemas complexos a partir dos dados do arquivo de entrada gerado pelo usuário, gerando então arquivos de saída onde são descritos os resultados da simulação. (Salvat et al, 2008).

Os resultados registrados incluem desde informações sobre energia e distribuição angular das partículas e energia depositada em cada corpo, a informações mais específicas, como distribuição de dose em um volume específico e fluência de partículas que atravessam um determinado corpo. Para que resultados extras, como os citados, sejam obtidos, o código PENELOPE conta com ferramentas desenvolvidas para cada um deles, que devem ser especificadas no arquivo de entrada.

A distribuição de dose, por exemplo, é obtida adicionando-se um comando de mesmo nome ao arquivo de entrada da simulação. Esse comando permite registrar a distribuição de dose em um volume específico da geometria da simulação. Este volume deve ser um paralelepípedo, e sua definição é dada através das posições de seus vértices nas três coordenadas espaciais, $x, y$ e z. O ponto de deposição de dose é tomado como o voxel onde a partícula é absorvida e sua trajetória deixa de ser seguida. 
A fluência de partículas pode ser registrada através do uso de uma ferramenta denominada impact detector. Para a utilização do impact detector, um corpo da geometria da simulação deve ser definido como detector. Cada corpo pode compor apenas um impact detector. Para realizar o registro do espectro de energia e da distribuição angular das partículas detectadas a ferramenta impact detector utiliza a subrotina STEP. Em corpos definidos como detector, a subrotina STEP para a partícula que entra no detector, na superfície deste, enviando um sinal de controle ao programa principal que registra em um arquivo específico as variáveis de estado da partícula. 


\section{Modelagem dos feixes de radioterapia}

Para que seja possível a comparação de diferentes técnicas de radioterapia através de simulação Monte Carlo é importante realizar a comparação do feixe simulado aos dados de referência. Essa comparação, chamada de validação da modelagem, é feita em condições de referência e visa garantir a confiabilidade dos resultados simulados.

Nesse trabalho foi realizada a validação da modelagem para cada um dos feixes estudados: radioterapia 3D, IORT com feixe de elétrons e IORT com feixe de raios- $X$ de baixa energia através da comparação de resultados obtidos com a literatura.

As validações das simulações deram-se através da comparação dos perfis de dose e das curvas de porcentagem de dose profunda (PDP) geradas pela simulação com os dados apresentados na literatura, em trabalhos onde também foi utilizado método Monte Carlo.

Todas as simulações descritas foram realizadas através do pacote de simulação Monte Carlo, PENELOPE 2008.

\subsection{Radioterapia 3D}

\subsubsection{Espectro do feixe primário}

Foi simulado o feixe de fótons de $6 \mathrm{MV}$ gerado por um acelerador linear da marca Siemens, utilizando-se espectros obtidos na literatura (Sheikh-Bagheri e Rogers, 2002). Em uma primeira simulação, buscava-se avaliar a modelagem em condições de referência. A realização dessa simulação é de interesse para avaliar as características primárias do feixe, isto é, suas características dosimétricas em condições básicas, sem que nenhuma modificação seja imposta ao feixe. Portanto, foi simulado um campo quadrado de $10 \times 10 \mathrm{~cm}^{2}$ incidindo em um objeto simulador cúbico de água de $30 \times 30 \times 30 \mathrm{~cm}^{3}$ com uma distância fonte superfície de $100 \mathrm{~cm}$.

Foi utilizado, como fonte de radiação, o espectro de fótons desse acelerador, obtido no trabalho de Sheikh-Bagheri e Rogers (2002) e apresentado na Figura 5. Em situações reais, o processo de produção de raios-X gera, com diferentes probabilidades, fótons de diferentes energias que define o mecanismo pelo qual como o fóton irá interagir com a matéria. Portanto, utilizar um espectro polienergético como fonte primária para a simulação garante que os diferentes processos de interação possíveis para o espectro estudado sejam simuladas. O mesmo não aconteceria se fosse utilizada apenas a energia nominal do feixe como parâmetro para descrição da fonte de radiação. 


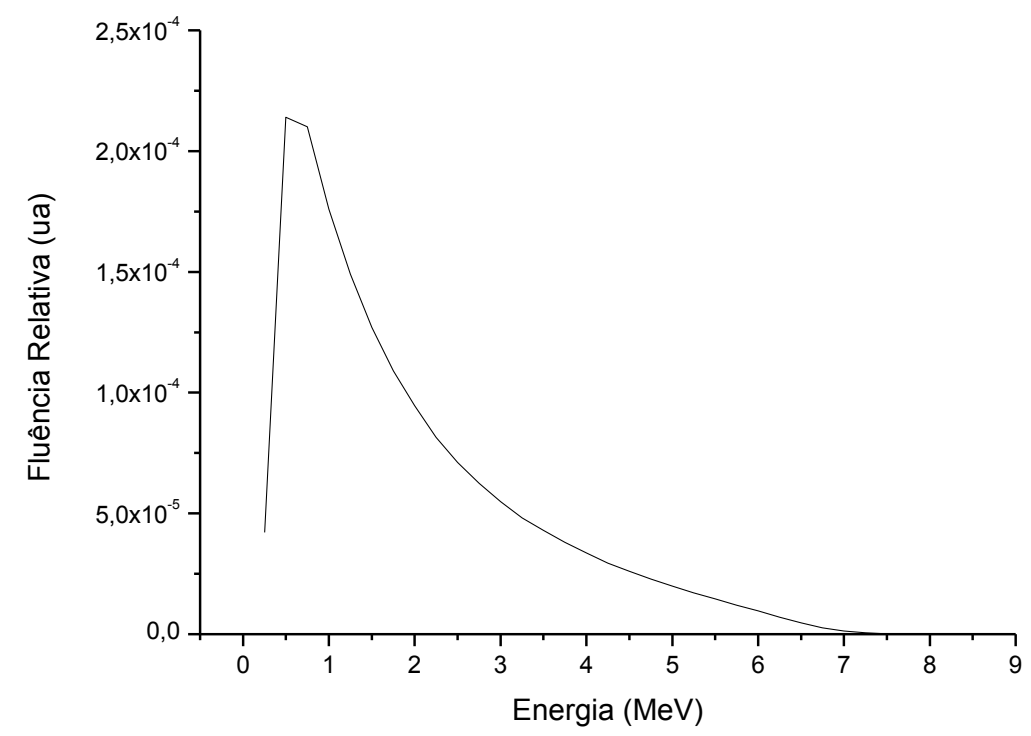

Figura 5:Espectro de fótons de 6 MV gerado pelo acelerador Siemens KD.

Os parâmetros de controle da simulação, $W_{c c}$ e $W_{c r}$, determinam as perdas de energia de partículas carregadas, por colisões inelásticas e por bremsstrahlun. Para a simulação do feixe de 3DRC, esses parâmetros foram mantidos em seu valor padrão, $10^{7} \mathrm{eV}$. A energia de corte, que define a energia mínima para a qual a trajetória da partícula deve ser acompanhada, foi definida em $1 \mathrm{keV}$ para elétrons e fótons e $100 \mathrm{keV}$ para pósitrons. Os parâmetros $C_{1}$ e $C_{2}$, que determinam o grau de detalhamento da simulação foram mantidos em 0,1 .

Em 3DR de mama é comum a utilização de filtros em cunha, acessórios de tratamento cuja função é homogeneizar a dose dentro do volume a ser tratado. Por ser constantemente utilizado, torna-se interessante considerar a modificação que esse acessório causa no feixe. Portanto, foram realizadas simulações com filtro em cunha posicionado entra a fonte e a geometria do objeto simulador. Dois tamanhos de filtro foram simulados: 30 e 45 graus. Os tamanhos dos filtros foram definidos de forma a estarem de acordo com o tamanho mais utilizado na clínica e com o volume mamário a ser simulado.

A simulação do filtro utiliza, como feixe primário, o mesmo feixe utilizado para a simulação do campo aberto, cujo espectro está apresentado na figura 5. Assim como para a simulação de feixe aberto, foi utilizado, para a simulação com cada um dos filtros, campo de $10 \times 10 \mathrm{~cm}^{2}$, incidindo em um objeto simulador cúbico de água de $30 \mathrm{~cm}$ de aresta e distância fonte superfície de $100 \mathrm{~cm}$.

Preencher o espaço entre filtro e objeto simulador com ar garante que a simulação represente condições de espalhamento e absorção de partículas iguais às condições reais. Portanto, foi acrescentado, para as simulações com filtro, um envoltório de ar, como 
apresentado na Figura 6. O envoltório consiste em um cubo de $50 \times 50 \times 50 \mathrm{~cm}^{3}$, grande o suficiente para que contenha todas as estruturas da geometria.

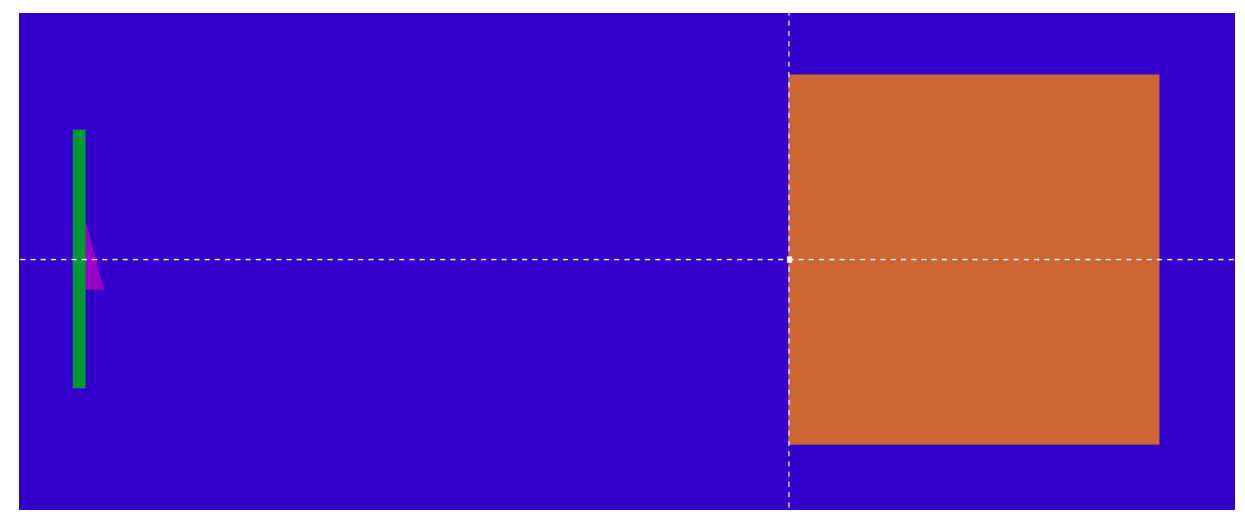

Figura 6: Geometria utilizada para simulação do filtro físico de 30 graus. Na figura tem-se o objeto simulador em laranja, o filtro físico em roxo e seu suporte, representado na cor verde. Todos os objetos da geometria estão envoltos em ar, azul.

Os filtros foram modelados de acordo com as dimensões dos filtros físicos disponíveis no Setor de Radioterapia do Hospital das Clínicas da Faculdade de Medicina de Ribeirão Preto (HC - FMRP). O material que compõe o filtro é, conforme descrito no Manual do Fabricante do aparelho dessa unidade, aço inoxidável. O filtro foi posicionado a $57,9 \mathrm{~cm}$ do objeto simulador, conforme descrito no trabalho de Lopes (2013). O suporte ao qual o filtro está afixado também foi simulado. Suas dimensões correspondem àquelas do suporte dos filtros físicos e o material de que é composto é o alumínio.

Nessas simulações o espectro de partículas gerado após o filtro é de grande interesse. 0 feixe primário é modificado pela interação com o filtro e o feixe modificado será, então, responsável pela distribuição de dose em água. Portanto, deseja-se uma simulação detalhada do espectro do feixe gerado. Os parâmetros $W_{c c}$ e $W_{c r}$ foram modificados e definidos como 0 e -1 , para as simulações dos dois filtros, de 30 e de 45 graus. A energia de corte das partículas foi mantida para as duas simulações, sendo $1 \mathrm{keV}$ para elétrons e fótons e $100 \mathrm{keV}$ para pósitrons. Os parâmetros $C_{1}$ e $C_{2}$, foram mantidos em 0,1.

As simulações foram validadas através da comparação dos perfis de isodose e das curvas de PDP encontrados na literatura (Lopes, 2013). Através das curvas de PDP foram avaliadas as profundidades em que ocorrem porcentagens de dose de interesse clínico: $D_{\text {máx }}, D_{80 \%} e$ $D_{50 \%}$.

A avaliação dos perfis de dose é de interesse na validação dos feixes de 3DR devido à utilização dos filtros em cunha. A homogeneização do feixe gerada pela utilização do filtro leva a uma angulação característica nas curvas de isodose. Portanto, a comparação da angulação do perfil gerado pela simulação e do perfil apresentado na literatura constitui outro parâmetro para validação da modelagem adotada. 


\subsubsection{Distribuição de dose na água}

As simulações do feixe de $6 \mathrm{MV}$, utilizado em 3DR, com campo aberto e com a utilização de filtro em cunha, de 30 e de 45 graus, permitiu o estudo de sua distribuição de dose em água, através das curvas de PDP e perfis de dose. Os perfis de dose foram traçados na profundidade de dose máxima, tanto para os dados simulados quanto para os dados da literatura.

\subsubsection{Campo aberto}

A comparação da curva de PDP simulada à curva de PDP da literatura, para o campo aberto, está apresentada na Figura 7.

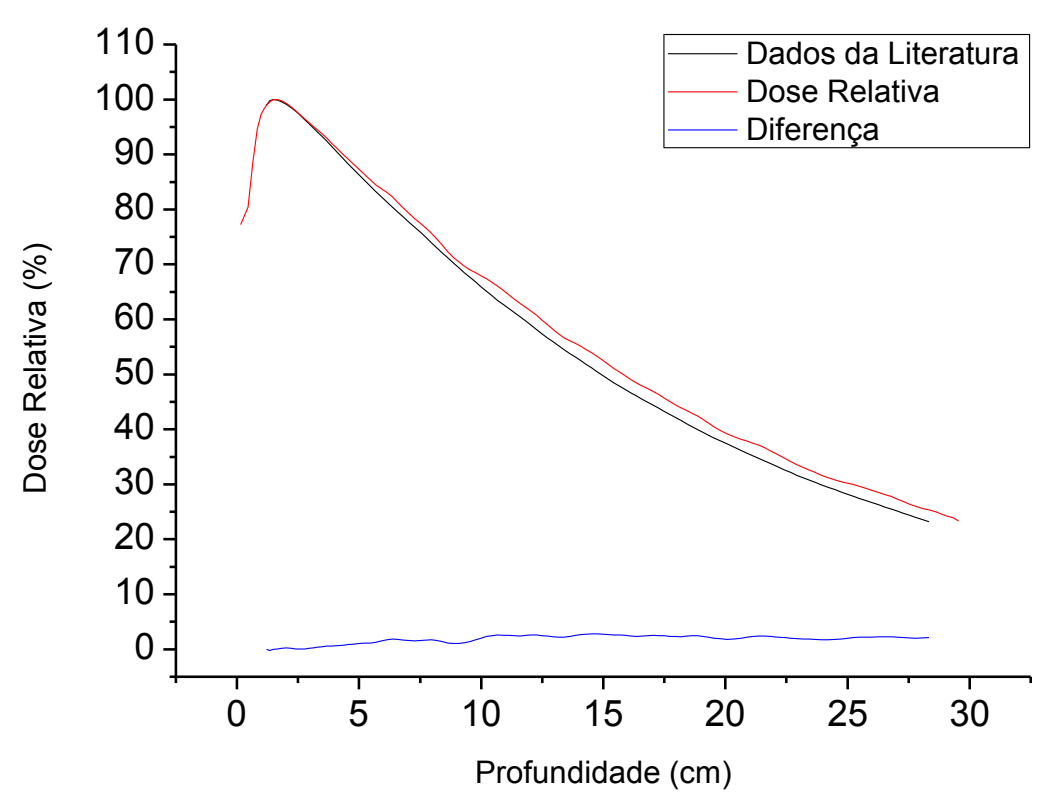

Figura 7: Curva de PDP para campo aberto. Dados de simulação Monte Carlo (vermelho), da literatura (preto) e a diferença entre as curvas (azul).

É possível observar que, a curva simulada aproxima-se da curva de PDP da literatura em toda sua extensão, principalmente para regiões de baixa profundidade, até $5 \mathrm{~cm}$, onde a diferença entre as curvas não ultrapassa 0,94 pp. A maior diferença entre as doses que ocorrem em uma mesma profundidade é de $2,78 \mathrm{pp}$, para a profundidade de $14,54 \mathrm{~cm}$. A diferença entre os dados está dentro da incerteza da simulação, de aproximadamente $4 \%$. A profundidade em que ocorrem as doses de interesse $D_{\max }, D_{80 \%}$ e $D_{50 \%}$ estão apresentadas na Tabela 1. 
Tabela 1: Profundidades nas quais ocorrem doses de interesse para feixe de teleterapia convencional para campo aberto.

\begin{tabular}{|l|l|l|l|}
\hline & $D_{\max }(\mathrm{cm})$ & $D_{80 \%}(\mathrm{~cm})$ & $D_{50 \%}(\mathrm{~cm})$ \\
\hline Literatura & 1,49 & 6,47 & 14,91 \\
\hline Simulação & 1,65 & 6,87 & 15,81 \\
\hline Diferença & 0,16 & 0,4 & 0,9 \\
\hline
\end{tabular}

O maior deslocamento de dose em profundidade é observado para a dose de $50 \%$, de $0,9 \mathrm{~cm}$. Esses resultados indicam uma correlação aceitável entre os dados obtidos no presente trabalho e aqueles apresentados no trabalho de comparação.

Os perfis de dose, obtidos através de simulação do feixe de $6 \mathrm{MV}$ com campo aberto, e da literatura, ambos traçados no ponto de máxima dose, estão apresentados na Figura 8.

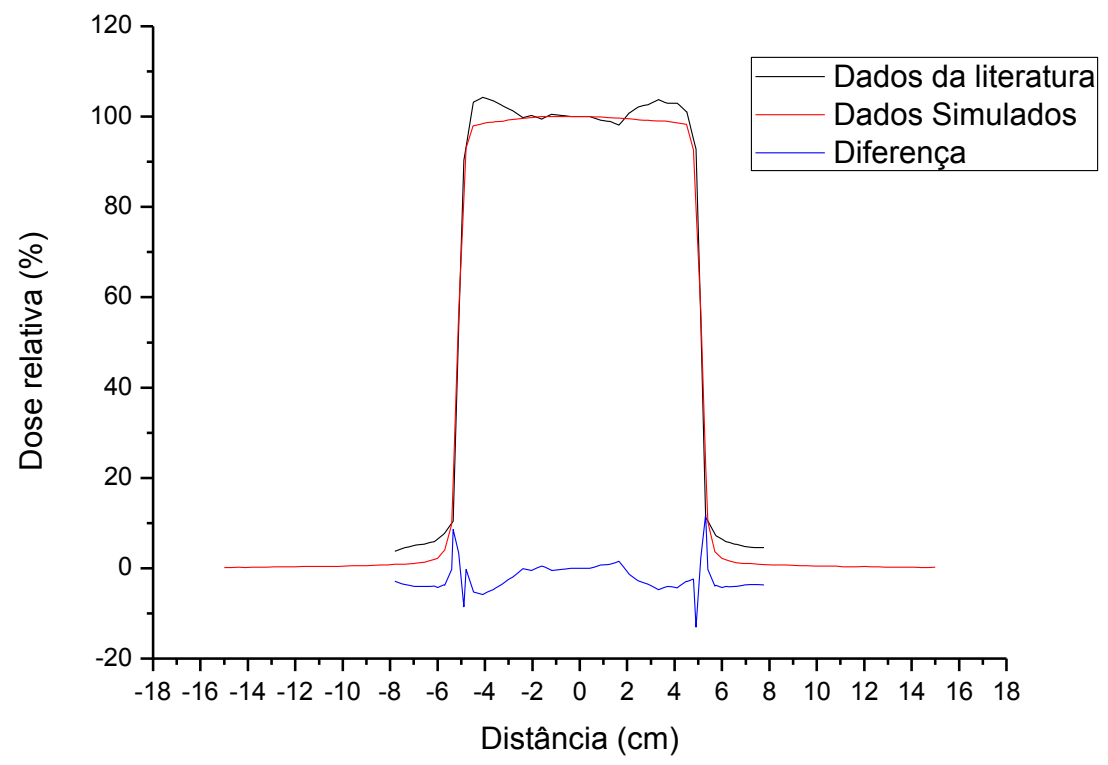

Figura 8: Perfil de dose para campo aberto. Dados de simulação Monte Carlo (vermelho), da literatura (preto) e a diferença entre as curvas (azul).

Em regiões de dose maiores que $80 \%$, o perfil simulado tem variação máxima na entrega de dose, em relação ao perfil da literatura, de 7,42\%. Para a região de doses maiores que $80 \%$ a maior diferença entre o perfil simulado e o perfil da literatura é de 5,69 pp, a uma distância de 4,2 cm do centro do campo, onde o perfil da literatura apresenta aumento característico da dose. Eles não ocorrem no perfil simulado pois foi utilizado na simulação o espectro do eixo central, que não representa a fluência energética maior nas bordas do campo, como ocorre no feixe real. Ao comparar-se a totalidade das curvas encontrou-se a 
maior diferença, em pontos percentuais, de $-13,0$ pp a uma distância de $4,9 \mathrm{~cm}$ do centro do campo, portanto próximo a região de penumbra.

\subsubsection{Filtros físicos}

A curva de PDP obtida através de simulação para o filtro de 30 graus está apresentada na Figura 9.

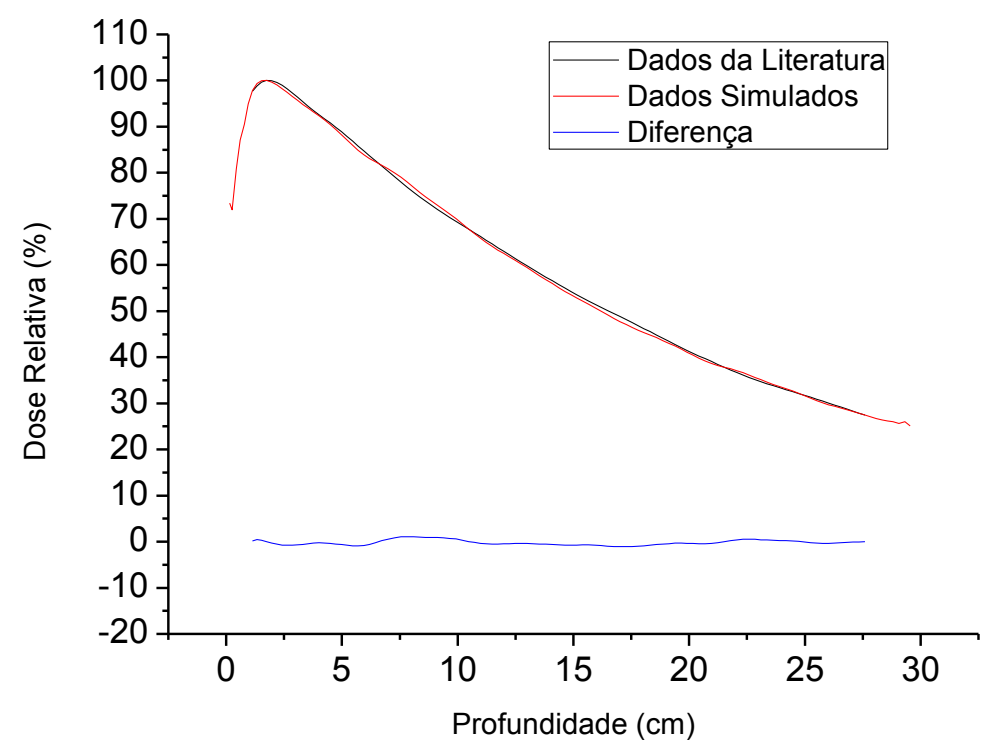

Figura 9: Curva de PDP para filtro de 30 graus. Dados de simulação Monte Carlo (vermelho), da literatura (preto) e a diferença entre as curvas (azul).

Pode-se observar que a curva de PDP simulada, para o filtro de 30 graus, que as curvas de PDP simulada e da literatura estão próximas em toda sua extensão. A maior diferença entre doses ocorridas em uma mesma profundidade foi de $17,75 \mathrm{pp}$ em 0,25 cm. A comparação foi feita ponto a ponto, e, a uma profundidade de $0,25 \mathrm{~cm}$ os pontos da curva da literatura foram interpolados. Após a região de build up, a maior diferença entre as curvas foi de $1,10 \mathrm{pp}$, em $7,82 \mathrm{~cm}$.

Na Tabela 2 estão apresentadas as posições para as quais ocorrem as doses de interesse. O maior deslocamento de dose em profundidade ocorreu para a dose de $50 \%$, sendo de $0,21 \mathrm{~cm}$.

Tabela 2: Profundidades nas quais ocorrem doses de interesse para feixe de teleterapia convencional com filtro de 30 graus.

\begin{tabular}{|l|l|l|l|}
\hline & $D_{\max }(\mathrm{cm})$ & $D_{80 \%}(\mathrm{~cm})$ & $D_{50 \%}(\mathrm{~cm})$ \\
\hline Literatura & 1,74 & 7,07 & 16,41 \\
\hline Simulação & 1,74 & 7,27 & 16,20 \\
\hline Diferença & - & 0,20 & $-0,21$ \\
\hline
\end{tabular}


Para o filtro de 30 graus, o perfis de dose, da simulação e da literatura, traçados na profundidade de dose máxima, estão apresentados na Figura 10.

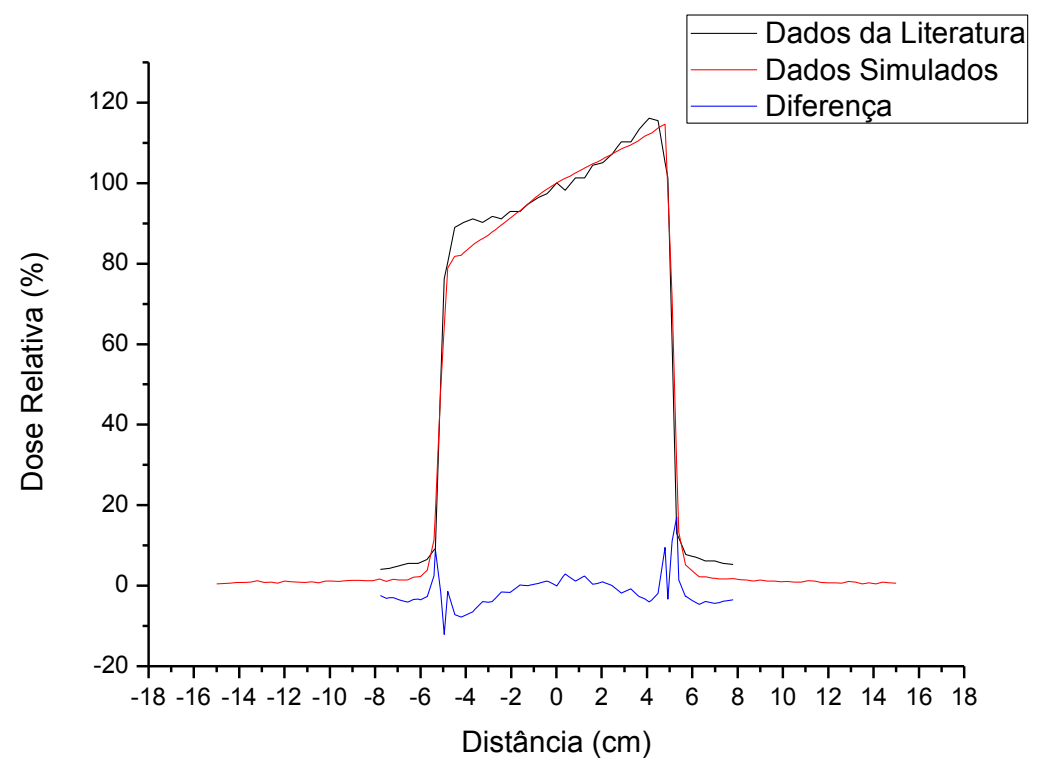

Figura 10: Perfil de dose para filtro de 30 graus. Dados de simulação Monte Carlo (vermelho), da literatura (preto) e a diferença entre as curvas (azul).

O perfil simulado apresenta a angulação característica causada pelo filtro. Analogamente ao campo aberto, a maior diferença em pontos percentuais ( $p p$ ), entre dados simulados e da literatura, foi de 17,00 pp em uma distância de 5,31 cm, na região de doses menores que $80 \%$, portanto na região de penumbra do campo. Para a região central do campo, onde ocorrem doses maiores que $80 \%$ a maior diferença entre as curvas foi de 9,48 pp, em um distância de 4,8 cm do centro do campo, onde o pico da curva simulada aparece deslocado em $0,71 \mathrm{~cm}$ em relação ao pico da curva da literatura.

A comparação entre a curva de PDP simulada, para o filtro de 45 graus, e a curva de PDP da literatura está apresentada na Figura 11. 


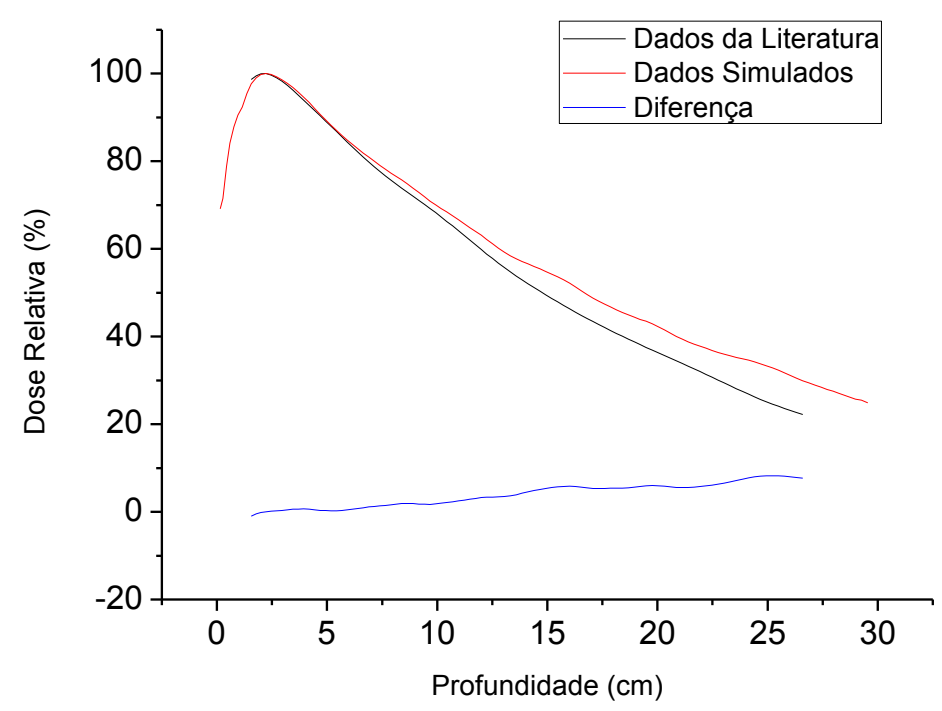

Figura 11: Curva de PDP para filtro de 45 graus. Dados de simulação Monte Carlo (vermelho), da literatura (preto) e a diferença entre as curvas (azul).

Para o filtro de 45 gruas, a curva de PDP simulada aproxima-se da curva de PDP da literatura desde a região de build up até uma profundidade de $5 \mathrm{~cm}$. A maior diferença entre as curvas é de 14,46 pp, em 0,27 cm. Novamente essa diferença ocorre devido à necessidade de interpolar e filtrar os dados da referência para que seja realizada a comparação ponto a ponto dos dados. Após a região de build up a maior diferença entre as curvas ocorrem em $25,22 \mathrm{~cm}$, sendo de $8,25 \mathrm{pp}$.

Os deslocamentos para as doses de interesse estão apresentados na Tabela 3. O máximo deslocamento da dose em profundidade ocorreu, para a dose de 50\%, de 1,91 cm.

Tabela 3: Profundidades nas quais ocorrem doses de interesse para feixe de teleterapia convencional com filtro de 45 graus.

\begin{tabular}{|l|l|l|l|}
\hline & $D_{\max }(\mathrm{cm})$ & $D_{80 \%}(\mathrm{~cm})$ & $D_{50 \%}(\mathrm{~cm})$ \\
\hline Literatura & 2,23 & 6,86 & 14,77 \\
\hline Simulação & 2,23 & 7,15 & 16,68 \\
\hline Diferença & - & 0,29 & 1,91 \\
\hline
\end{tabular}

A análise das curvas de PDP e das posições em que ocorrem a dose máxima, dose de $80 \%$ e dose de $50 \%$, indica que o feixe simulado no presente trabalho torna-se mais endurecido, após passagem pelo filtro, do que o feixe de comparação, apresentado na literatura. A obtenção de um feixe mais duro pode ser resultado de divergências nas modelagens adotadas no presente trabalho e no estudo de comparação. O material utilizado para a simulação do filtro, a sua posição e orientação em relação ao feixe, são aspectos que 
podem divergir entre o presente trabalho e o trabalho de comparação, diferenciando o feixe simulado do feixe da literatura.

O perfil para o filtro de 45 graus está apresentado na Figura 12.

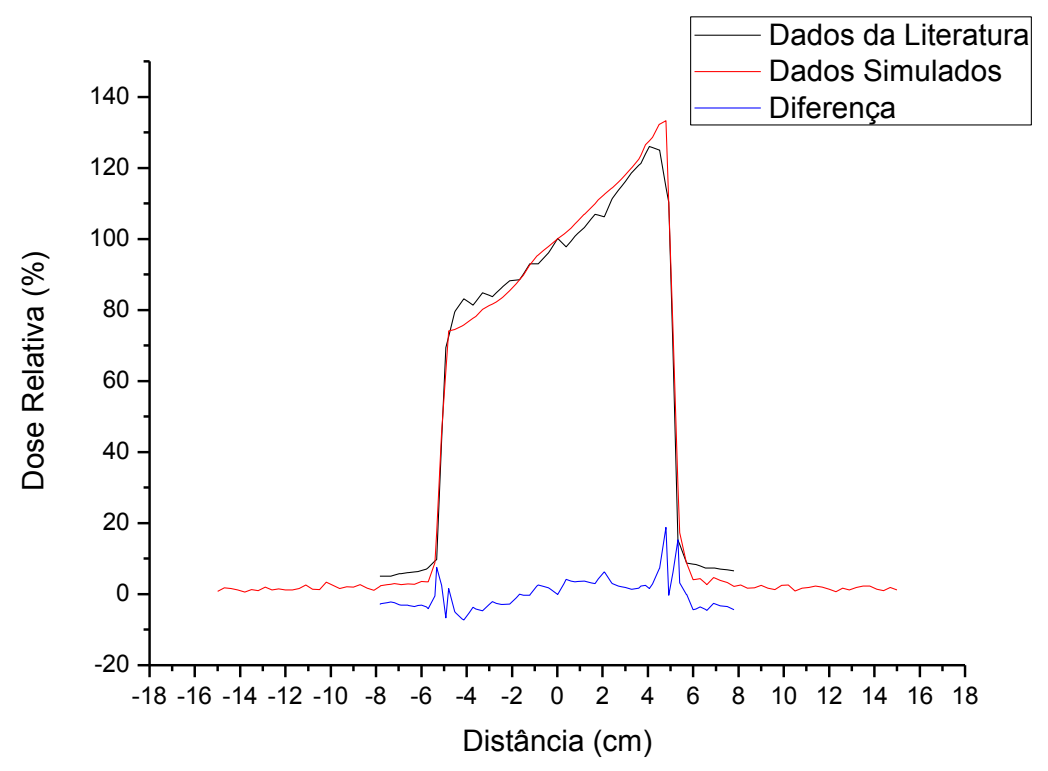

Figura 12: Perfil de dose para filtro de 45 graus. Dados de simulação Monte Carlo (vermelho), da literatura (preto) e a diferença entre as curvas (azul).

O perfil para o filtro de 45 graus mostra a angulação esperada para o filtro de 45 graus. Nesse caso a curva simulada apresenta maior diferença em relação à curva da literatura a uma distância de 4,8 cm do centro, onde ocorre o pico da curva simulada. Essa diferença foi de $18,79 \mathrm{pp}$, e o deslocamento entre os picos foi de $0,73 \mathrm{~cm}$. Deve-se observar que os dados da literatura são influenciados por ruído. $O$ ponto de $100 \%$ encontra-se em um pico de ruído, alterando a normalização de toda a curva e contribuindo para a diferença entre os dados simulados e da literatura.

De forma geral, é possível inferir, pela angulação dos perfis simulados com filtros de 30 e de 45 graus, que a dose na simulação é homogeneizada conforme ocorre na prática, de forma que o espectro após o filtro tenha comportamento próximo ao esperado. Embora os resultados ultrapassem o limite de $5 \%$ aceito na clínica a modelagem adotada nessa seção será utilizada para os próximos estudos.

\subsubsection{Avaliação do espectro transmitido}

$\mathrm{Na}$ avaliação de doses de tratamento será utilizada uma geometria mais complexa, que representa o tórax feminino e possibilita a simulação do tratamento com as técnicas estudadas. $\mathrm{O}$ aumento da complexidade da geometria leva a um aumento do tempo de 
simulação e da capacidade de processamento exigida para isso, portanto é importante otimizar os demais aspectos da simulação.

Uma forma de otimizar as simulações do presente trabalho é eliminar a simulação da passagem de cada partícula do feixe primário pelo filtro e utilizar como feixe inicial para simulações mais complexas o espectro após o filtro. O código PENELOPE traz diversas ferramentas, com diferentes graus de detalhamento, para registro do espectro em um ponto ou corpo existente na simulação.

Com o objetivo de selecionar a ferramenta mais vantajosa, foi realizada a avaliação do espectro de fótons após o filtro. A avaliação da homogeneidade da fluência de fótons em diferentes posições após o filtro (centro e laterais) permitiu avaliar o uso do espectro do eixo central em todas as simulações. Desta forma, foi necessária a avaliação do espectro de radiação após o filtro no eixo central, à direita (parte mais fina do filtro) e a esquerda( parte mais espessa do filtro).

Para esse estudo foi tomada como base a geometria utilizada para modelagem do filtro: composta por objeto simulador cúbico de água de $30 \mathrm{~cm}$ de aresta, filtro físico e seu suporte, e envoltório de ar. Foram adicionados a essa geometria três detectores esféricos de $0,5 \mathrm{~cm}$ de raio, preenchidos com ar, e posicionados após o filtro, de forma que o feixe interagisse com diferentes espessuras do filtro antes de atravessar os detectores, como mostrado na Figura 13. Os detectores armazenam informações de fluência e energia das partículas que os atravessam. A definição de corpos como detectores e o registro das partículas que o atravessam é realizado através da ferramenta chamada de impact detector, disponível no pacote de simulação Monte Carlo PENELOPE.

O denominado detector 1 está posicionado após a região de maior espessura do filtro; o detector 2 está no eixo central e o detector 3 está colocado após a região de menor espessura do filtro. Foram registradas partículas de energias entre $10^{5}$ e $10^{7} \mathrm{eV}$, divididas em 100 intervalos de energia.

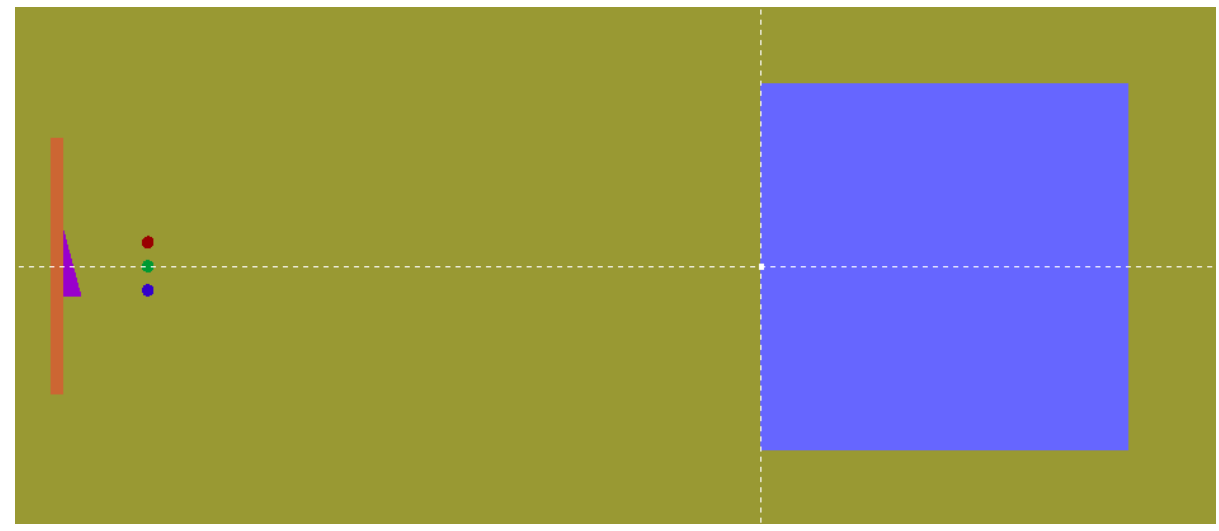

Figura 13: geometria utilizada para avaliação do espectro pós filtro. Objeto simulador de $30 \mathrm{~cm}$ de lado (azul), filtro de 30 graus e suporte (roxo e laranja, respectivamente) e os detectores 1 (marinho), 2 (verde) e 3 (vermelho). 
Os espectros obtidos após interação do feixe primário em posições de diferentes espessuras do filtro estão apresentados na Figura 14.

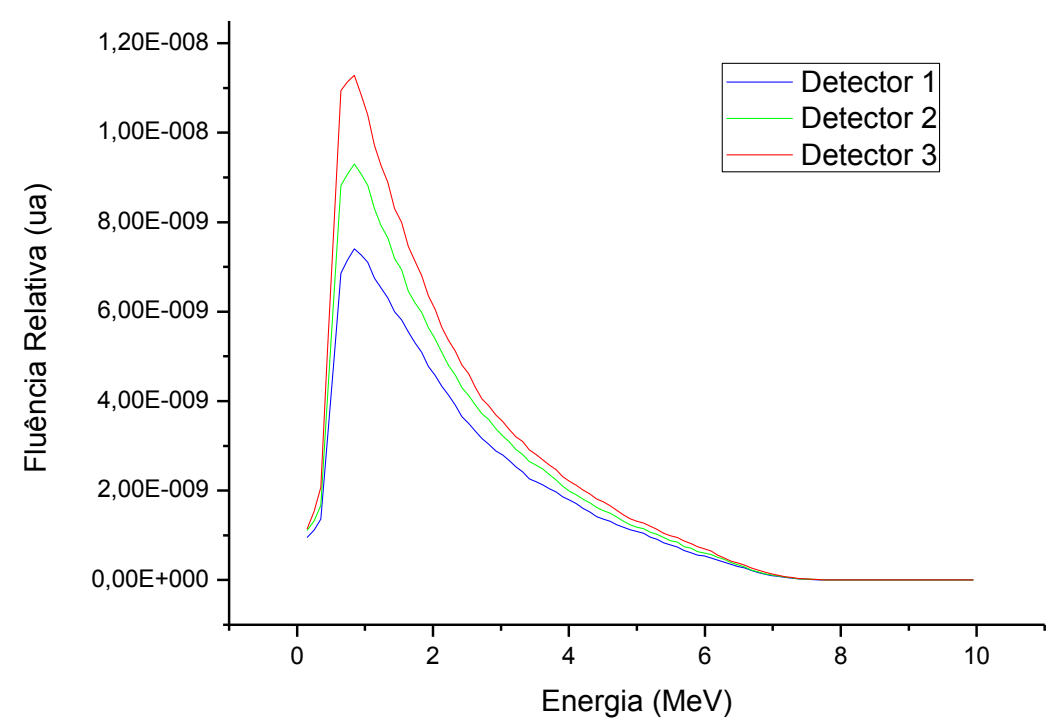

Figura 14:Espectros transmitidos nos detectores 1 (azul), 2 (verde) e 3 (vermelho).

O detector 1 , correspondente à posição de menor espessura do filtro, teve a maior fluência, por ser menos atenuado, enquanto que o espectro transmitido no detector 3 , posicionado após a região de maior espessura do filtro, foi mais atenuado e, portanto, apresenta menor fluência de fótons.

Enquanto o feixe foi modificado em intensidade, a energia manteve-se a mesma, ou seja, não houve criação de fótons de outras energias e o espectro se mantém o mesmo em toda a extensão do campo. Portanto, conclui-se que o espectro central representa o comportamento médio do espectro de partículas após interação com o filtro. Dessa forma, a utilização da ferramenta impact detector gera informações suficientes sobre o espectro transmitido para que o espectro do eixo central possa ser utilizado como feixe primário nas próximas simulações.

O espectro central obtido após o filtro de 30 graus está apresentado na Figura 15. 


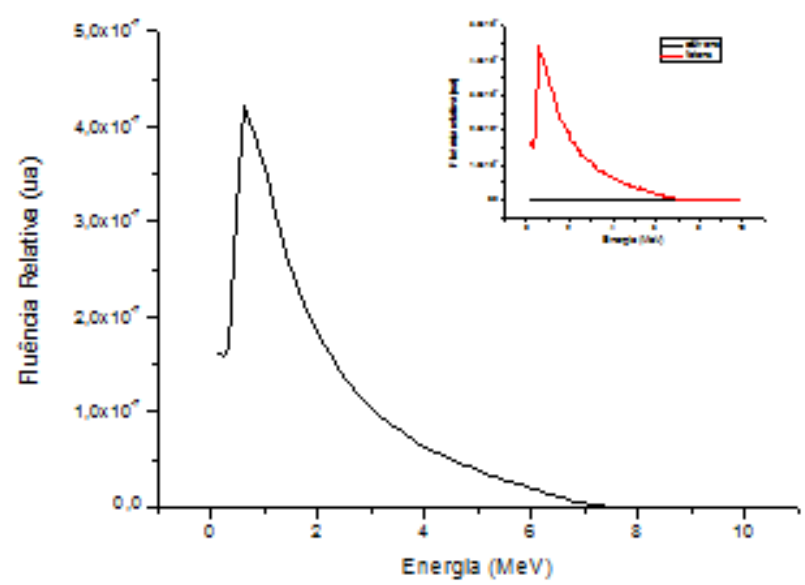

Figura 15: Espectro de fótons central após o filtro de 30 graus. No adendo pode-se observar a diferença entre a quantidade de fótons e elétrons presentes no espectro.

O espectro central obtido após o filtro de 45 graus está apresentado na Figura 16.

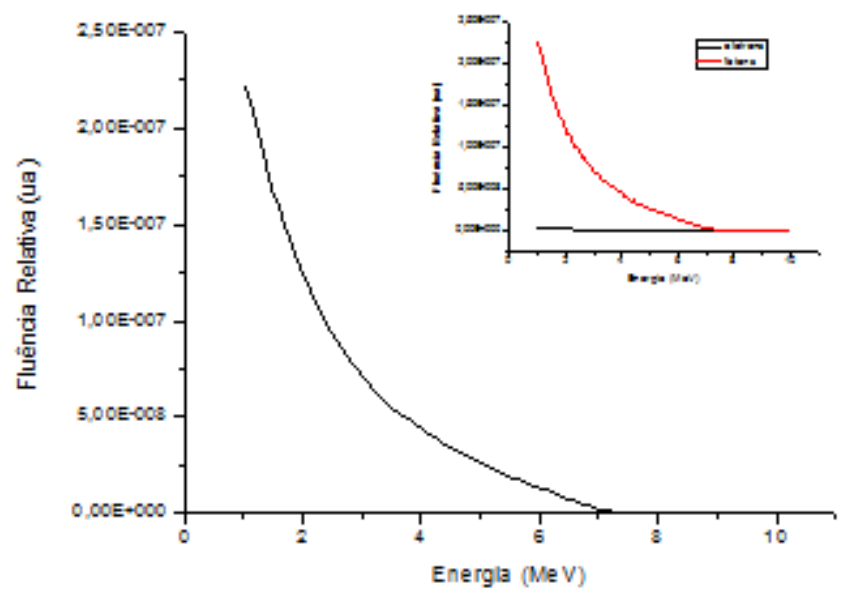

Figura 16: Espectro de fótons central após o filtro de 45 graus. No adendo pode-se observar a diferença entre a quantidade de fótons e elétrons no espectro.

\subsection{Radioterapia intra-operatória por feixe de elétrons}

\subsubsection{Espectro do feixe primário}

Com o intuito de simular o tratamento através da unidade de IORT NOVAC7, deve-se conhecer o feixe e avaliar a modelagem adotada para representá-lo. Para isso, foram realizadas simulações de geometria simples, que possibilitam o estudo da distribuição de dose na água gerada pelo NOVAC7 e suas características dosimétricas. 
A geometria utilizada para esse estudo contou com um aplicador, característico da unidade de terapia NOVAC7, e objeto simulador apresentados na Figura 17. O aplicador consistiu em um cilindro de acrílico (PMMA), preenchido por ar, de 0,5 cm de espessura e $10 \mathrm{~cm}$ de diâmetro total. $O$ objeto simulador foi um cubo de água de $20 \mathrm{~cm}$ de lado. $O$ tamanho do objeto simulador foi definido conforme descrito na literatura (Pimpinella et al, 2007).
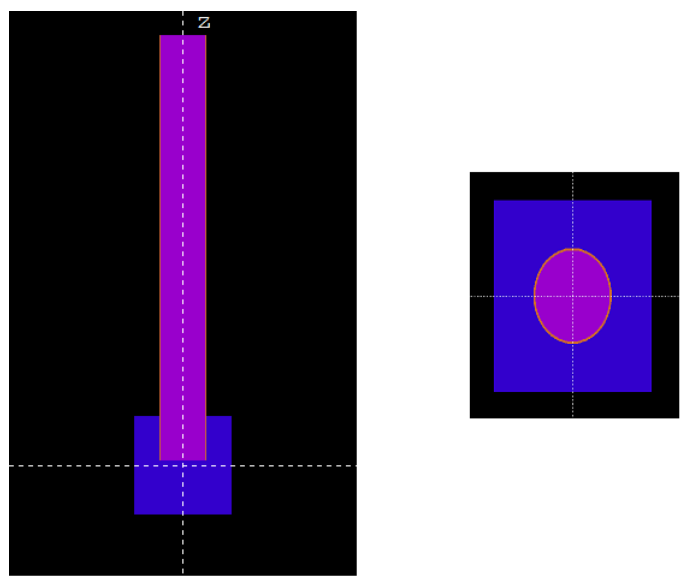

a

b

Figura 17: geometria utilizada para váıuação da modelagem do aceler auur NOVAC7. Aplicador cilíndrico (laranja), preenchido por ar (roxo) posicionado em um objeto simulador de água (azul). Vista frontal (a) e vista superior (b).

Foram utilizados os espectros polienergéticos disponíveis na literatura para o NOVAC7, de energias nominais de 5, 7 e $9 \mathrm{MeV}$, apresentados na Figura 18 (Mihailescu e Borcia, 2014).

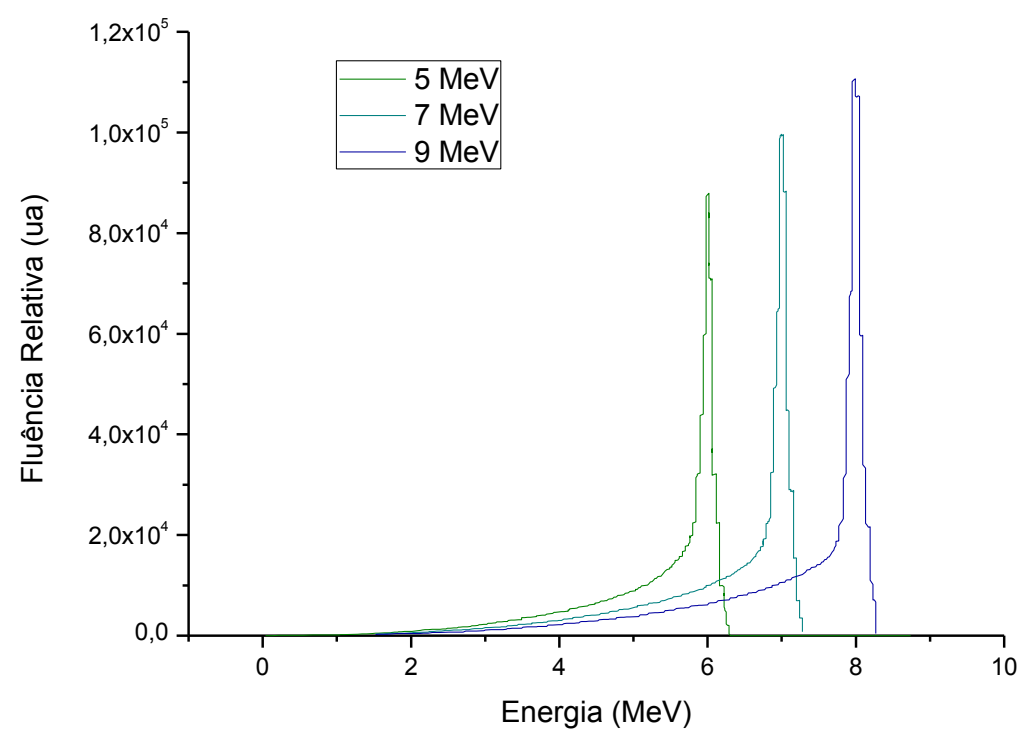

Figura 18: Espectro de elétrons gerado pelo acelerador NOVAC7 para as energias de 5 (verde), 7 (ciano) e 9 $\mathrm{MeV}$ (azul). 
Os parâmetros de controle da simulação foram mantidos os mesmo para todas as energias simuladas. Os parâmetros que controlam a simulação foram mantidos nos valores $W_{c c}=W_{c r}=10^{7}$. As energias de corte foram modificadas de acordo com o material. Para ar e PMMA, a energia de corte para os elétrons foi definida como $100 \mathrm{keV}$, para os fótons a energia de corte foi de $1 \mathrm{keV}$ e para pósitrons, também $100 \mathrm{keV}$. Para a água, onde se quer caracterizar a distribuição de dose, a contribuição dos elétrons deve ser melhor considerada, portanto sua energia de corte foi estabelecida em $1 \mathrm{keV}$, assim como para fótons. A energia de corte dos pósitrons permaneceu $100 \mathrm{keV}$.

A validação da modelagem adotada foi realizada através da comparação dos dados simulados com dados de PDP disponíveis na literatura (Pimpinella et al 2007).

\subsubsection{Distribuição de dose na água}

As curvas de PDP obtidas com a simulação do feixe gerado pelo NOVAC7 foram normalizadas para o máximo valor de dose fora do aplicador, para cada uma das energias: 5, 7 e $9 \mathrm{MeV}$. Os dados simulados foram então comparados com os dados disponíveis no trabalho de Pimpinella e colaboradores, (2007).

Na Figura 19 estão apresentadas a curva de PDP, simulada e da literatura, para o feixe de $5 \mathrm{MeV}$.

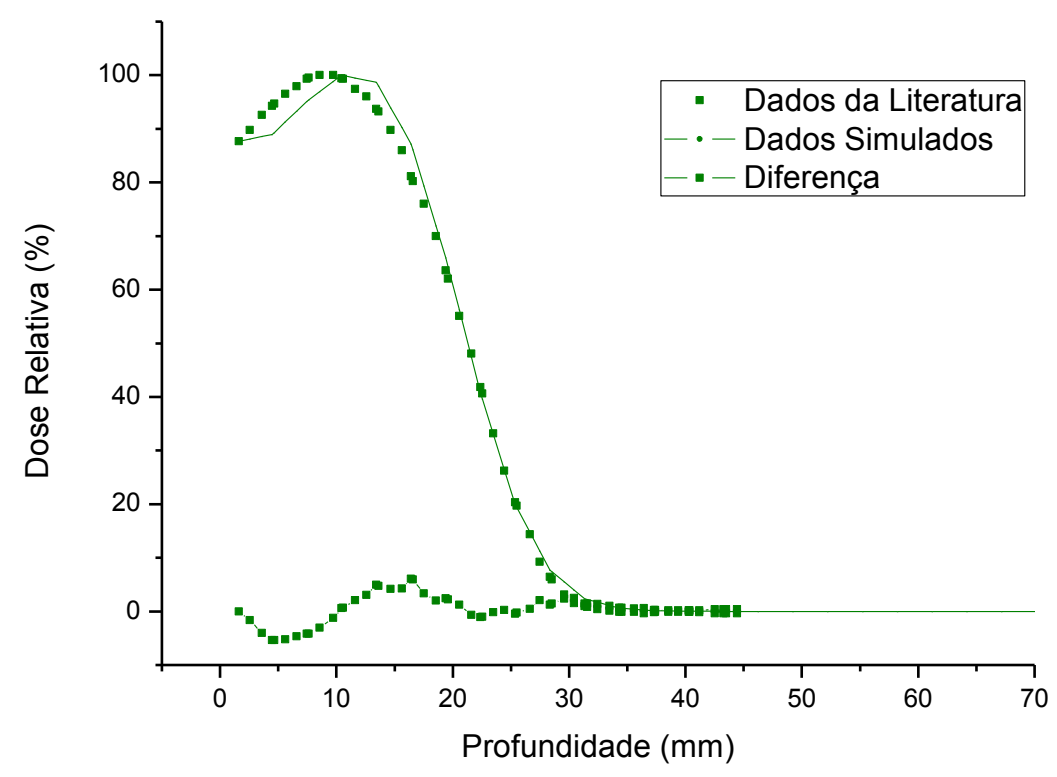

Figura 19: Curvas de PDP para as energias de $5 \mathrm{MeV}$. Os dados simulados (linha cheia), dados da literatura (pontos) e a diferença entre as curvas (linha + ponto). 
A maior diferença observada entre simulação e literatura, para o feixe de $5 \mathrm{MeV}$, foi de $6,44 \mathrm{pp}$ na profundidade de $16,42 \mathrm{~mm}$ próximo ao build up para a curva da literatura. 0 deslocamento entre as curvas, para a dose de $90 \%$, isodose de referência para radioterapia com elétrons (Beddar et al, 2006), foi de 1,22 mm, analisado após a região de máxima dose.

O alcance dos elétrons para porcentagens de interesse está apresentado na Tabela 4. 0 maior deslocamento em profundidade observado para a dose máxima foi de 3,74 $\mathrm{mm}$. 0 alcance prático divergiu em 1,17 mm entre dados simulados e da literatura.

Tabela 4: Profundidades nas quais ocorrem doses de interesse para feixe de elétrons intra-operatório de $5 \mathrm{MeV}$

\begin{tabular}{|l|l|l|l|l|}
\hline & $R_{\max }(\mathrm{mm})$ & $R_{80 \%}(\mathrm{~mm})$ & $R_{50 \%}(\mathrm{~mm})$ & $R_{\mathrm{p}}(\mathrm{mm})$ \\
\hline Literatura & 8,57 & 16,57 & 21,31 & 29,91 \\
\hline Simulação & 10,45 & 17,52 & 21,29 & 28,74 \\
\hline Diferença & 1,88 & 0,95 & $-0,02$ & 1,17 \\
\hline
\end{tabular}

A Figura 20 mostra as curvas de PDP para o feixe de $7 \mathrm{MeV}$.

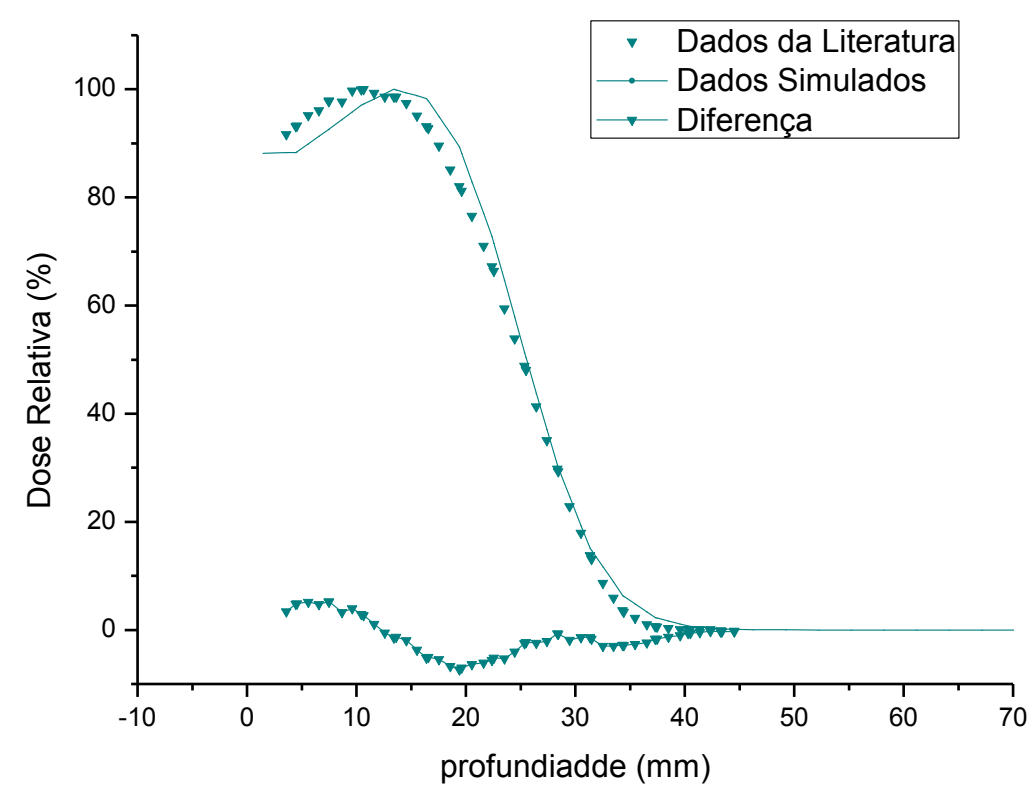

Figura 20: Curvas de PDP para as energias de $7 \mathrm{MeV}$. Os dados simulados (linha cheia), dados da literatura (pontos) e a diferença entre as curvas (linha + ponto).

Para o feixe de $7 \mathrm{MeV}$ a maior diferença entre curva de PDP simulada e a literatura, foi de 7,33 pp na profundidade de 17,51 mm. Para a curva de PDP simulada, a dose de $90 \%$ ocorreu para a profundidade de 19,61 mm, estando deslocada em 1,95 mm em relação a curva de PDP da literatura.

A comparação dos alcances para o feixe de $7 \mathrm{MeV}$ está apresentada na Tabela 5. 0 maior deslocamento entre as curvas ocorre para a dose máxima, de 2,76 mm. O alcance 
prático para o feixe simulado foi de $34,91 \mathrm{~mm}$, divergindo do valor da literatura em $0,54 \mathrm{~mm}$.

Tabela 5: Profundidades nas quais ocorrem doses de interesse para feixe de elétrons intra-operatório de $7 \mathrm{MeV}$

\begin{tabular}{|l|l|l|l|l|}
\hline & $R_{\max }$ & $R_{80 \%}$ & $R_{50 \%}$ & $R_{p}$ \\
\hline Literatura $(\mathrm{mm})$ & 10,67 & 19,91 & 25,16 & 35,45 \\
\hline Simulação $(\mathrm{mm})$ & 13,43 & 21,09 & 25,05 & 34,91 \\
\hline Diferença $(\mathrm{mm})$ & 2,76 & 1,18 & $-0,11$ & 0,54 \\
\hline
\end{tabular}

A curva de PDP simulada para o feixe de $9 \mathrm{MeV}$ e sua comparação com dados da literatura está apresentada na Figura 21.

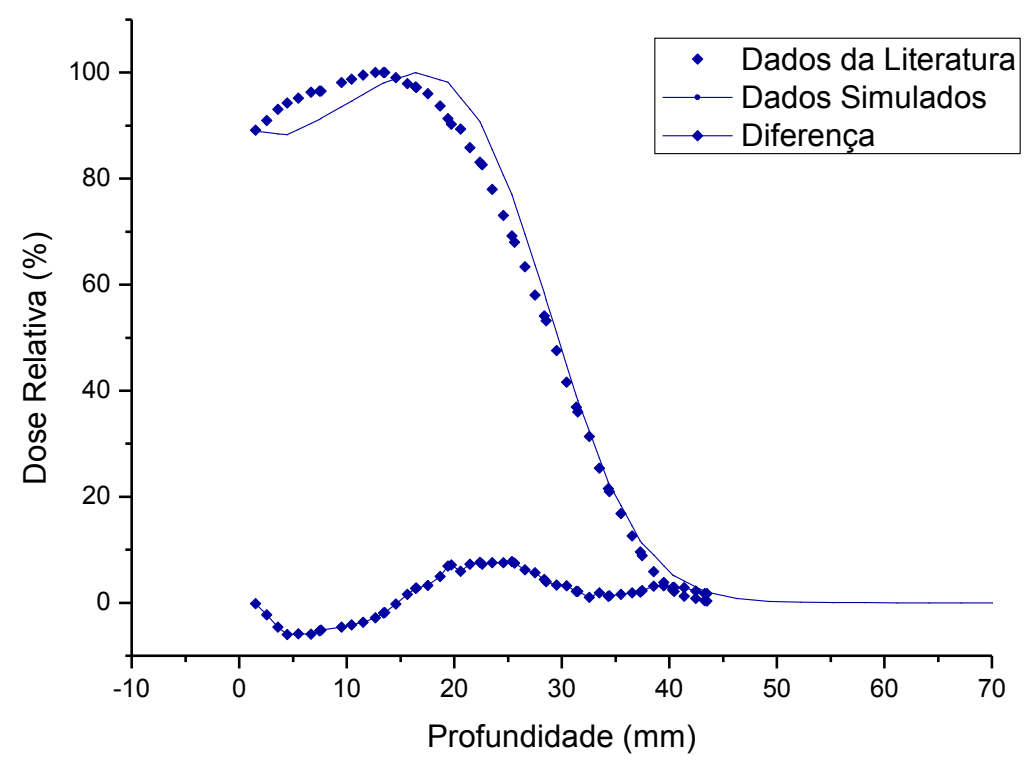

Figura 21: Curvas de PDP para as energias de $9 \mathrm{MeV}$. Os dados simulados (linha cheia), dados da literatura (pontos) e a diferença entre as curvas (linha + ponto).

A maior diferença observada entre simulação e literatura foi de 7,78 pp, para a energia de $9 \mathrm{MeV}$ na profundidade de 23,49 $\mathrm{mm}$. Analisando a profundidade para a qual ocorre a dose de $90 \%$, confirma-se que a modelagem apresentou maiores diferenças para o feixe de $9 \mathrm{MeV}$, apresentando um deslocamento entre as curvas de até 5,16 $\mathrm{mm}$ na região de buildup. O deslocamento na região de build up leva a entrega de dose em profundidades baixas. Em tratamento com IORT deseja-se irradiar o leito tumoral, portanto uma região próxima ao aplicador, de forma que o deslocamento encontrado não traz prejuízo a simulação dessa técnica.

A maior diferença entre os alcances para o feixe de $9 \mathrm{MeV}$ ocorreu, assim como para as outras energias, para a máxima dose, de 3,74 mm, como apresentado na Tabela 6 . 0 alcance 
prático foi de $39,70 \mathrm{~mm}$ para os dados simulados e de 40,67 $\mathrm{mm}$ para os dados da literatura, apresentando uma diferença de $0,97 \mathrm{~mm}$ entre eles.

Tabela 6: Profundidades nas quais ocorrem doses de interesse para feixe de elétrons intra-operatório de $9 \mathrm{MeV}$

\begin{tabular}{|l|l|l|l|l|}
\hline & $R_{\max }(\mathrm{mm})$ & $R_{80 \%}(\mathrm{~mm})$ & $R_{50 \%}(\mathrm{~mm})$ & $R_{\mathrm{p}}(\mathrm{mm})$ \\
\hline Literatura & 12,68 & 23,11 & 29,10 & 40,67 \\
\hline Simulação & 16,42 & 24,57 & 29,66 & 39,70 \\
\hline Diferença & 3,74 & 1,46 & 0,56 & 0,97 \\
\hline
\end{tabular}

Com esses resultados, é possível perceber que a modelagem adotada leva a um feixe mais energético em comparação com a literatura, diminuindo a entrega de dose em profundidades pequenas ao mesmo tempo em que alcança profundidades maiores. Entretanto, é importante salientar que, por se tratar de feixe de elétrons, estão sendo avaliadas distâncias milímétricas. Portanto, as divergências encontradas podem ser aceitas.

Os dados da literatura, utilizados para comparação, são obtidos também através de método Monte Carlo, e, como tal, estão sujeitos a incertezas de modelagem desconhecidas. Além disso, diferentes códigos Monte Carlo utilizam diferentes aproximações para a simulação do transporte de partículas, de forma que a simples utilização de diferentes códigos leva a resultados diferentes. Qualquer um desses aspectos pode contribuir para a divergência entre os dados simulados e da literatura, entretanto, não há como quantificar a contribuição ou apontar a exata causa das divergências.

\subsection{Radioterapia intra-operatória por raios-X de baixa energia}

\subsubsection{Espectro do feixe primário}

Para a modelagem do feixe gerado pelo Intrabeam, ao contrário da 3DR e do feixe de elétrons, não foi utilizado o espectro de raios-X encontrado na literatura. A configuração diferenciada deste aplicador, que conta com um alvo de ouro em formato hemisférico, uma sonda de $9,0 \mathrm{~cm}$ de comprimento e tem a fonte de elétrons a apenas $1,6 \mathrm{~cm}$ do alvo, torna preferível a simulação de toda a produção do feixe de raios- $X$, partindo de uma fonte de elétrons monoenergéticos de $50 \mathrm{kVp}$.

A fonte de radiação foi posicionada no interior da sonda, a 1,6 cm do alvo, em seu centro de curvatura. A sonda foi modelada segundo o descrito no trabalho de Yanch e Harte (1996) e foi posicionada na superfície de um objeto simulador cúbico de água de $30 \times 30 \times 30 \mathrm{~cm}^{3}$, conforme apresentado na Figura 22. 


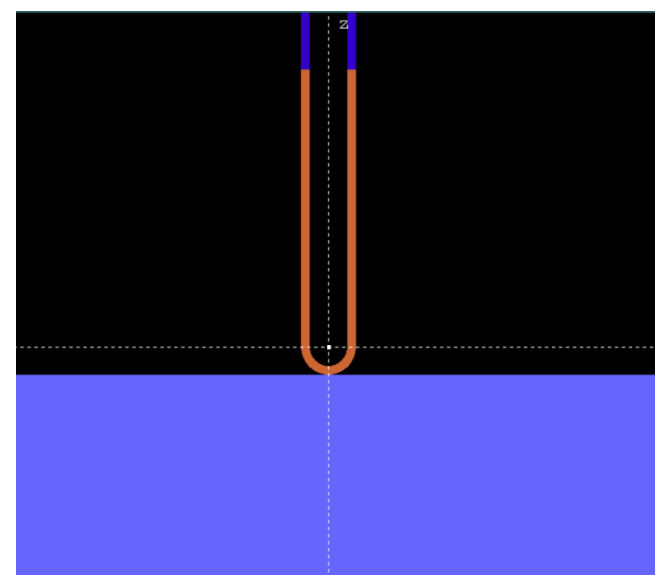

Figura 22: geometria utilizada para validação da modelagem do feixe produzido pelo acelerador Intrabeam. Em detalhe, a sonda do acelerador e parte do objeto simulador.

Assim como para a validação do feixe modificado com filtros para 3DR, na simulação do feixe gerado pelo Intrabeam o espectro de raios- $X$ deve ser simulado detalhadamente, uma vez que ele será responsável pela deposição de dose no tecido a ser tratado e suas características dosimétricas devem ser estudadas. Dessa forma os parâmetros de simulação foram definidos como $W_{c c}=0$ e $W_{c r}=-1$. A energia de corte das partículas foi definida em 1 keV para todos os tipos de partícula. Os parâmetros $C_{1}$ e $C_{2}$ foram mantidos em 0,1.

O espectro de raios- $X$ produzido pela simulação no objeto simulador foi, assim como para o espectro após o filtro nas simulações do feixe de 3DR, obtido através da ferramenta impact detector do pacote de simulação Monte Carlo PENELOPE. O detector consistia em um cilindro de água de $1,5 \mathrm{~mm}$ de raio e $0,5 \mathrm{~mm}$ de altura, onde foram registradas partículas com energias de 1 a $51 \mathrm{keV}$ em 500 intervalos de 0,1 keV. O espectro simulado foi comparado com o espectro disponível na literatura (Watson e Seuntjens, 2016). A comparação entre os espectros representa, nesse caso, mais uma ferramenta de validação da modelagem, pois indica se os raios- $X$ estão sendo produzidos conforme esperado para a configuração de fonte de radiação pretendida.

Foi realizada uma comparação ponto a ponto dos dois espectros, simulado e da literatura, apresentada na Figura 23. 


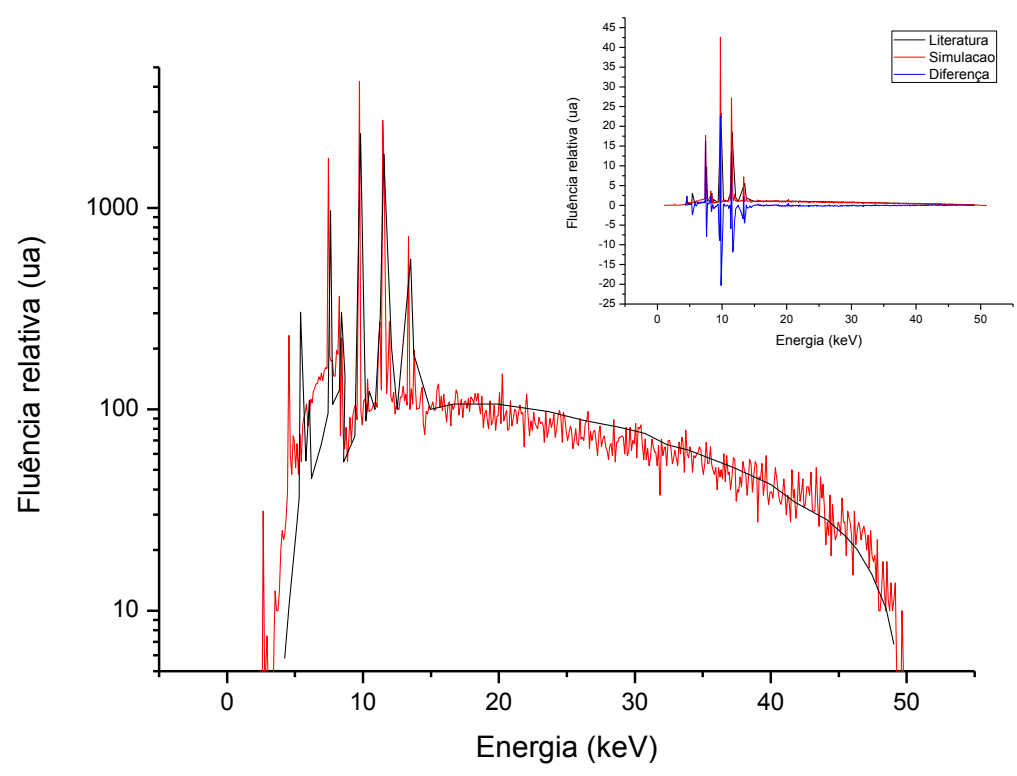

Figura 23: Espectros de raios-X simulado (vermelho) e encontrado na literatura (preto) em escala logarítmica. No adendo está apresentado os dois espectros, em escala linear, juntamente com a curva de diferença ponto a ponto entre espectros.

A maior diferença relativa encontrada entre simulação e literatura foi de 22,6 pp, ocorrendo para a energia de 9,75 keV. Em energias baixas, como 9,75 keV, ocorrem, no espectro simulado, linhas de energia que não existem no espectro da literatura. A existência de ar entre as extremidades do alvo, que tem formato esférico, e o detector contribui para o espectro detectado, gerando as linhas de baixa energia visualizadas. A influência dessas linhas nas características dosimétricas do feixe foi avaliada através da comparação das curvas de PDP simuladas com a curva de PDP obtida na literatura (Watson e Seuntjens, 2016).

\subsubsection{Distribuição de dose em água}

A Figura 24 apresenta a comparação entre a curva de PDP simulada e da literatura. 


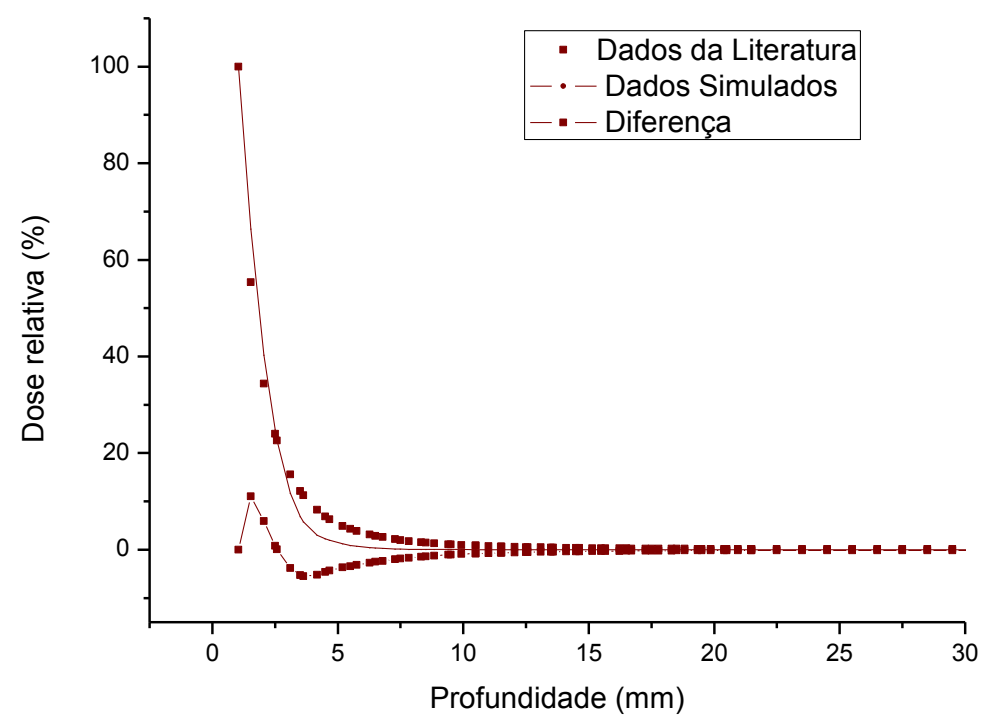

Figura 24:Curvas de PDP simulada (linha cheia), encontrada na literatura (pontos) e diferença ponto a ponto entre elas (linha+pontos).

Ao comparar-se a curva de PDP simulada com a literatura, a maior diferença percentual observada entre elas foi de 11 pp em 1,53 mm, região de doses mais altas. Na profundidade de prescrição, a $10 \mathrm{~mm}$, a diferença não passou de 0,92 pp (Figura 17). Essa diferença pode ser explicada pela presença de fótons de energias mais baixas no espectro.

Na figura 25 a curva de PDP simulada sem as linhas de baixa energia foi comparada à curva de PDP da literatura.

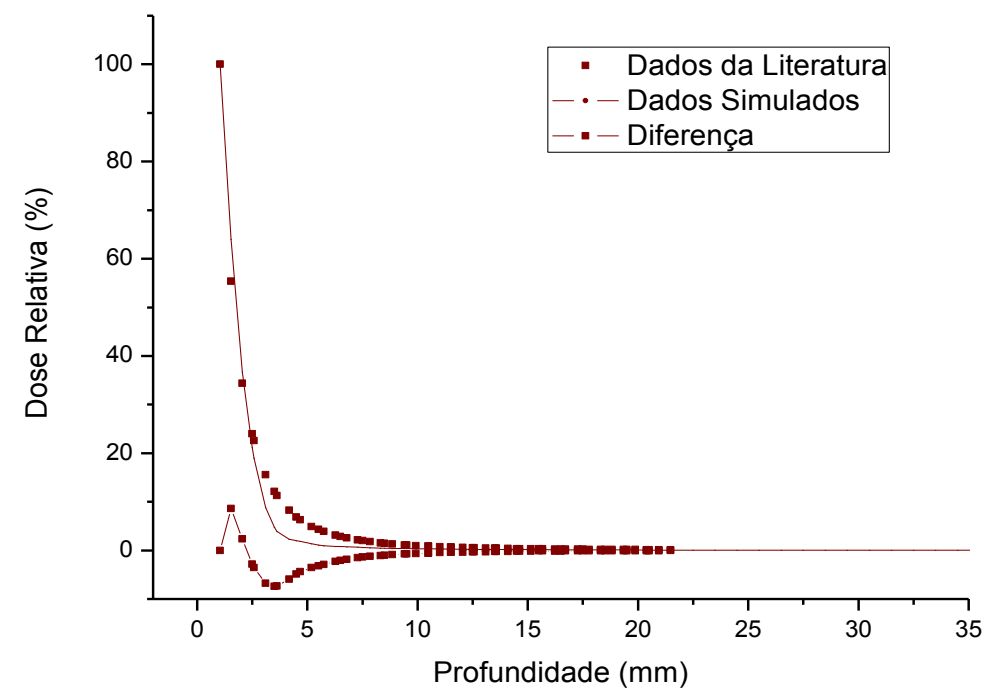

Figura 25: Curva de PDP simulada com espectro onde as linhas de menor energia foram retiradas manualmente (linha cheia) e a PDP obtida na literatura (pontos). Também está apresentada a diferença entre essas curvas (linha+pontos). 
Comparando-se, então, a curva de PDP simulada sem as linhas de baixa energia do espectro com a curva da literatura temos uma diferença máxima de $8,6 \mathrm{pp}$ na profundidade de 1,5 mm. Essa diferença foi calculada ponto a ponto, entretanto, as tendências das PDP com a profundidade nas duas distribuições é coincidente, como mostra a Figura 23 Por se tratar de uma profundidade bastante próxima à fonte de radiação, a presença de linhas de baixa energia não constitui fator de grande influência para o tratamento, em especial na profundidade de prescrição, o que nos permite utilizar a fonte de radiação como modelado, gerando todo o espectro a partir de elétrons de $50 \mathrm{keV}$.

$\mathrm{Na}$ tabela 7 estão apresentadas as profundidades onde ocorrem porcentagens de dose de interesse. Através dessa análise a maior diferença ocorre para a dose de $50 \%$, região de queda brusca na deposição de dose.

Tabela 7: Profundidades nas quais ocorrem doses de interesse para raios-X de baixa energia intra-operatório.

\begin{tabular}{|l|l|l|l|}
\hline & $D_{\max }(\mathrm{mm})$ & $D_{80 \%}(\mathrm{~mm})$ & $D_{50 \%}(\mathrm{~mm})$ \\
\hline Literatura & 1,05 & 1,26 & 1,67 \\
\hline Simulação & 1,05 & 1,33 & 1,86 \\
\hline Diferença & - & 0,07 & 0,19 \\
\hline
\end{tabular}

\section{Simulação do tratamento}

Com o objetivo de comparar o tratamento para câncer de mama aplicado através das diferentes técnicas, 3DR, IORT por feixe de elétrons e IORT por feixe de raios- $\mathrm{X}$, foram realizadas simulações que pudessem representar as condições nas quais se dá o tratamento.

Tanto quanto possível, foi adotada, na simulação, a configuração padrão na clínica, para o posicionamento dos campos e dos aplicadores utilizados em cada modalidade de radioterapia estudada. As simulações foram realizadas utilizando uma geometria representativa do formato e material que compõe a mama.

Foram obtidas distribuições de dose total e dentro da mama. As distribuições permitem uma avaliação qualitativa da deposição de dose, através das curvas de isodose. Para as técnicas de IORT a representação da deposição de dose é interessante por não ter sido foco de estudo na literatura existente. 


\subsection{Desenvolvimento da geometria realística}

Para que a simulação gere resultados condizentes com o que se esperaria do tratamento é necessário, mais uma vez, que a representação da situação seja a mais próxima possível da real.

Uma vez que se deseja estudar a distribuição de dose obtida para o tratamento para câncer de mama através das técnicas determinadas, deve-se utilizar uma geometria que represente toda a área que pode ser afetada pelo tratamento, não apenas a mama, mas também o tórax da paciente. Foi então desenvolvida uma geometria que reproduzisse o tórax feminino em formato, posicionamento das estruturas e tecidos que as compõe.

A geometria de tórax feminino desenvolvida teve como base o arquivo "male.geo", disponibilizado pelo PENELOPE. Esse arquivo corresponde ao corpo de um homem, da cabeça aos pés, contando com membros inferiores, superiores e órgãos internos. Os órgãos, como pulmão, coração e estômago, foram retirados e a geometria foi limitada de forma que apenas o tórax permanecesse representado. A retirada desses corpos foi realizada para que a simulação fosse otimizada, já que manter os órgãos internos na geometria levaria a um comprometimento do tempo da simulação, que seria parcialmente gasto no transporte das partículas nessas estruturas. Essa estratégia se justifica, ainda, pelo foco do trabalho ser a distribuição de dose dentro da mama.

Finalmente, foram adicionados corpos cônicos, que simulam as mamas em si. Foram desenvolvidas estruturas com três diferentes tamanhos, representando diferentes volumes mamários, classificados, como grande, médio e pequeno, conforme apresentados na Figura 26 (McGhee e Steele, 2011)

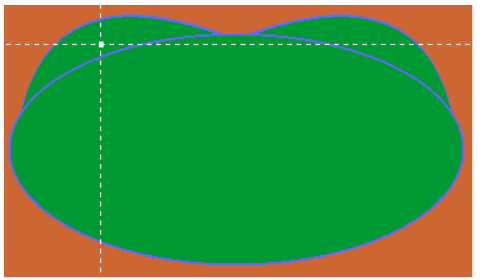

a

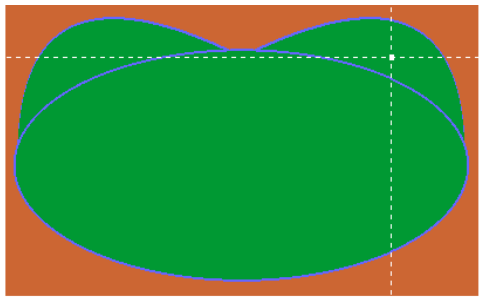

b

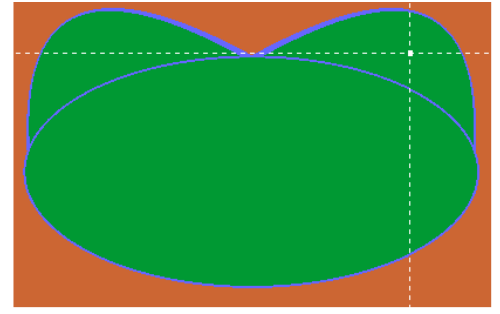

C

Figura 26: geometria de tórax feminino utilizada para simulação do tratamento de volume mamário pequeno (a), médio (b) e grande (c). O mesmo material está apresentado na mesma cor.

Os materiais que compõem a geometria são: tecido mole, pele e ar. O tecido mole preenche o interior das mamas e do tórax, enquanto a pele os reveste. $\mathrm{O}$ ar envolve todas as estruturas. Os três volumes mamários foram utilizados para simulação do tratamento com cada uma das técnicas estudadas nesse trabalho. 


\subsection{Radioterapia 3D}

\subsubsection{Irradiação de mama}

Com base na simulação de validação descrita na seção 3.1, foi utilizado, como fonte de radiação para a simulação do tratamento através de 3DR o espectro de fótons após interação com o filtro. O espectro do filtro de 30 graus, apresentado na Figura 15, foi utilizado como fonte de radiação para as simulações com geometria de mama de volume grande. Para as geometrias de volume mamário pequeno e médio foi utilizado o filtro de 45 graus, cujo espectro está apresentado na Figura 16.

A fonte foi posicionada a $50 \mathrm{~cm}$ do isocentro, distância equivalente à posição do filtro e, portanto também é correspondente a posição onde o espectro foi gerado.

Segundo protocolos de 3DR a irradiação de mama é realizada combinando-se dois campos paralelos e opostos entre si, denominados campo interno e externo (Borges; Cunha; Teixeira, 2013). Na clínica, o tamanho do campo é definido de acordo com o volume mamário. O campo deve cobrir toda a extensão da mama, enquanto simultaneamente poupa o tórax. Entretanto, a irradiação de uma parcela do tórax é inevitável pela própria configuração do volume alvo e da divergência dos campos de radiação.

Para as simulações o tamanho de campo foi definido a partir de uma margem de aproximadamente $1,0 \mathrm{~cm}$ das extremidades da mama, de forma que o volume mamário fosse completamente irradiado. O tamanho do campo foi ajustado para cada um dos volumes de mama simulados.

Para determinação da distribuição de dose foi definida, para o ar e para a pele, a mesma energia de corte: $100 \mathrm{keV}$ para todas as partículas. Para o tecido mole, material que compõe a mama, é desejável uma simulação mais detalhada. Para esse material a energia de corte foi definida como $1 \mathrm{keV}$, para todos os tipos de partícula. Os parâmetros Wcc e W cr foram mantidos em $10^{7}$. E os parâmetros $C_{1}$ e $C_{2}$ foram definidos em 0,05 .

Os campos, interno e externo, foram simulados separadamente e suas distribuições somadas através de um código específico desenvolvido em Matlab ${ }^{\circledR}$ para manipulação dos arquivos de saída das simulações.

\subsubsection{Distribuição de dose de tratamento}

As distribuições obtidas para a simulação do tratamento através de 3DR estão apresentas na Figura 27. A distribuição foi registrada em um cubo de $30 \times 30 \times 30 \mathrm{~cm}^{3}$, e tem resolução espacial de 0,297 cm. 

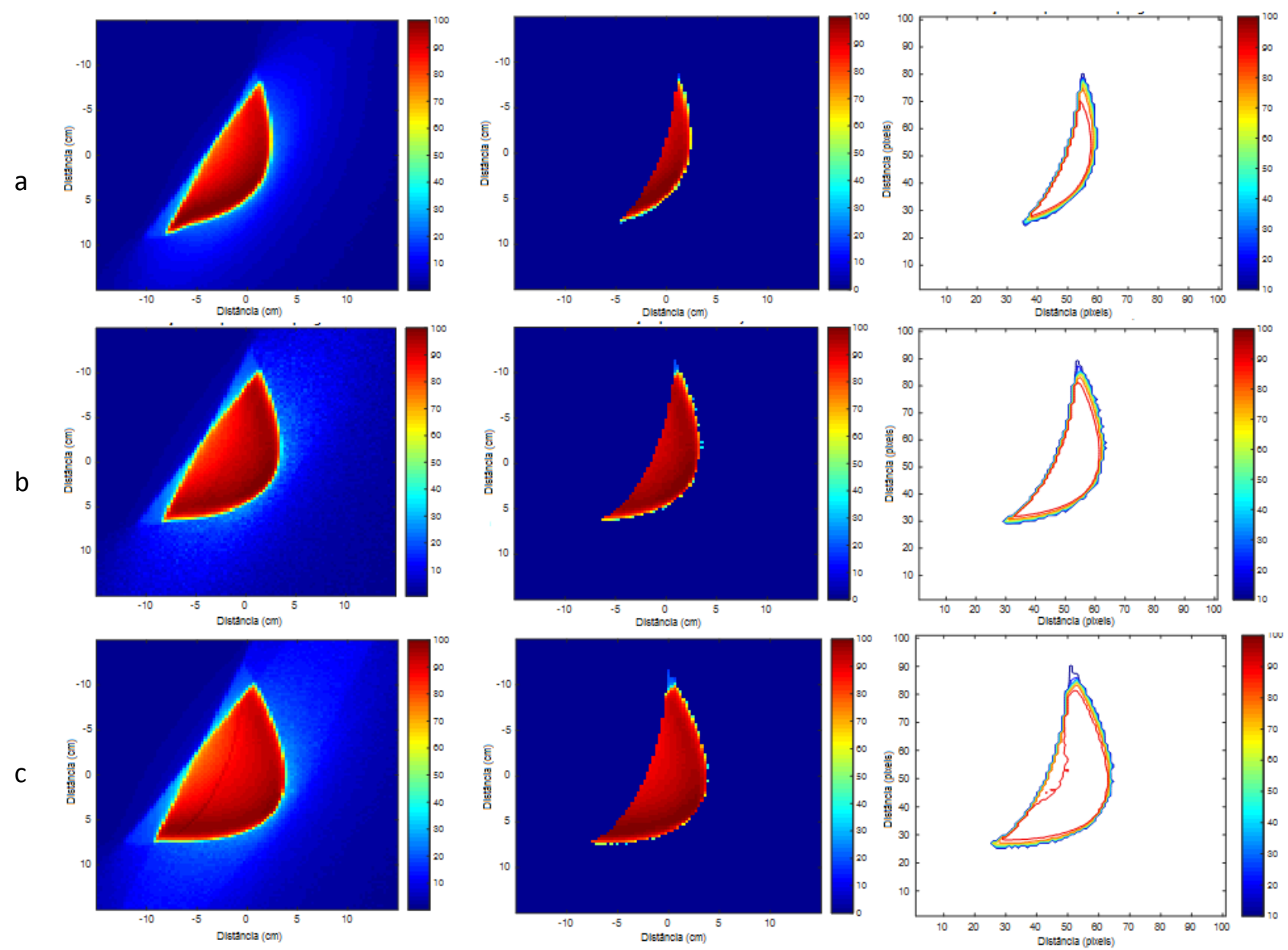

Figura 27: Distribuições de dose obtidas ao simular-se o tratamento com radioterapia 3D para volume mamário a. pequeno, b. médio e c. grande. As figuras da primeira coluna referem-se a distribuição de todo o campo de radiação, na segunda coluna e na terceira coluna estão apresentadas as linhas de isodose.

Através das distribuições de dose, pode-se perceber que as maiores doses são entregues no interior da mama, porém parte considerável da dose está distribuída dentro do tórax, o que pode ser explicado por terem sido consideradas margens grandes na definição do tamanho do campo. Essa é, no entanto, uma característica intrínseca a esse tipo de técnica de tratamento e, ao mesmo tempo, uma das possíveis vantagens de uso de IORT para irradiação de tumores mamários.

O menor volume mamário recebe doses mais altas, quando considerado em sua totalidade. A distribuição de dose na mama de menor volume indica que um lado da mama recebe doses mais altas em comparação com o outro, caracterizando uma distribuição heterogênea, que pode ser explicada por seu formato. Esse aspecto da distribuição também pode ser gerado por um deslocamento do isocentro. No tratamento simulado o isocentro pode estar deslocado de um campo para outro, levando a angulação e distância fontesuperfície distintas para cada um deles, gerando um entrega de dose maior para um campo em relação ao outro. 
A entrega de dose é mais homogênea para o volume médio, pois todo o volume da mama é coberto por doses altas, maiores que $80 \%$. Para a geometria de maior volume mamário a distribuição de dose volta a ser heterogênea, pois doses mais baixas, de até $70 \%$ são entregues dentro da mama.

A adequação da posição do isocentro poderia gerar, para todos os volumes mamários estudados, distribuições de dose mais uniformes e homogêneas, conforme obtido na otimização do plano. As distribuições apresentadas indicam que os planos simulados deveriam ser otimizados.

\subsection{Radioterapia intra-operatória por feixe de elétrons}

\subsubsection{Irradiação de mama}

Para a simulação do tratamento através de IORT por feixe de elétrons, foi adicionada, à geometria de tórax feminino, o aplicador do Novac7, cujas especificações estão descritas na seção 3.2. A geometria total da simulação, composta por objeto simulador de mama e aplicador está apresentada na Figura 28.

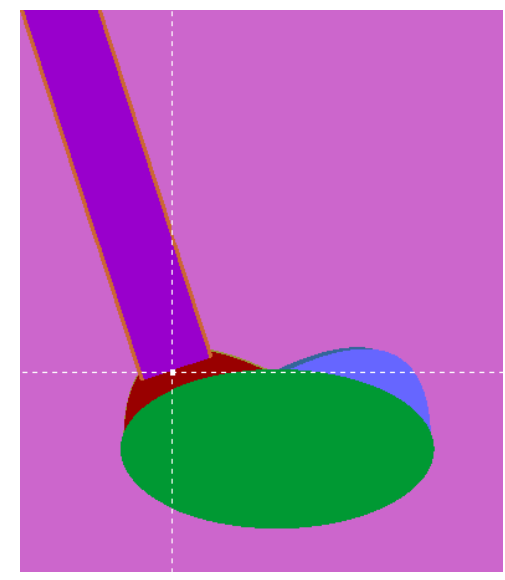

Figura 28: geometria utilizada para simulação do tratamento com radioterapia intra-operatória por feixe de elétrons.

O aplicador foi angulado de forma que sua base ficasse paralela ao tórax. Todo o diâmetro do aplicador deve estar inserido na mama. O diâmetro foi ajustado de acordo com a geometria: para a geometria de volume mamário pequeno foi utilizado o aplicador de $8,0 \mathrm{~cm}$ de diâmetro, enquanto que para os outros volumes manteve-se o aplicador de 10,0 cm de diâmetro utilizado no estudo de validação do feixe.

Assim como na validação, foi utilizado o espectro apresentado no trabalho de Mihailescu e Borcia (2014) posicionado no topo do aplicador, a $87,0 \mathrm{~cm}$ do isocentro. A energia de corte para as partículas que interagem com o tecido mole, componente da mama, foi estabelecida 
em $500 \mathrm{keV}$. Esse valor foi definido considerando o alcance do elétron em relação ao tamanho do voxel analisado, de 0,198 cm. Elétrons com energias menores que $500 \mathrm{keV}$ tem alcance menor que $0,198 \mathrm{~cm}$, e, portanto, a partícula não tem energia suficiente para penetrar no voxels seguinte. Assim, a partir dessa energia a localização da deposição de dose está definida e a partícula pode ser desconsiderada. Para todos os outros materiais, que incluem pele, ar e acrílico, a energia de absorção foi definida em $1 \mathrm{MeV}$. Os parâmetros $\mathrm{W}_{c c}$ e $W_{c r}$ foram definidos em 0 e -1 , enquanto que os parâmetros $C_{1}$ e $C_{2}$ foram mantidos em 0,1 .

Para as simulações com as geometrias de diferentes volumes mamários e com diferentes energias de feixe de elétrons, disponibilizadas pelo NOVAC7, foram geradas as distribuições de dose total e dentro da mama.

\subsubsection{Distribuição de dose de tratamento}

Na Figura 29 estão apresentadas as distribuições de dose total, limitada no interior da mama, e as linhas de isodose para a simulação do tratamento através de IORT por feixe de elétrons de $5 \mathrm{MeV}$, para as geometrias de volume mamário pequeno, médio e grande. 

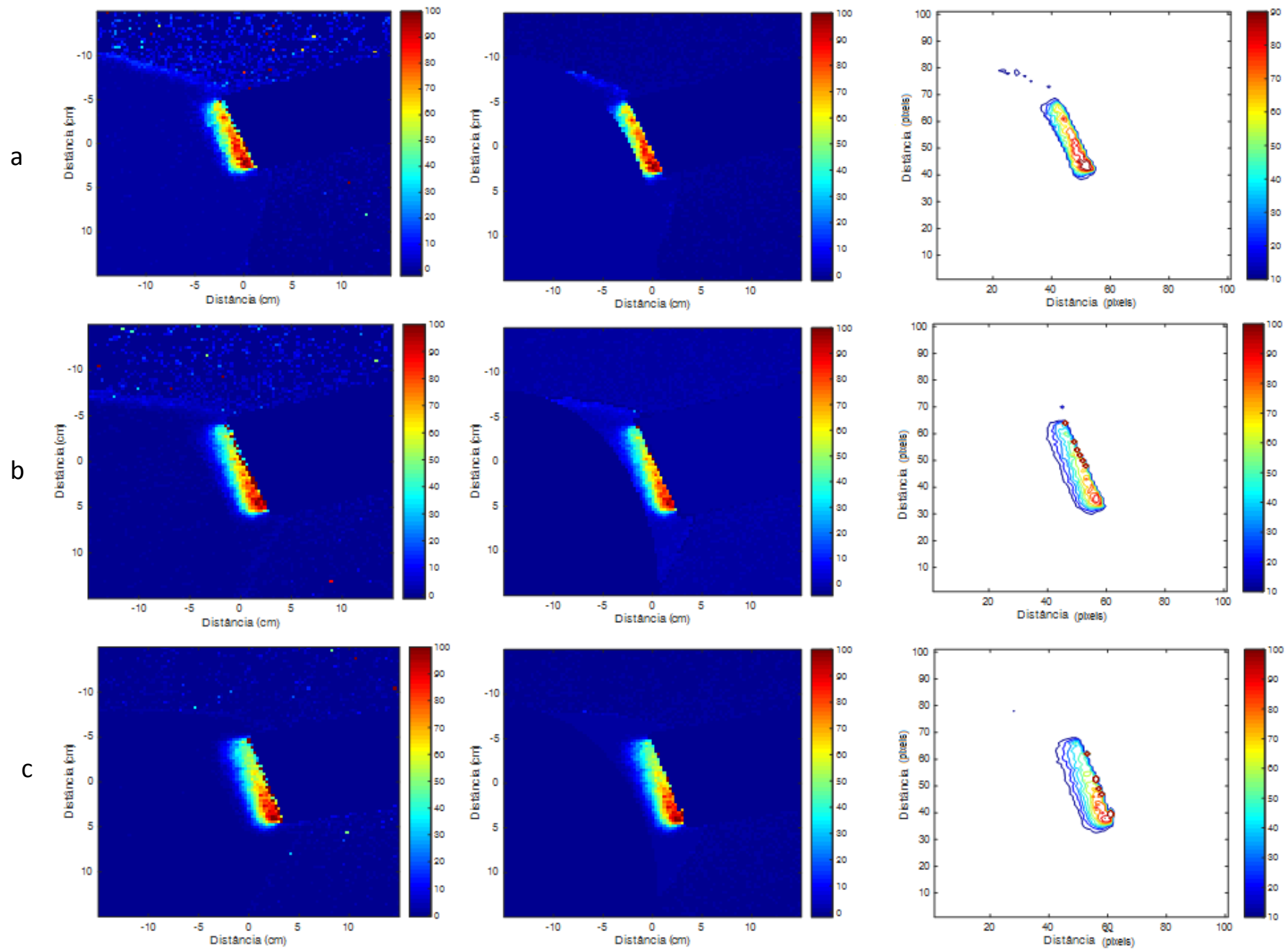

Figura 29: distribuições de dose simulação do tratamento radioterapia intra-operatória por feixe de elétrons de

$5 \mathrm{MeV}$ para as geometrias de volume mamário a. pequeno, b. médio e c. grande. Na primeira coluna está apresentada a distribuição total, enquanto na segunda coluna tem-se a distribuição apenas dentro da mama.

$\mathrm{Na}$ terceira estão apresentadas as curvas de isodose.

Para uma melhor visualização da entrega de dose na mama, a distribuição foi normalizada para o maior valor de dose dentro da mama e a escala de cores foi limitada para $100 \%$, já que valores de dose maiores são depositadas nos voxels de interface ar-mama.

Independentemente do tamanho da mama, para a energia de $5 \mathrm{MeV}$, as distribuições de dose indicam que toda a dose é entregue dentro da mama, livrando completamente a parede do tórax de altas doses. Para a mama de menor volume, a deposição de dose completa a extensão da mama em profundidade, enquanto que para a mama grande não apresenta toda a sua profundidade irradiada. Além disso, a distribuição mostra-se mais homogênea para a mama de menor volume devido ao tamanho do aplicador utilizado.

Percebe-se que as distribuições têm aspecto angulado, ocasionado pela angulação do aplicador e o plano escolhido para sua representação. Para que fosse possível a visualização da distribuição de dose completa no eixo central, foram realizadas simulações com o 
aplicador posicionado sem angulação. Analogamente ao mostrado na Figura 29, estão apresentadas na Figura 30 as distribuições total, dentro da mama e as linhas de isodose no eixo central, com o aplicador posicionado sem angulação para o feixe de $5 \mathrm{MeV}$.

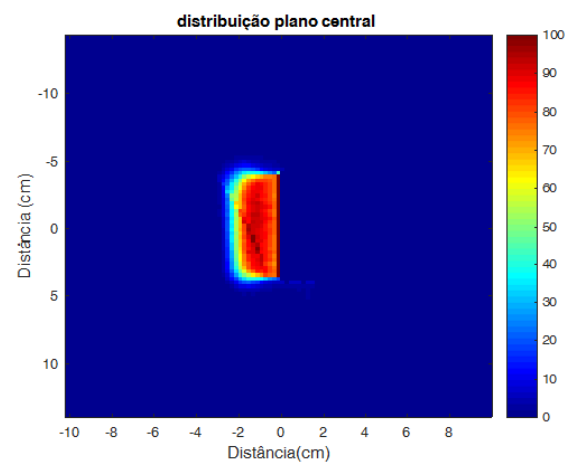

distribuição plano central

b

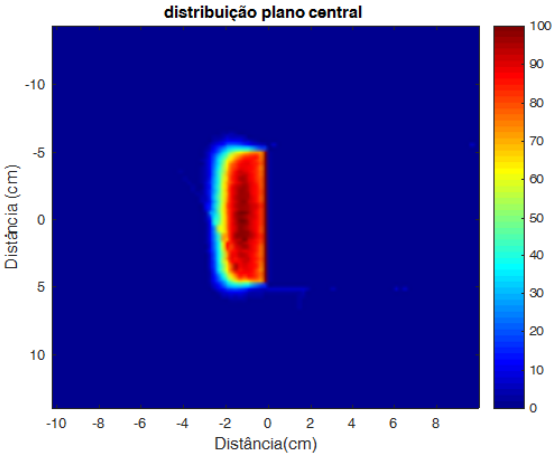

distribuição plano central

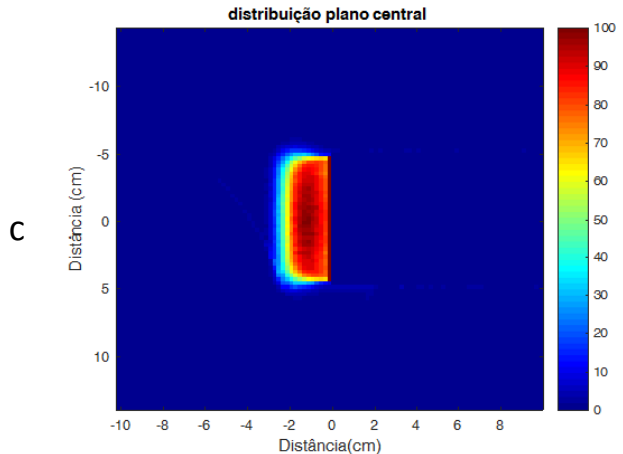

distribuição plano central

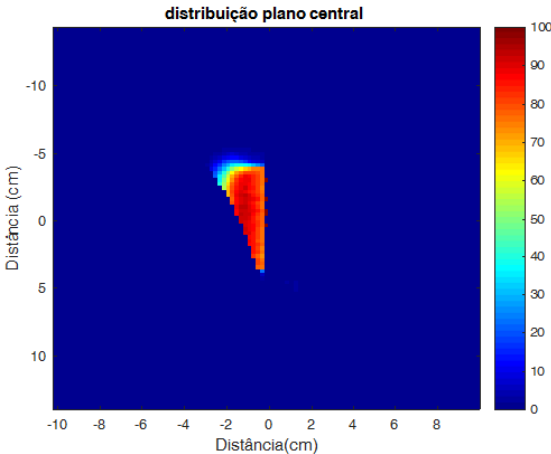

distribuição plano central

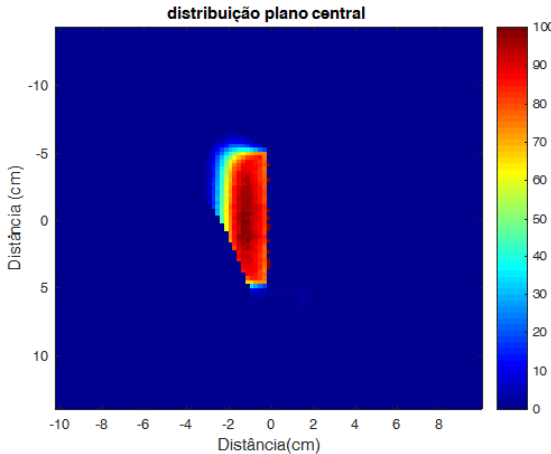

distribuição plano central

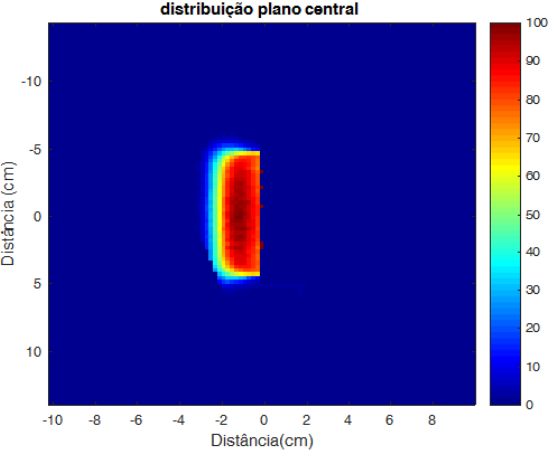

curvas de isodose
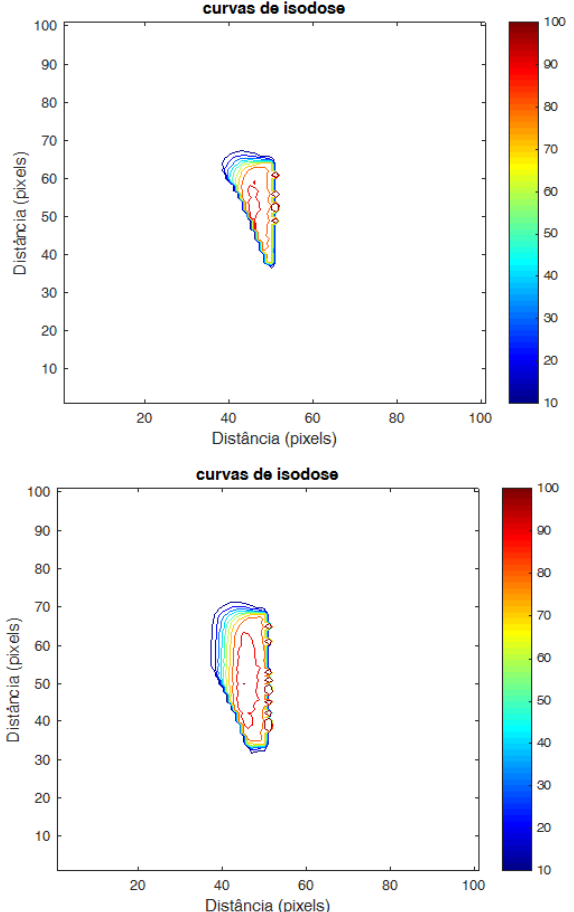

curvas de isodose

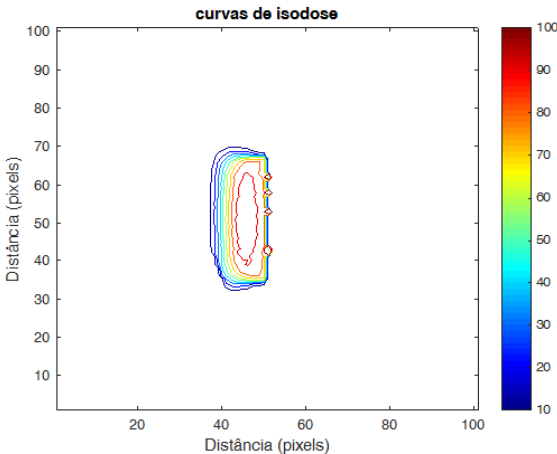

Figura 30: distribuições de dose simulação do tratamento no plano central sem angulação do aplicador radioterapia intra-operatória por feixe de elétrons de $5 \mathrm{MeV}$ para as geometrias de volume mamário a. pequeno, b. médio e c. grande. Na primeira coluna está apresentada a distribuição total, enquanto na segunda coluna tem-se a distribuição apenas dentro da mama. Na terceira estão apresentadas as curvas de isodose.

As distribuições apresentam comportamento esperado para feixe de elétrons, apresentando formato abaulado nas extremidades e região de build up. É possível perceber que sem a angulação do aplicador pode ocorrer uma maior entrega de dose no tórax, portanto o posicionamento do aplicador deve ser cuidadosamente considerado nessa técnica. 
As distribuições de dose para o feixe de 7 MeV estão apresentadas na Figura 31.

a
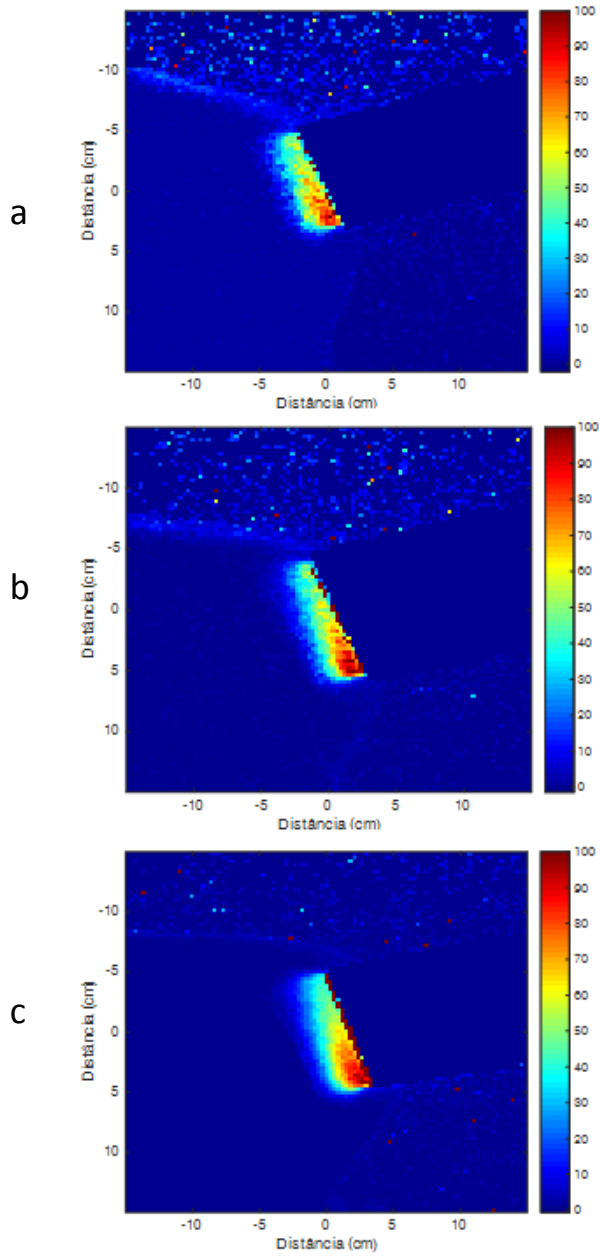
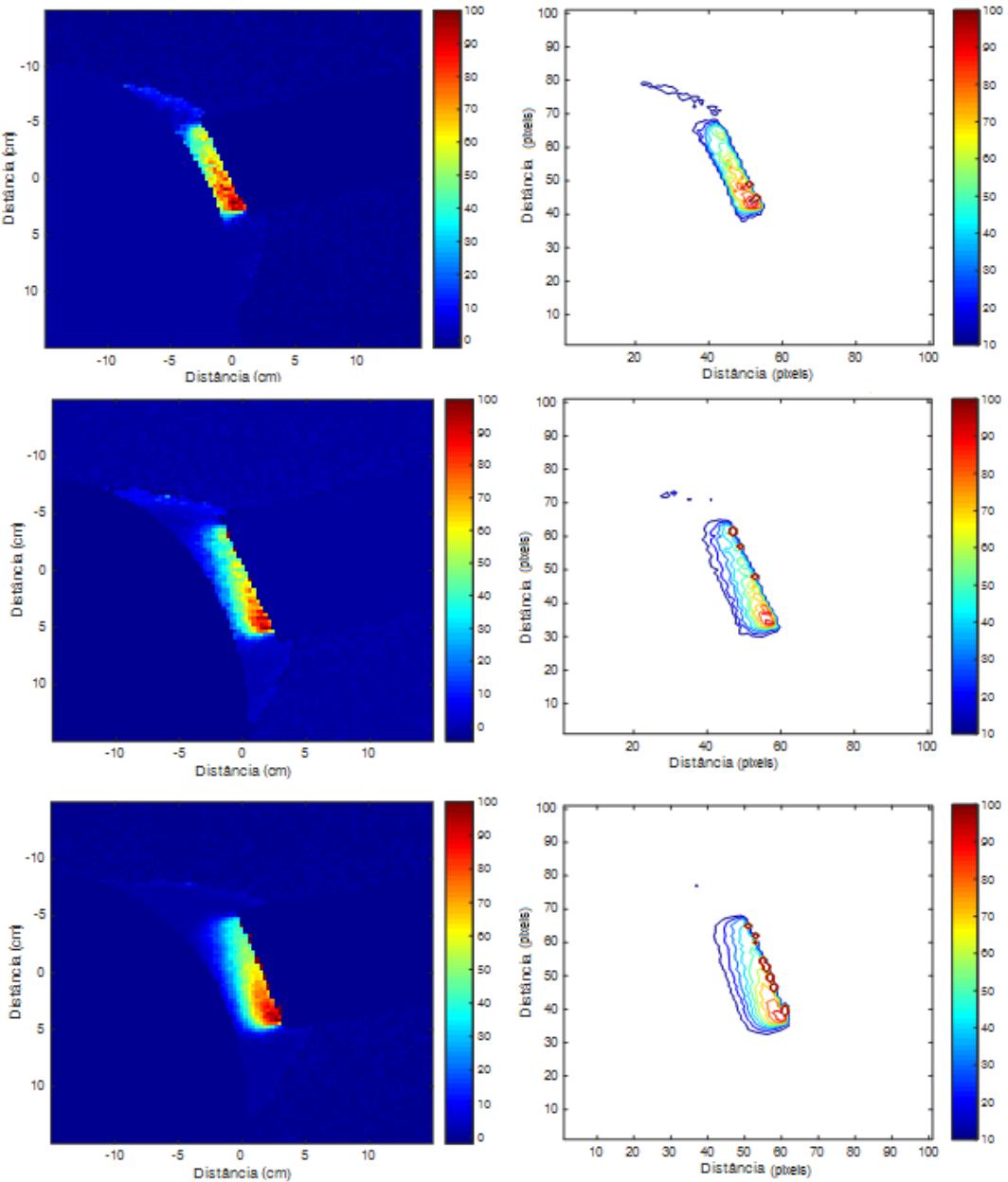

Figura 31: distribuições de dose simulação do tratamento radioterapia intra-operatória por feixe de elétrons de

$7 \mathrm{MeV}$ para as geometrias de volume mamário a. pequeno, b. médio e c. grande. Na primeira coluna está apresentada a distribuição total, enquanto na segunda coluna tem-se a distribuição apenas dentro da mama.

Na terceira estão apresentadas as curvas de isodose.

Para a energia de $7 \mathrm{MeV}$, a distribuição de dose para a geometria de menor volume mamário indica que a profundidade de entrega de dose atingida por esse feixe é maior que a espessura da mama, depositando doses de até $60 \%$ no tórax. A mama de volume médio é irradiada sem que haja entrega de dose no tórax, porém a região mais profunda da mama recebe apenas doses baixas, de até $40 \%$. O mesmo ocorre para a mama de maior volume, enquanto uma espessura maior da mama é irradiada, quando comparada a espessura irradiada pelo feixe de $5 \mathrm{MeV}$, a região mais profunda da mama ainda não recebe dose relevante para o tratamento. Esses alcances das distribuições de doses estão associados, entretanto, ao posicionamento do aplicador no momento do tratamento.

Novamente, para melhor visualização da distribuição, que aparece angulada devido ao plano de corte apresentado em relação a angulação do aplicador, foram realizadas simulações com o aplicador sem angulação, cujas distribuições estão apresentadas na Figura 32. 

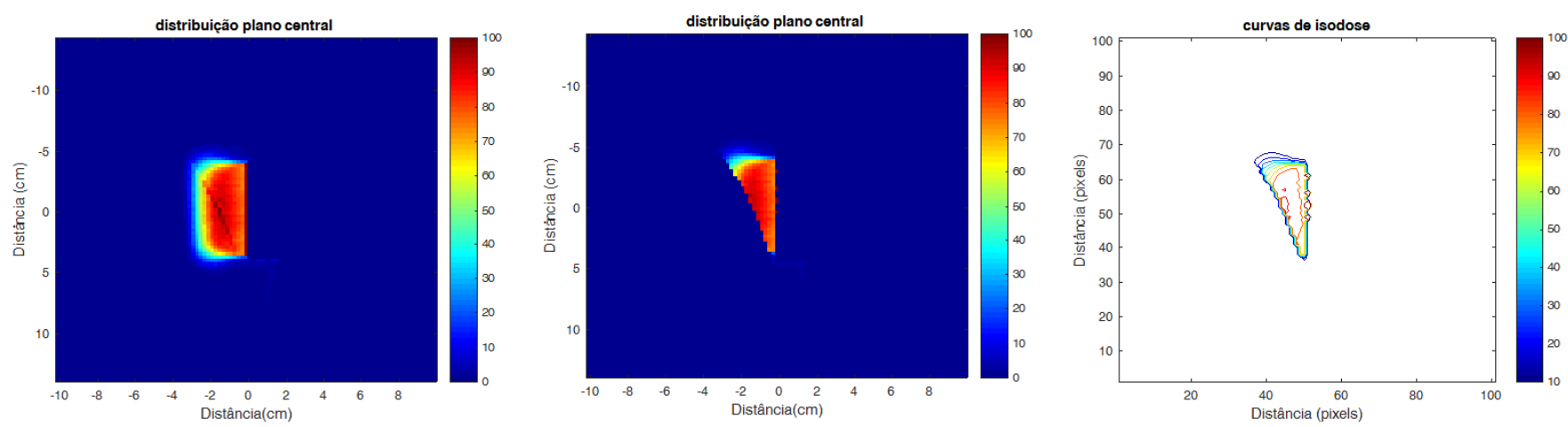

distribuição plano centra
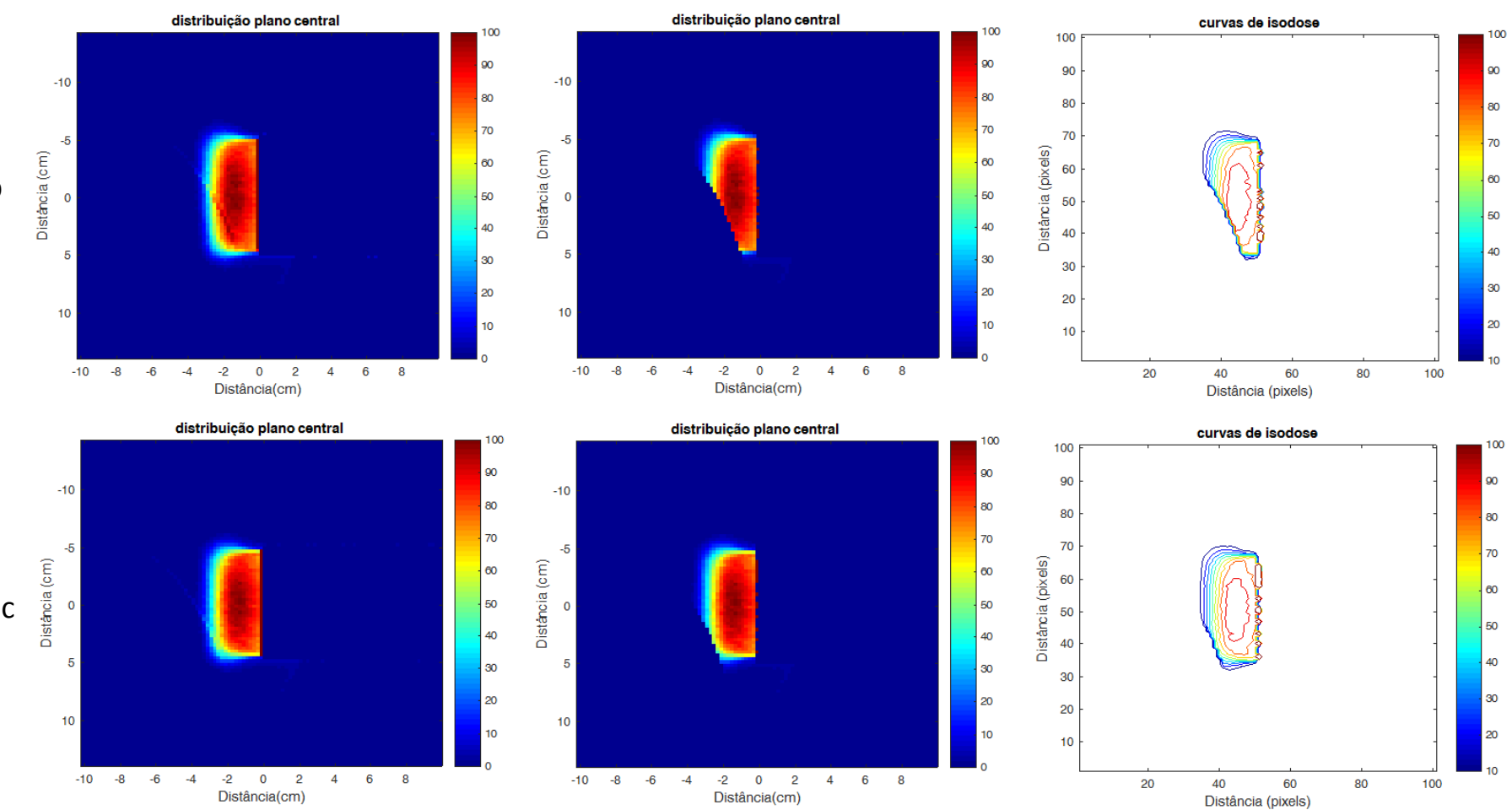

Figura 32: distribuições de dose simulação do tratamento no plano central sem angulação do aplicador - radioterapia intraoperatória por feixe de elétrons de $7 \mathrm{MeV}$ para as geometrias de volume mamário a. pequeno, b. médio e c. grande. $\mathrm{Na}$ primeira coluna está apresentada a distribuição total, enquanto na segunda coluna tem-se a distribuição apenas dentro da mama. Na terceira estão apresentadas as curvas de isodose.

Como visto para o feixe de $5 \mathrm{MeV}$, as distribuições de dose obtidas com o feixe de $7 \mathrm{MeV}$ também apresentam o comportamento característico de distribuição de elétrons. 0 posicionamento do aplicador, sem angulação, aumenta a entrega de dose dentro do tórax, sobretudo para as mama de volume pequeno e médio, o indicando como fator de peso para o resultado do tratamento.

A Figura 33 mostra as distribuições de dose para o feixe de $9 \mathrm{MeV}$. 

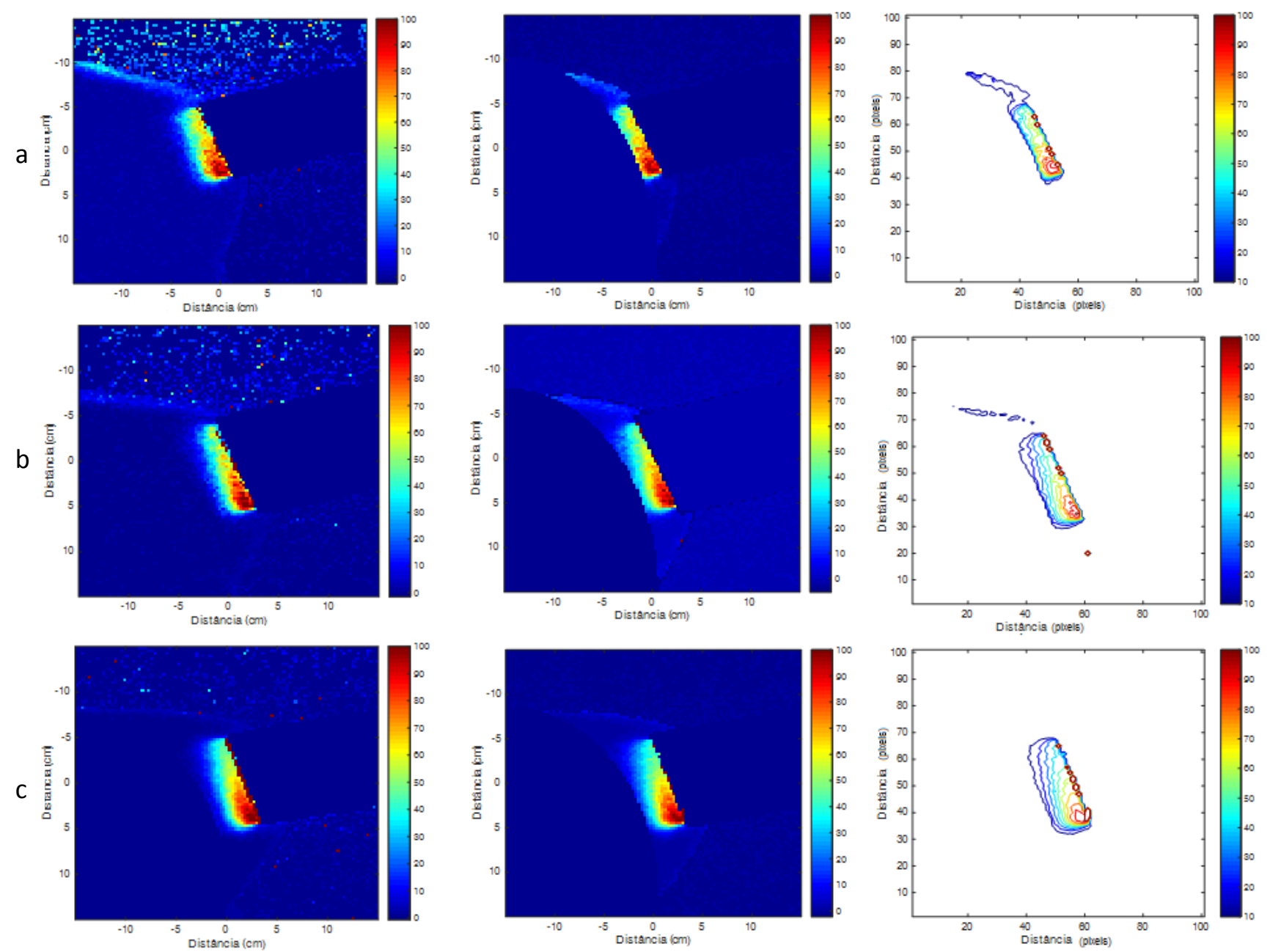

Figura 33: distribuições de dose simulação do tratamento radioterapia intra-operatória por feixe de elétrons de

$9 \mathrm{MeV}$ para as geometrias de volume mamário a. pequeno, b. médio e c. grande. Na primeira coluna está apresentada a distribuição total, enquanto na segunda coluna tem-se a distribuição apenas dentro da mama. $\mathrm{Na}$ terceira estão apresentadas as curvas de isodose.

A distribuição de dose referente ao feixe de $9 \mathrm{MeV}$ mostra que, para a menor mama doses de até $50 \%$ são entregues dentro do tórax. Para a geometria de volume mamário médio doses de $40 \%$ podem ser entregues dentro do tórax. A energia de $9 \mathrm{MeV}$ mostra-se suficiente para que toda a espessura da mama de maior volume seja irradiada, entregando doses muito baixas ao tórax, menores que $30 \%$. Novamente, as isodoses dentro da mama e do tórax são função do posicionamento do aplicador no momento do tratamento.

A angulação do aplicador em relação ao plano de corte apresentado indica uma distribuição angulada. Para melhor visualização da distribuição no plano central estão apresentadas, na Figura 34, as distribuições para o feixe de $9 \mathrm{MeV}$ sem angulação do aplicador. 

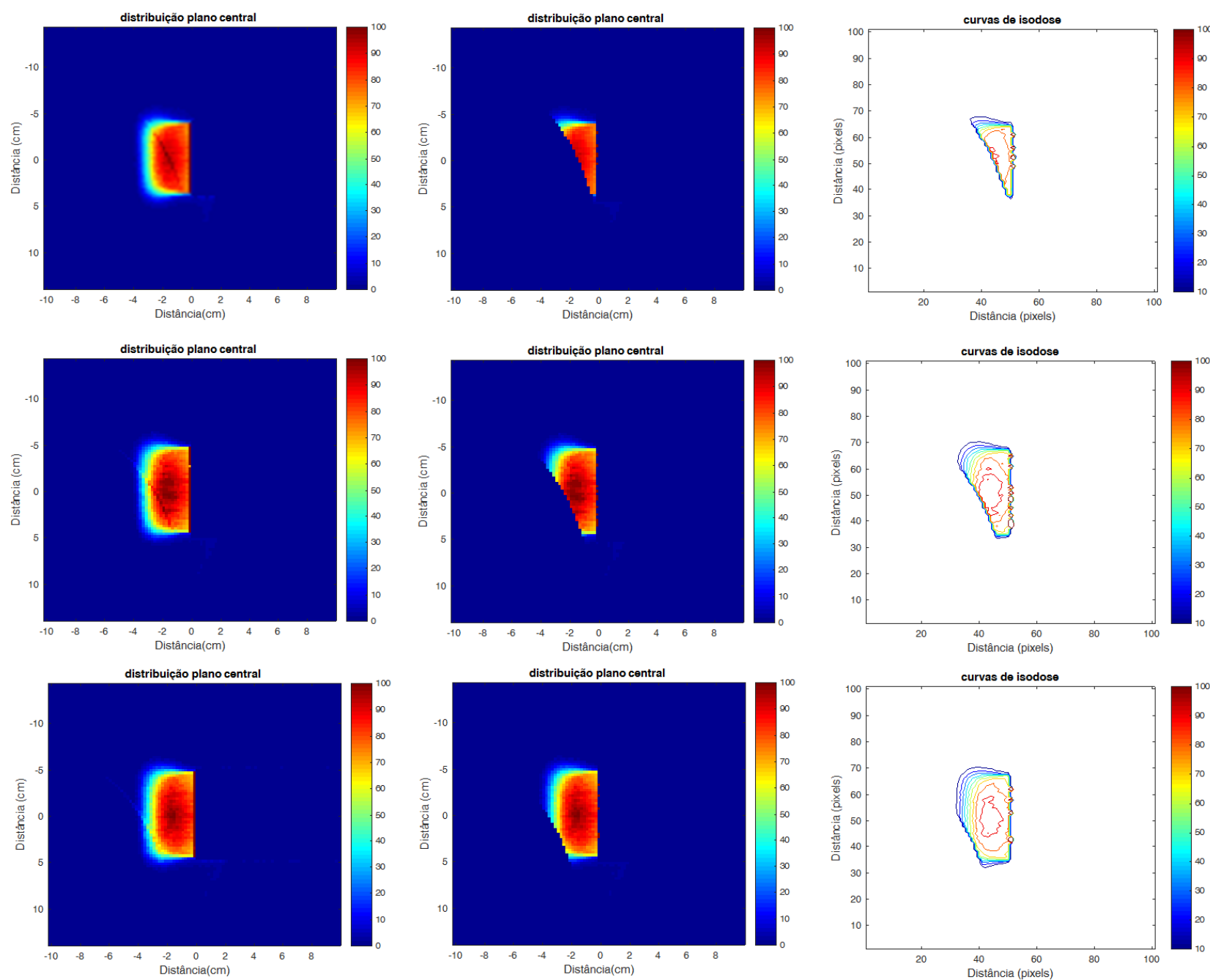

Figura 34: distribuições de dose simulação do tratamento no plano central sem angulação do aplicador - radioterapia intraoperatória por feixe de elétrons de $9 \mathrm{MeV}$ para as geometrias de volume mamário a. pequeno, b. médio e c. grande. $\mathrm{Na}$ primeira coluna está apresentada a distribuição total, enquanto na segunda coluna tem-se a distribuição apenas dentro da mama. Na terceira estão apresentadas as curvas de isodose.

As distribuições de dose apresentam o formato característico esperado para feixe de elétrons, abaulado nas extremidades e com dose máxima ocorrendo após região de build up. É possível perceber que o posicionamento do aplicador influencia fortemente na entrega de dose dentro do tórax, uma vez que as distribuições de dose onde o aplicador não foi angulado indicam maior dose no tórax em relação às distribuições de dose com o aplicador angulado.

Os resultados obtidos permitem perceber que o volume mamário, além da energia do feixe, também é relevante para a determinação das doses no volume alvo e tecidos sadios. De modo geral, a energia do feixe determina a profundidade de tecido irradiada. Dessa forma, energias mais altas são mais adequadas para volumes mais espessos ou alvos mais profundos e, ao mesmo tempo, mais distantes de tecidos sadios.

Em todas as energias estudadas as distribuições de dose apresentam doses elevadas na interseção tecido mole/ar. Essa região de superdosagem pode ser causada pela modelagem 
do feixe, que apresenta diferenças na entrega de dose de até 7,78 pp em relação à literatura em profundidades pequenas, como mostrado na curvas de PDD apresentadas no capítulo 3.

\subsection{Radioterapia intra-operatória por raios- $X$ de baixa energia}

\subsubsection{Irradiação de Mama}

Para tratamento utilizando o acelerador dedicado a radioterapia intra-operatória, Intrabeam, é acoplado à sonda um aplicador de resina (Eaton e Duck, 2010). Para a simulação foi adicionada à geometria da sonda, utilizada na validação e descrita na seção 3.3, a geometria do aplicador. Toda essa geometria foi então inserida na geometria de tórax feminino, de modo que houvesse aproximadamente $1,0 \mathrm{~cm}$ de tecido acima do aplicador, conforme mostrado na Figura 35.

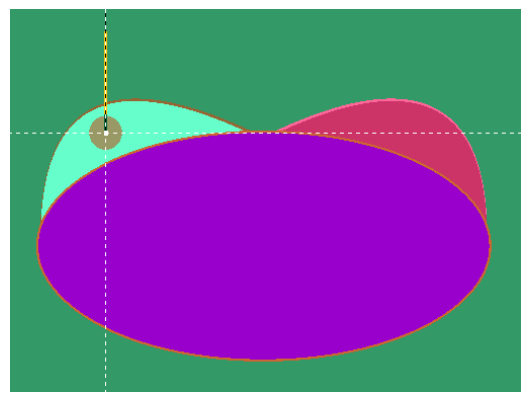

Figura 35: geometria utilizada para simulação do tratamento com radioterapia intra-operatória com feixe de raios-X de baixa energia.

Para a geometria de volume mamário pequeno foi utilizado um aplicador de $2,0 \mathrm{~cm}$ de diâmetro, enquanto que para as geometrias de volume médio e grande foi utilizado um aplicador de 3,0 cm de diâmetro.

Nesse caso é desejável que toda a simulação seja detalhada, visto que está sendo gerado o feixe de fótons, e que esse será atenuado pelo aplicador. Portanto, os parâmetros de controle da simulação foram definidos em $W c c=0$ e $W c r=-1$. A energia de corte foi definida como $1 \mathrm{keV}$ para todos os materiais. $C_{1}$ e $C_{2}$ foram mantidos em 0,1. Os parâmetros foram mantidos os mesmo para as três diferentes geometrias utilizadas.

A simulação do tratamento através de IORT por feixe de raios-X de baixa energia foi avaliada através da distribuição de dose. 


\subsubsection{Distribuição de dose de tratamento}

As distribuições de dose, total e limitada ao volume da mama, e as curvas de isodose para as geometrias de mama de volume pequeno, médio e grande, estão apresentadas na Figura 36.
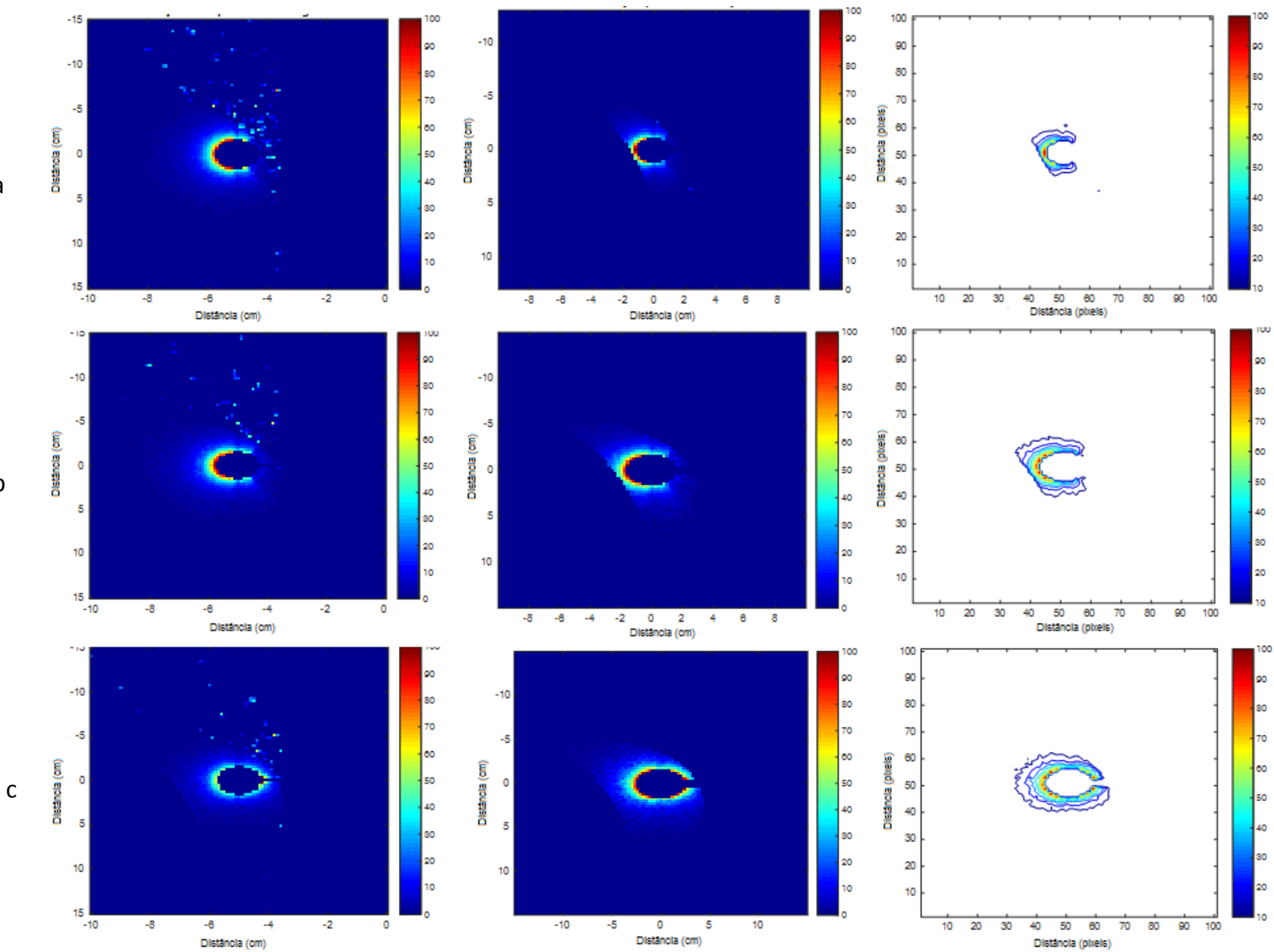

Figura 36: distribuições de dose simulação do tratamento radioterapia intra-operatória por raios-x de baixa energia para volume mamário a. pequeno, b. médio e c. grande. As figuras da primeira coluna referem-se à distribuição de todo o campo de radiação, na segunda coluna está apresentada a distribuição apenas dentro da mama e na terceira coluna tem-se as linhas de isodose dentro do volume mamário.

A distribuição de dose obtida não é isotrópica, apresentando uma direção preferencial. As maiores doses ocorrem na região inferior do aplicador, próximas a parede torácica. Para as geometrias de volume mamário pequeno e médio, doses maiores que $50 \%$ da dose máxima ocorrem apenas para regiões localizadas abaixo do eixo central do aplicador.

Observando as superfícies de isodose, percebe-se que a distribuição de dose do Intrabeam é bastante heterogênea. Essa heterogeneidade é causada pelo alto gradiente de dose, característico desse feixe, por causa de sua baixa energia de fótons. Para a geometria 
de mama de menor volume, a dose decai de $100 \%$ na superfície imediatamente após o aplicador para aproximadamente $17,36 \%$ em $1,0 \mathrm{~cm}$, corroborando resultados descritos na literatura (Vaydia et al, 2014; Esposito et al, 2015b). Para as mamas de volume média e grande, onde é utilizado um aplicador maior, a dose em $1,0 \mathrm{~cm}$ cai para $21,13 \%$ e $32,50 \%$, respectivamente.

Para a mama de menor volume, tem-se que parte da distribuição ocorre no tórax. Doses de até $50 \%$ podem ser depositadas fora da mama. Para a mama de volume médio apenas doses menores de $30 \%$ são depositadas no tórax, enquanto que toda a dose é entregue dentro da mama de maior volume. A profundidade atingida pela dose é dependente do tamanho do aplicador. Por ser maciço o aplicador atua como um filtro, atenuando raios- $X$ de menor energia e endurecendo o feixe. Portanto aplicadores maiores levam a deposição de dose em maiores profundidades. Entretanto, uma vez que o tamanho do aplicador para conformar a cavidade cirúrgica, ele não é o único aspecto a ser considerado para evitar a deposição de dose no tórax. O posicionamento do aplicador tem influencia na profundidade das distribuições de dose, uma vez que pode ser colocado mais próximo ou distante da parede do tórax.

\section{Avaliação das técnicas radioterápicas}

As simulações realizadas demonstram que cada uma das técnicas estudadas gera distribuições de dose bastante diferentes entre si. A comparação dos tratamentos visa um melhor entendimento sobre a entrega da dose e os efeitos da utilização da IORT.

Para avaliar o tratamento simulado para 3DR, IORT por feixe de elétrons e IORT por raios- $X$ de baixa energia podem ser utilizados parâmetros de avaliação do plano de tratamento estabelecidos na clínica, como índice de conformidade, índice de homogeneidade e histograma dose-volume, cuja base é o volume alvo.

A avaliação do plano de tratamento por IORT não está bem estabelecida. Por se tratar de uma técnica aplicada em uma única fração e durante o procedimento cirúrgico, não há uma rotina de otimização do planejamento. O posicionamento do aplicador e profundidade a ser irradiada são definidos no momento da aplicação. Em 3DR, por outro lado, ocorre um processo de personalização do planejamento do tratamento antes de sua aplicação. Durante esse processo, a isodose de planejamento é definida e selecionada caso a caso. Em IORT por raios- $X$ de baixa energia, define-se um ponto de cálculo da dose, a $1 \mathrm{~cm}$ do aplicador, independentemente de seu tamanho ou volume da mama. Já para IORT por elétrons, em função da geometria de seu aplicador, o volume alvo é definido com um cilindro de altura selecionada de acordo com a energia do feixe. 
O volume alvo e sua definição, entretanto, influenciam fortemente nos parâmetros de avaliação da qualidade do plano de cada uma das técnicas. Da mesma forma, a isodose selecionada ou que recaia sobre o ponto de cálculo irá influenciar nesses parâmetros.

\subsection{Radioterapia 3D}

$\mathrm{Na}$ 3DR, todo o volume da mama é considerado volume alvo. Nas simulações, a porção limitada à região da mama da matriz de dose 3D gerada pelo PENELOPE foi utilizada como volume alvo. As distribuições de doses nesses volumes são mostradas na Figura 37 para os três volumes mamários estudados.
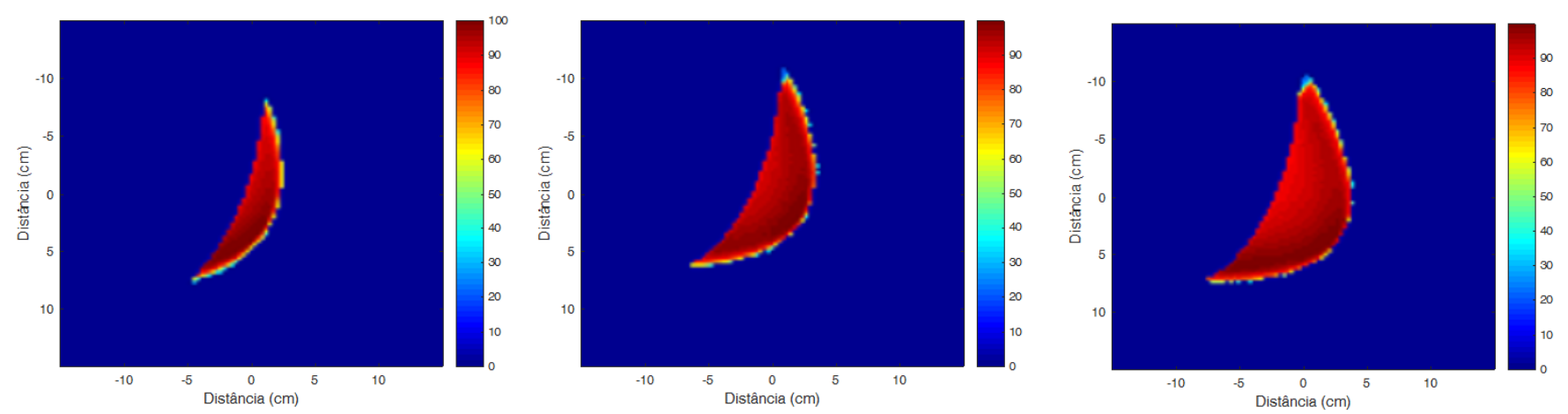

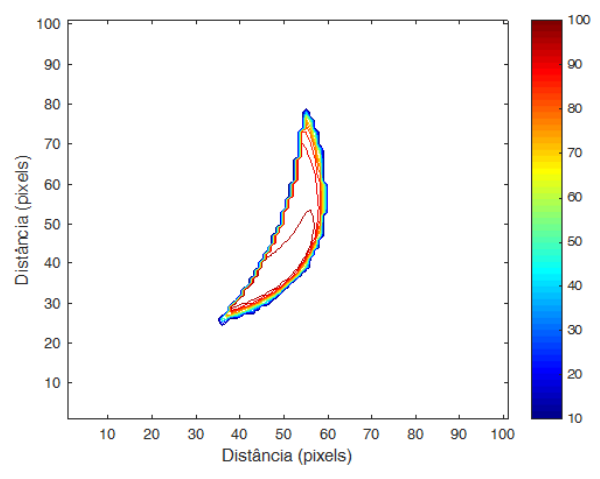

a

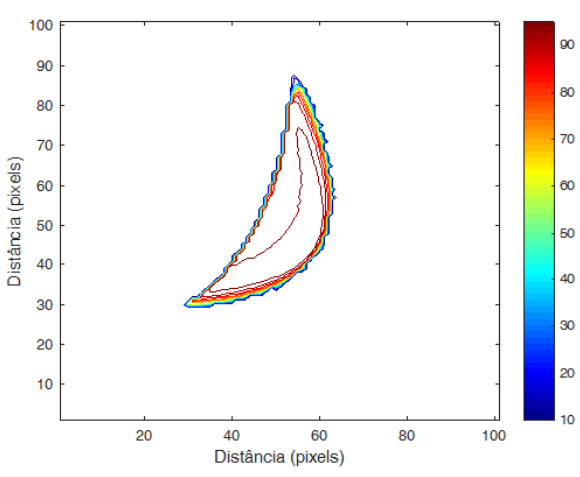

b

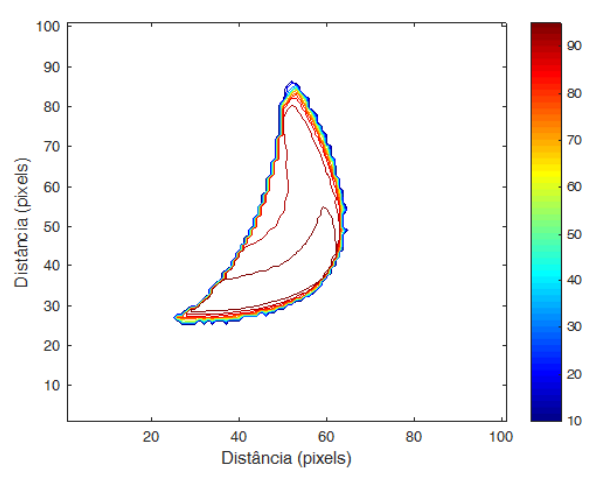

C

Figura 37: Distribuição de dose e curvas de isodoses no volume alvo para 3DR para geometria de volume mamário pequeno (a), médio (b) e grande (c).

Pode-se perceber, pelas das distribuições apresentadas, que o tratamento simulado requer otimização. As distribuições de dose mostram uma alta heterogeneidade dentro da mama, com pontos frios podendo ser visualizados nas extremidades do campo, enquanto que as doses mais altas estão concentradas no interior da mama. As curvas de isodose demonstram que doses maiores que $95 \%$ estão bastante interiorizadas no volume da mama. Esta distribuição ocorre devido à modelagem da simulação do tratamento, com tamanho e 
angulação dos campos produzindo os efeitos demonstrados. Uma modificação na modelagem do tratamento na simulação, entretanto, requer um alto custo computacional.

Em um planejamento para 3DR, a personalização do cálculo de dose se dá ao escolher a isodose que gere a melhor cobertura do volume alvo, enquanto preserva a homogeneidade da dose dentro dele. No presente trabalho, a isodose de $90 \%$ foi selecionada para análise dos parâmetros de avaliação do plano para todos os tamanhos de mama estudados, buscando uma cobertura satisfatória do volume alvo. Deve-se ressaltar que a isodose padrão escolhida na clínica é em torno de $95 \%$, de forma que a variação de dose permaneça dentro de um intervalo de até $5 \%$ de heterogeneidade de dose.

A Figura 38 mostra os histogramas dose-volume para 3DR para as geometrias de mama pequena, média e grande.

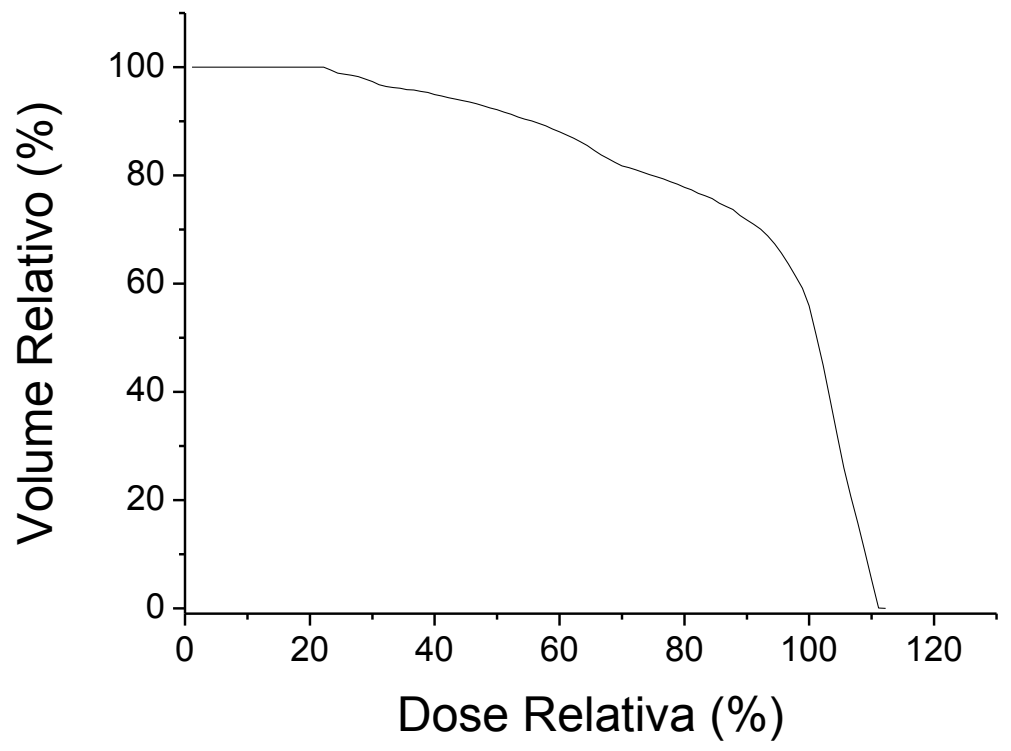

Figura 38: Histogramas dose-volume para 3DR, volume mamário pequeno (a), médio (b) e grande (c) (continua) 


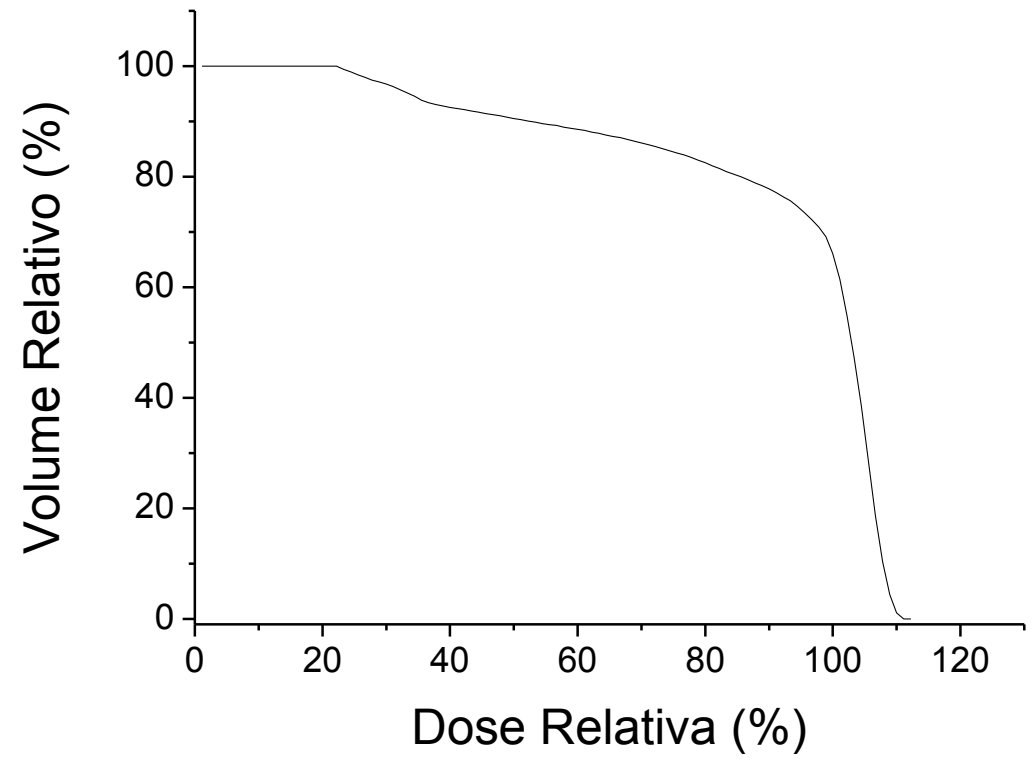

b

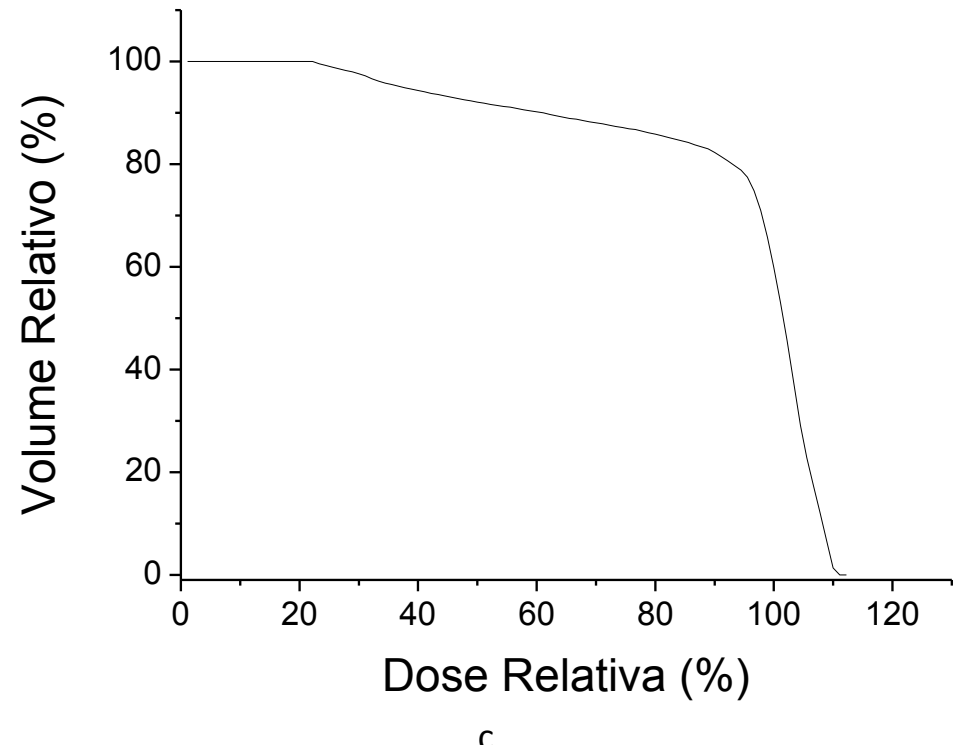

Figura 38: Histogramas dose-volume para 3DR, volume mamário pequeno (a), médio (b) e grande (c)

É possível perceber que ocorrem, nos histogramas dose-volume, valores de dose maiores que $100 \%$. Isto se deve à normalização adotada no presente trabalho, onde a isodose de prescrição foi normalizada para $100 \%$.

Os histogramas dose-volume mostram, para todos os tamanhos de mama, que o volume alvo não foi completamente coberto pela dose máxima, como já esperado a partir das distribuições de dose. A melhor cobertura do volume ocorre para a mama de volume médio, onde aproximadamente $67 \%$ do volume está coberto pela isodose de prescrição, seguida pela mama de maior volume, para a qual cerca de $60 \%$ do volume está coberto pela isodose de 
planejamento, e pela geometria de menor volume mamário, com apenas $57 \%$ do volume está coberto pela isodose de prescrição. Para a geometria de menor volume mamário, $80 \%$ do volume recebe doses de até $75 \%$, enquanto que para a geometria de mama média $80 \%$ do volume recebe doses de aproximadamente $85 \%$. Para a geometria de maior volume, doses de aproximadamente $92 \%$ são entregues em $80 \%$ do volume.

Na Tabela 8 estão apresentados os parâmetros de avaliação do plano para 3DR, para as geometrias de volume mamário pequeno, médio e grande.

Tabela 8: Parâmetros de avaliação do plano para 3DR

\begin{tabular}{|c|c|c|c|}
\hline Volume mamário & $\mathrm{IC}$ & $\mathrm{HI}$ & $\mathrm{TCl}$ \\
\hline Pequeno & 0,56 & 82,31 & 2,16 \\
\hline Médio & 0,66 & 83,01 & 2,29 \\
\hline Grande & 0,60 & 81,08 & 2,63 \\
\hline
\end{tabular}

Os índices apresentados foram calculados considerando-se a isodose de planejamento de $90 \%$. No geral, o índice de conformidade foi baixo, indicando que a isodose de planejamento não cobre todo o volume alvo, como mostrado através das isodoses dentro da mama. 0 maior IC foi obtido para a geometria de volume mamário médio, corroborando o mostrado pelo histograma dose-volume. Analogamente ao IC, O HI obtido para os três volumes estudados ficou acima do requerido para um caso clínico real. Não houve diferenças marcantes em seu valor para as três geometrias, demonstrando haver regiões quentes no interior do volume alvo independentemente do volume mamário. O TCl mostrou-se maior que 1 para todos os volumes mamários, indicando que o volume coberto pela isodose de 95\% corresponde a um volume pequeno em relação ao volume coberto pela isodose de prescrição. O TCl apresentou maior valor para a mama de maior volume, indicando que as regiões quentes são menores nesse volume quando comparadas às regiões quentes na mama de menor volume.

De modo geral, os parâmetros calculados estão distantes dos valores requeridos na clínica, indicando que o plano deveria ser otimizado. O processo de refinamento do plano em simulação Monte Carlo não é imediato como na clínica, uma vez que a distribuição de dose não pode ser visualizada enquanto a simulação é planejada. Dentro dos limites dos tratamentos simulados, a 3DR parece ser mais adequada para o tratamento de pacientes com volume mamário médio, conforme esperado dadas as características de planejamento de tratamento de mama, onde se tem a necessidade de utilização de filtro e de homogeneizar a dose nas extremidades do volume. 


\subsection{IORT por feixe de elétrons}

Assim como em teleterapia com feixe de elétrons, os protocolos estabelecidos pelo Grupo Oncológico de Radioterapia para IORT por feixe de elétrons, definem o volume alvo a partir da isodose de $90 \%$, sendo essa a mínima dose a cobrir o volume alvo (Beddar et al, 2006). Nesse trabalho foi adotada a mesma metodologia para definir o volume alvo para IORT por feixe de elétrons: apenas regiões irradiadas por doses maiores ou iguais a $90 \%$ constituem o volume alvo, produzindo uma relação interessante entre homogeneidade e cobertura.

\subsubsection{Feixe de elétrons de $5 \mathrm{MeV}$}

As distribuições de dose e curvas de isodose no volume alvo para o feixe de $5 \mathrm{MeV}$ estão apresentadas na Figura 39.
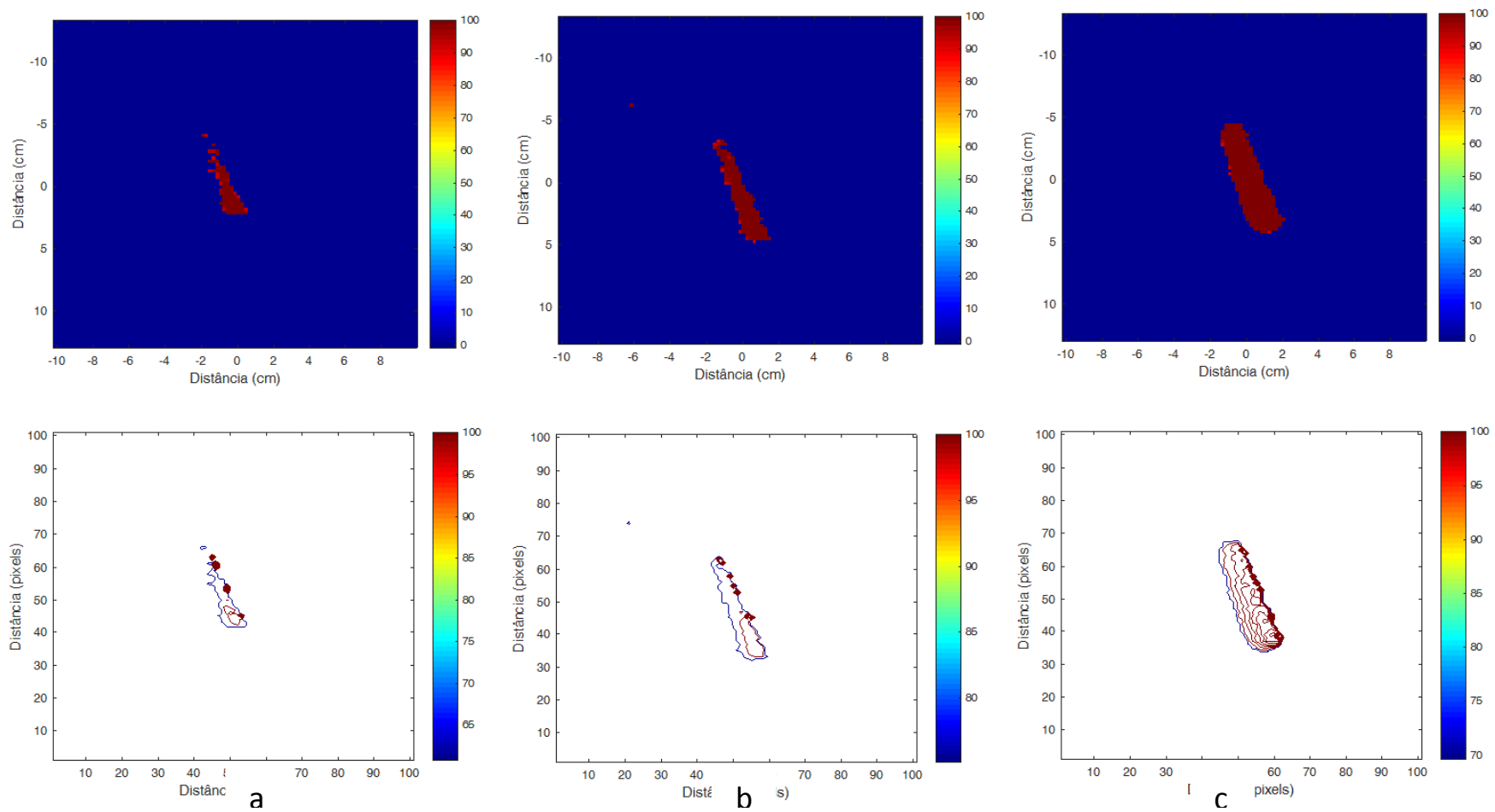

Figura 39: Distribuição de dose e curvas de isodose no volume alvo para IORT por feixe de elétrons para $5 \mathrm{MeV}$, para geometria de volume mamário pequeno (a), médio (b) e grande (c).

As distribuições de doses apresentadas não estão normalizadas. Como visto nas curvas de isodose, ocorrem, em regiões em contado com o ar que preenche o aplicador, uma superdosagem, com valores de dose muito superiores a $100 \%$. Para que fosse possível perceber que dentro do volume alvo existem apenas doses maiores que $90 \%$ a escala de cores das distribuições foi limitada para mostrar até doses de $100 \%$. 
A deposição de dose irregular ao longo dos planos apresentados se deve à angulação do aplicador em relação ao plano axial da geometria irradiada, no qual a figura está apresentada. Foi selecionado o plano axial devido a familiaridade de sua utilização na clínica. Entretanto, essa seleção impossibilita a análise qualitativa das distribuições, sendo realizada somente através dos histogramas dose-volume e parâmetros de avaliação do plano.

Os histogramas dose-volume para IORT por feixe de elétrons de $5 \mathrm{MeV}$ estão apresentados na Figura 40. Na figura são apresentados os histogramas limitados à dose de $100 \%$.

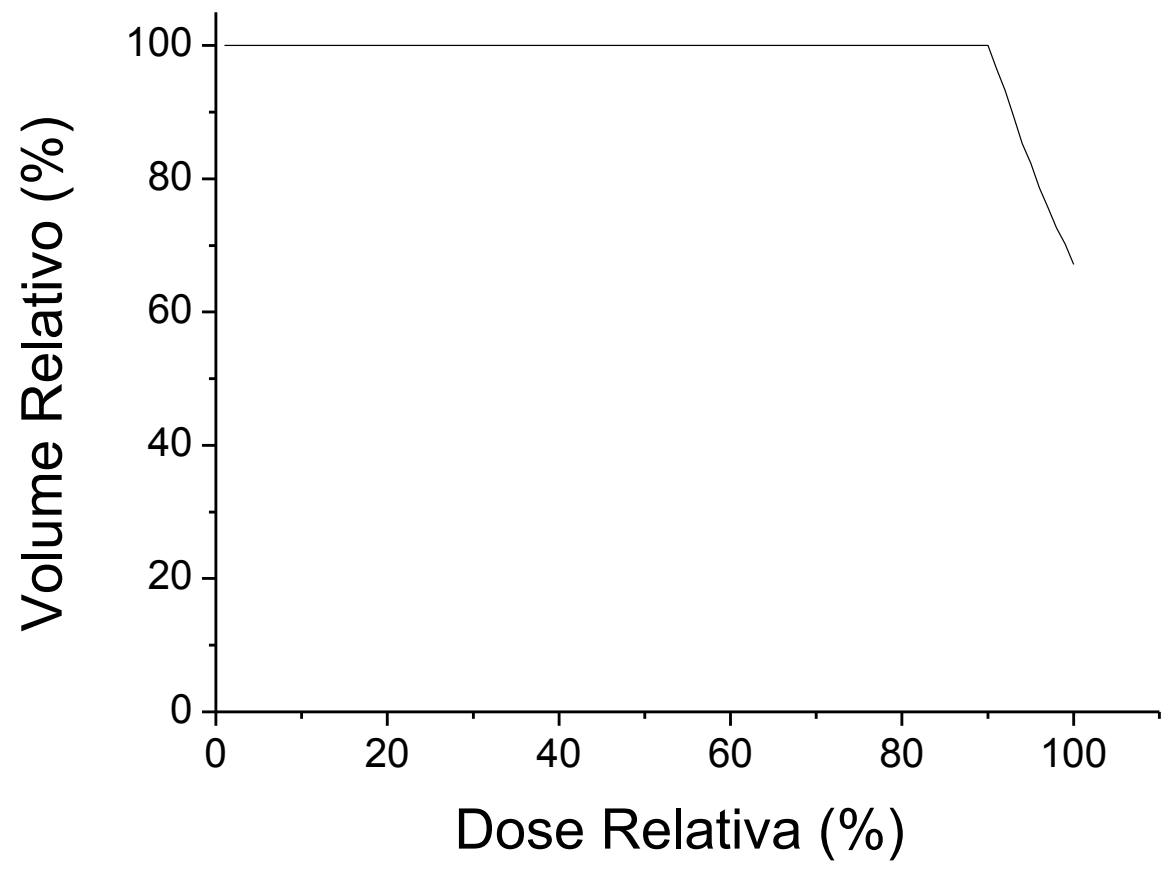

a

Figura 40: Histogramas dose-volume para IORT por elétrons de $5 \mathrm{MeV}$, para volume mamário pequeno (a), médio (b) e grande (c) (continua) 


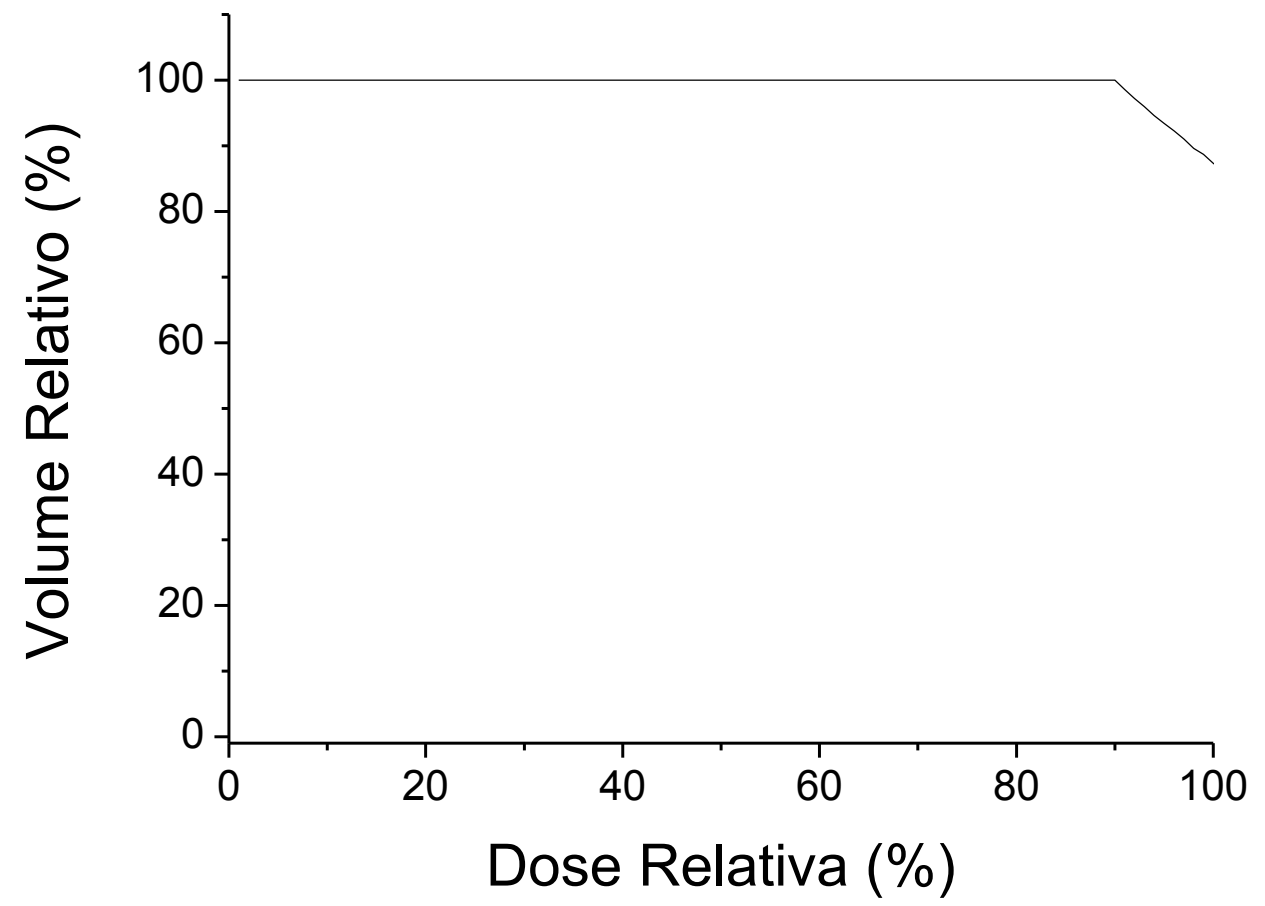

b

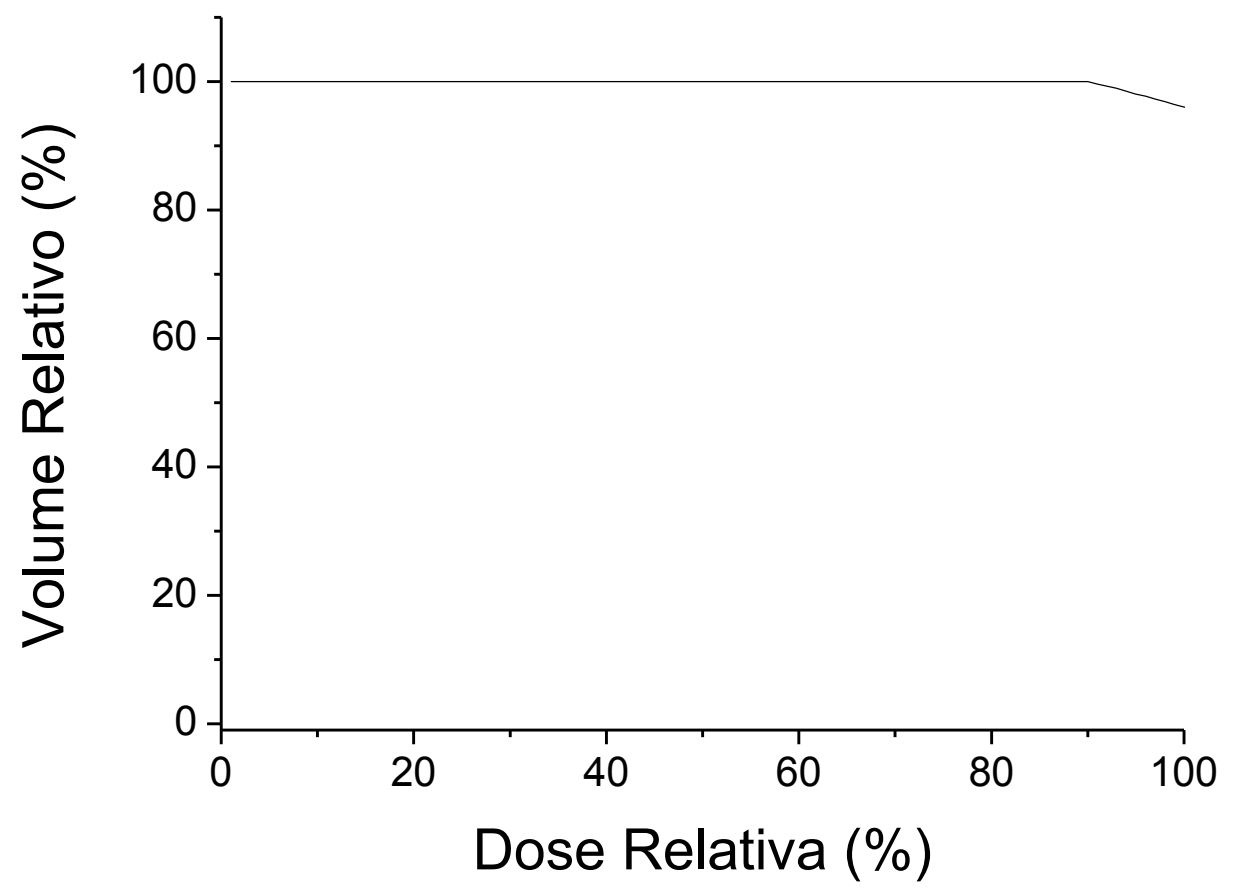

C

Figura 40: Histogramas dose-volume para IORT por elétrons de $5 \mathrm{MeV}$, para volume mamário pequeno (a), médio (b) e grande (c) 
Pode-se perceber, para todos os volumes mamários estudados, que $100 \%$ do volume está coberto pela isodose de $90 \%$, utilizada como isodose de prescrição, conforme esperado. Com o aumento do volume mamário, o histograma indica um aumento na área do volume alvo coberta por doses maiores que $90 \%$. Para a geometria de menor volume mamário, $80 \%$ do volume alvo recebe aproximadamente $95 \%$ da dose, aumentando para valores próximos a $100 \%$ para os volumes mamários médio e grande.

Na figura 41 estão apresentados os histogramas totais para IORT com feixe de elétrons de $5 \mathrm{MeV}$.

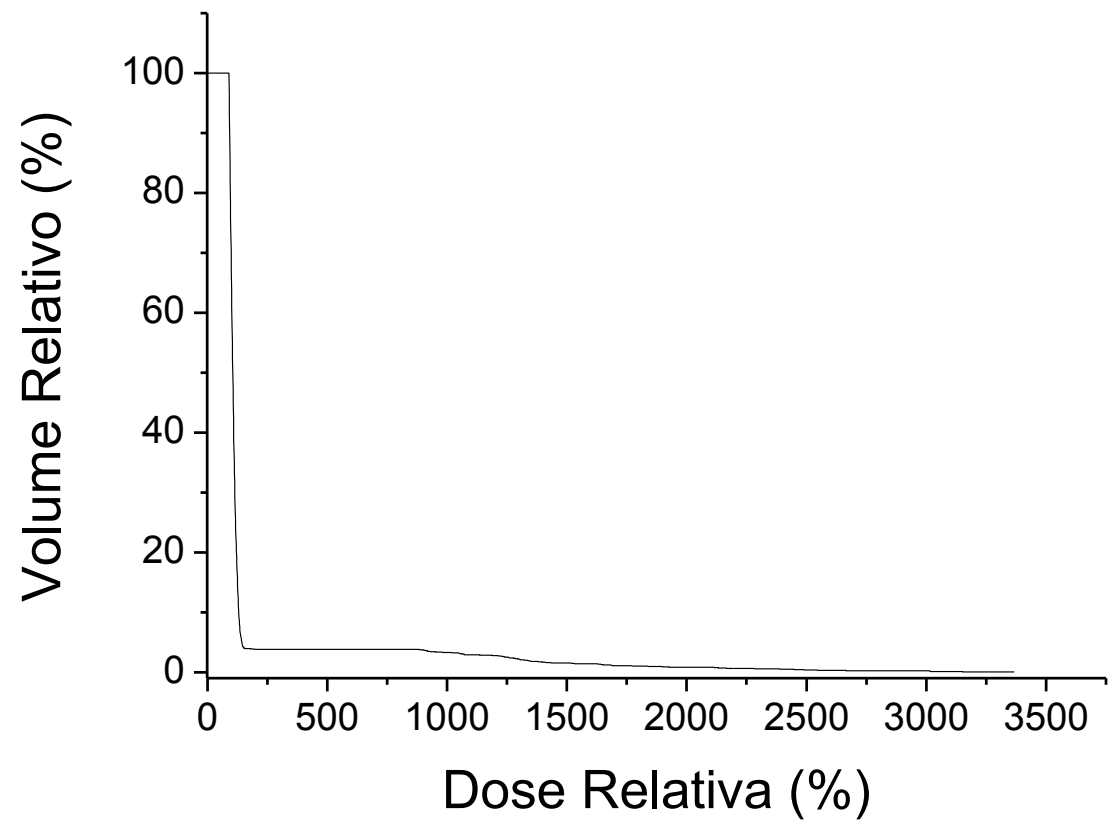

a

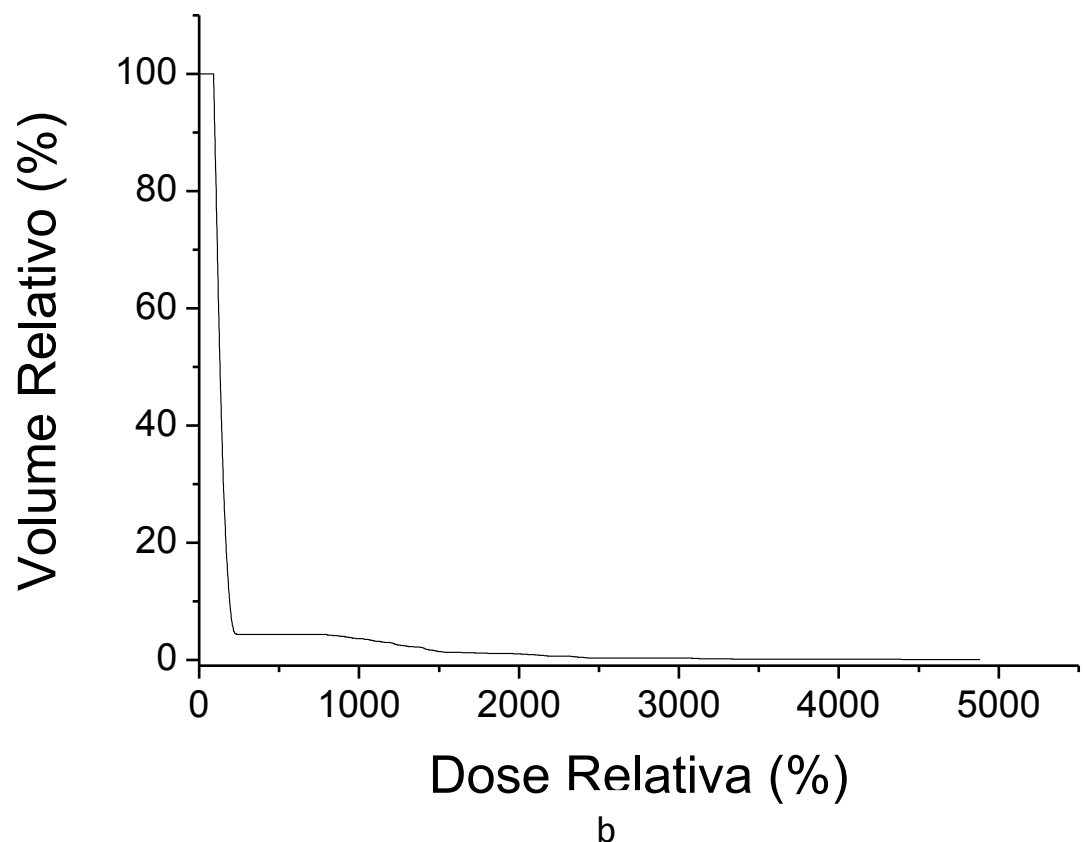

Figura 41: Histogramas dose-volume completo para IORT por elétrons de $5 \mathrm{MeV}$, para volume mamário pequeno (a), médio (b) e grande (c) (continua) 


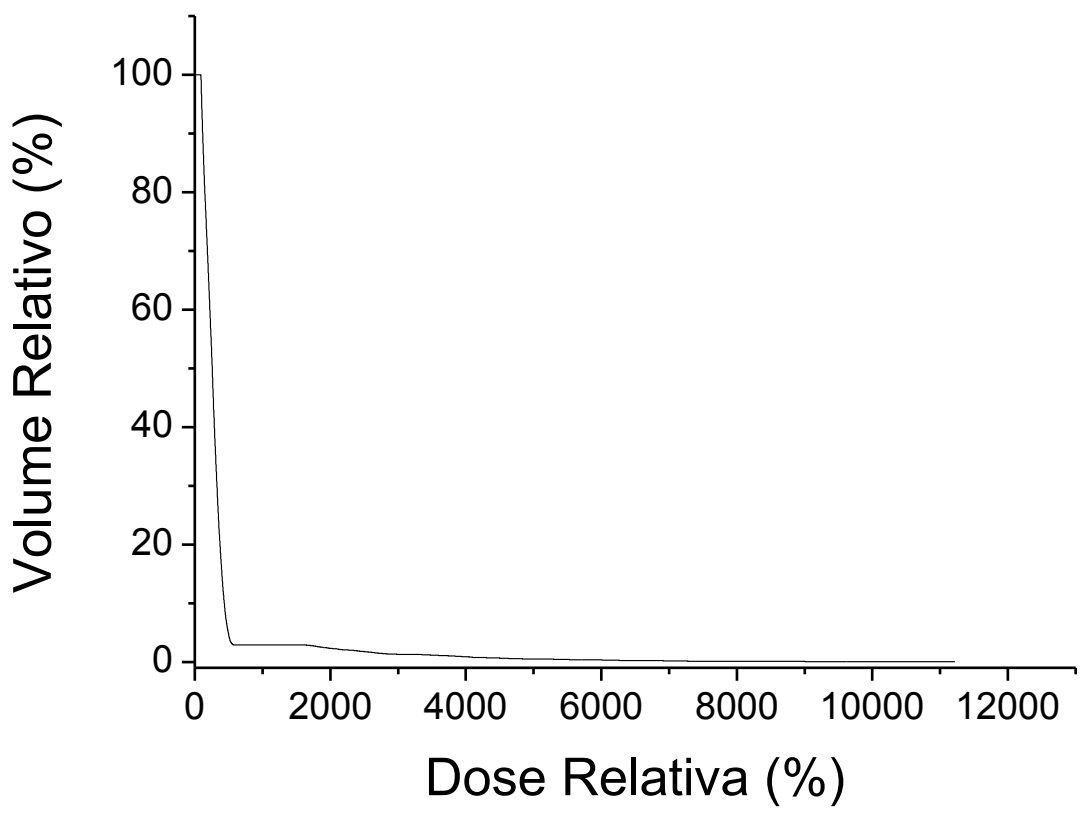

Figura 41: Histogramas dose-volume completo para IORT por elétrons de $5 \mathrm{MeV}$, para volume mamário pequeno (a), médio (b) e grande (c).

Como observado nas distribuições de dose, doses elevadas ocorrem em uma pequena parcela do volume, para todos os volumes mamários analisados. Os histogramas mostram que a dose aumenta com o aumento do volume mamário. Ocorre, em todos os volumes mamários, um aumento na fração do volume alvo coberto por altas doses na região de doses de aproximadamente $1000 \%$.

Os parâmetros de avaliação do plano para IORT com feixe de elétrons de $5 \mathrm{MeV}$ estão apresentados na Tabela 9.

Tabela 9: Parâmetros de avaliação do plano para IORT por elétrons de $5 \mathrm{MeV}$

\begin{tabular}{|c|l|l|l|}
\hline Volume mamário & $\mathrm{IC}$ & $\mathrm{HI}$ & $\mathrm{TCl}$ \\
\hline Pequeno & 1 & 10,44 & 1,01 \\
\hline Médio & 1 & 10,63 & 1,00 \\
\hline Grande & 1 & 5,31 & 1,00 \\
\hline
\end{tabular}

Os parâmetros de avaliação do plano foram obtidos com base na isodose de $90 \%$. Os IC perdem sua qualidade comparativa, atingindo valor 1 independentemente do volume mamário estudados, pois avaliam a relação entre o volume coberto pela isodose de prescrição em relação a totalidade do volume alvo. No presente estudo, os dois volumes são iguais uma vez que a isodose de prescrição foi estabelecida em $90 \%$ e o volume alvo foi definido em função da mesma isodose. Os valores de $\mathrm{HI}$, para os três volumes mamário estudados, indicam uma distribuição heterogênea. Essas heterogeneidades, e esses valores de $\mathrm{HI}$, ocorrem devido à presença dos pontos de superdosagem na interface da mama e do 
aplicador. $\mathrm{O}$ menor valor de $\mathrm{HI}$ ocorre para o maior volume mamário, indicando que para esse volume ocorre a distribuição mais homogênea, quando comparada às distribuições obtidas para os volumes médio e pequeno. Para todos os volumes mamários estudados os $\mathrm{TCl}$ apresentaram valores muito próximos de 1 , indicando que a isodose de prescrição está próxima à isodose de $95 \%$.

Os parâmetros de avaliação do plano indicam que a energia de $5 \mathrm{MeV}$ pode ser mais adequada para tratamento em volumes mamário grandes, entretanto indicam de forma geral uma distribuição de dose heterogênea, com regiões quentes. Além disso, é preciso lembrar-se que a energia do feixe escolhido para o tratamento guarda maior correlação com a extensão e localização tumoral do que simplesmente com os volumes mamários.

\subsubsection{Feixe de elétrons de $7 \mathrm{MeV}$}

As distribuições de dose dentro do volume alvo, obtidas com o feixe de $7 \mathrm{MeV}$ estão apresentadas na Figura 42.
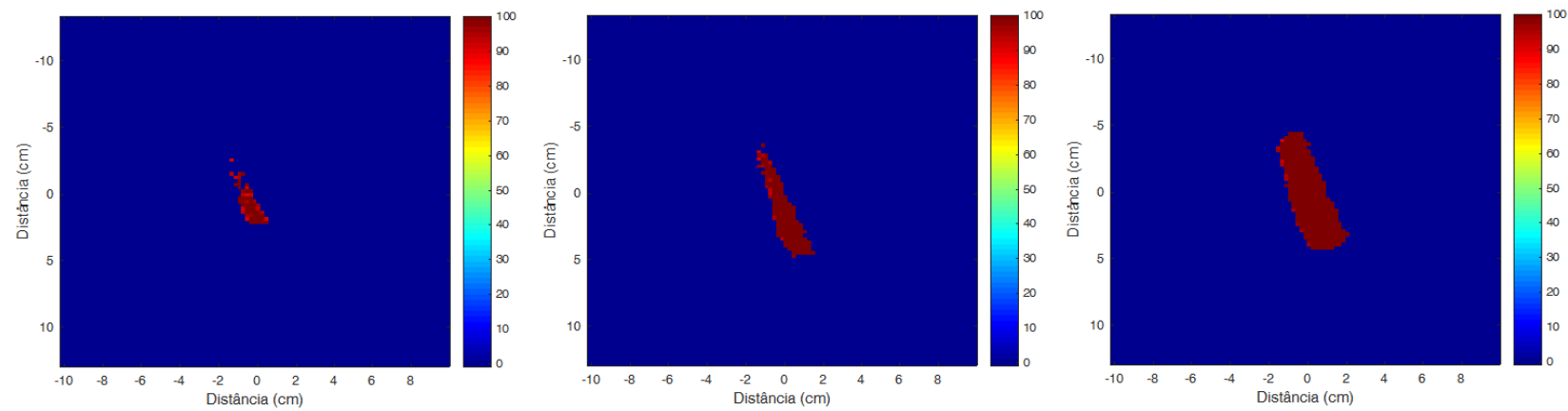

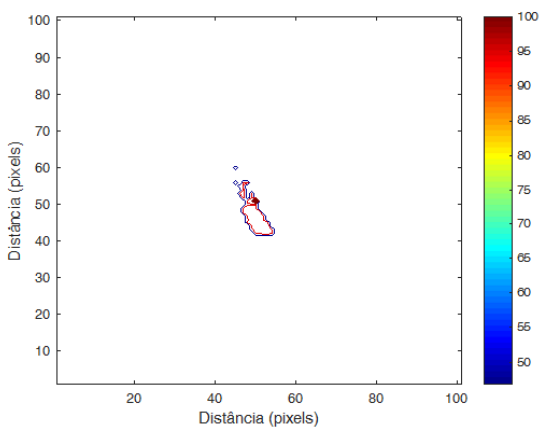

a

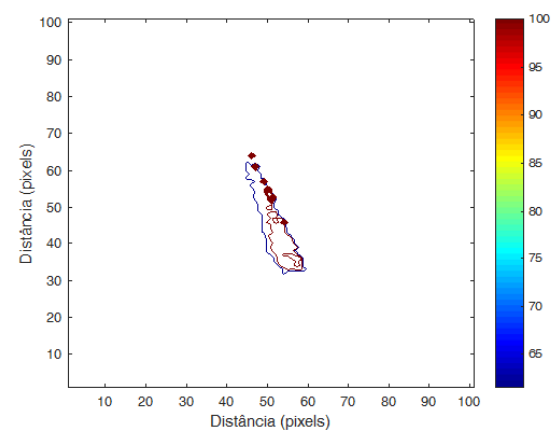

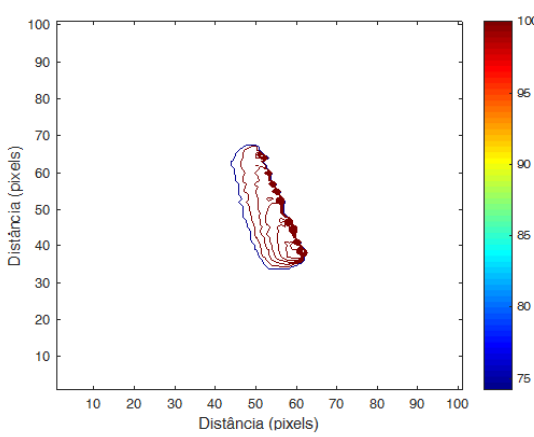

Figura 42: Distribuições de dose e curvas de isodose no volume alvo para IORT por feixe de elétrons de $7 \mathrm{MeV}$, volumes mamário pequeno (a), médio (b) e grande (c)

As distribuições de dose mostram que, para os três tamanhos de mama analisados ocorrem, dentro do volume alvo, apenas doses maiores que $90 \%$, conforme esperado dada sua definição. As curvas de isodose indicam a presença de doses elevadas em regiões em contato com o ar dentro do aplicador. A escolha do plano utilizado para apresentação das distribuições de dose impossibilita análises qualitativas a respeito das distribuições, uma vez que não as apresenta inteiramente. As distribuições de dose dentro do volume foram 
melhor estudadas através dos histogramas dose-volume e dos parâmetros de avaliação da qualidade do plano.

A Figura 43 apresenta os histogramas dose-volume para o feixe de IORT de $7 \mathrm{MeV}$, sendo apresentados os histogramas limitados à dose de $100 \%$.
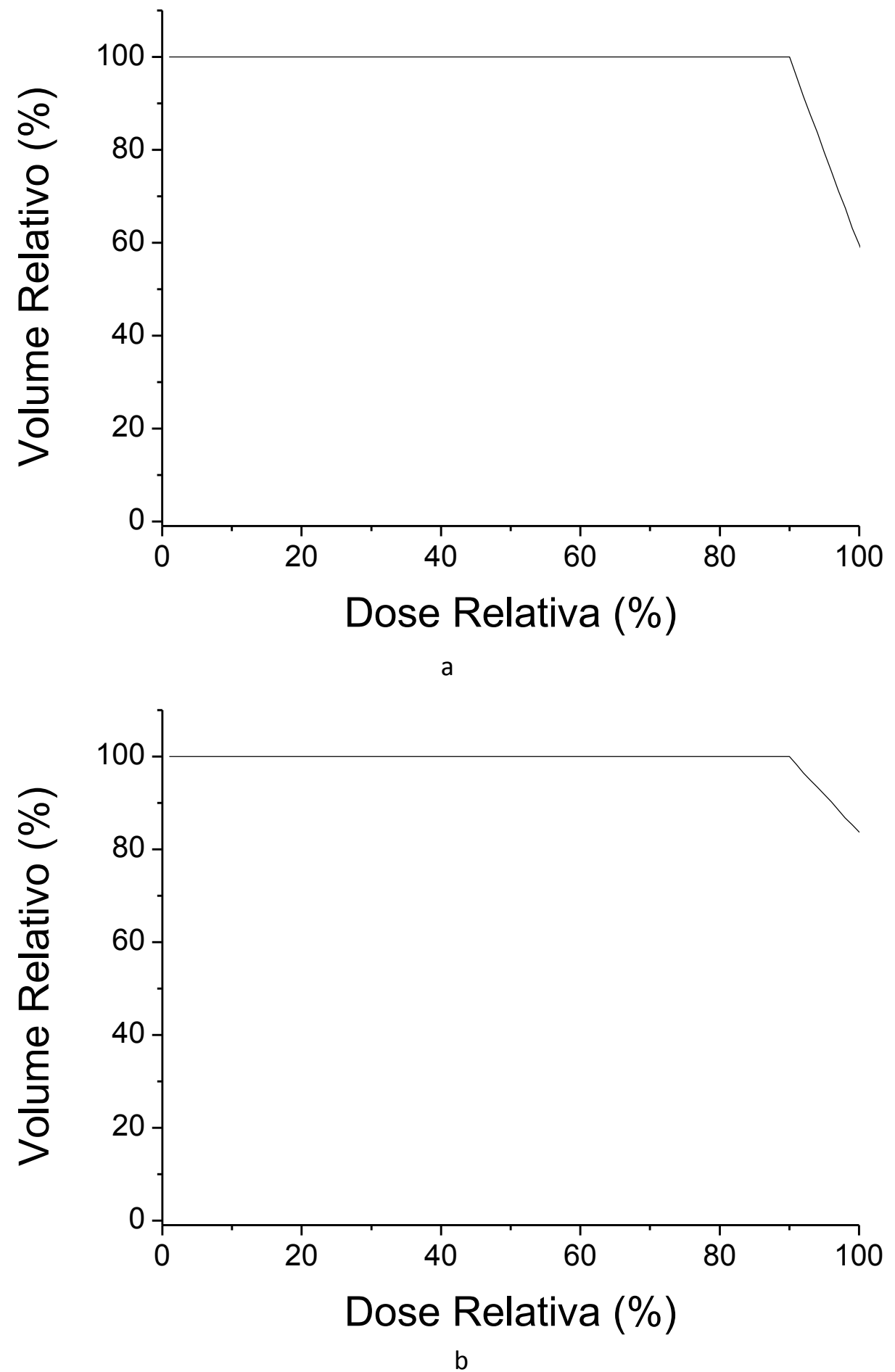

Figura 43:Histogramas dose-volume para IORT por elétrons de $7 \mathrm{MeV}$, para volume mamário pequeno (a), médio (b) e grande (c) (continua) 


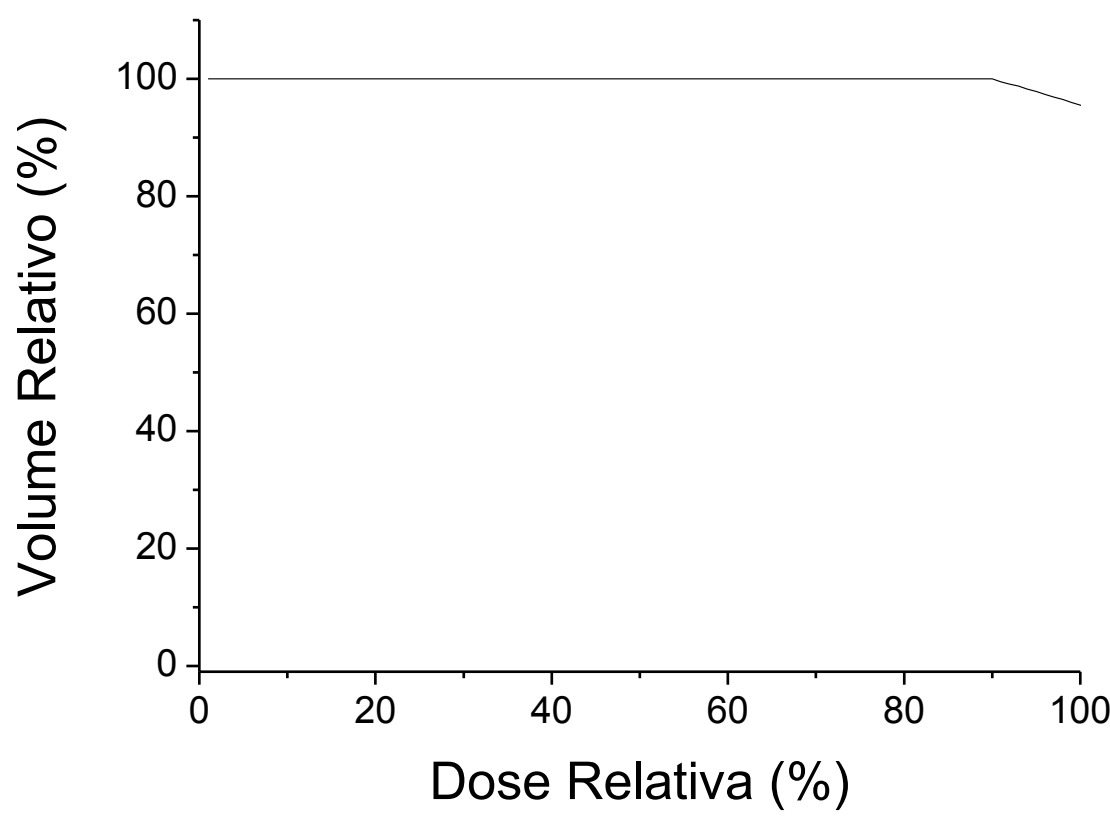

C

Figura 43:Histogramas dose-volume para IORT por elétrons de $7 \mathrm{MeV}$, para volume mamário pequeno (a), médio (b) e grande (c)

Para todos os volumes mamários, $100 \%$ do volume alvo está coberto pela isodose de planejamento, de $90 \%$, conforme esperado uma vez que esse foi o critério adotado para definir o volume alvo. Nos volumes mamários grande e médio, $80 \%$ do volume alvo recebe aproximadamente $100 \%$ da dose, enquanto que doses de aproximadamente $95 \%$ são entregues em $80 \%$ do volume alvo na mama de menor volume.

Na Figura 44 estão apresentados os histogramas dose-volume sem limitação de dose.

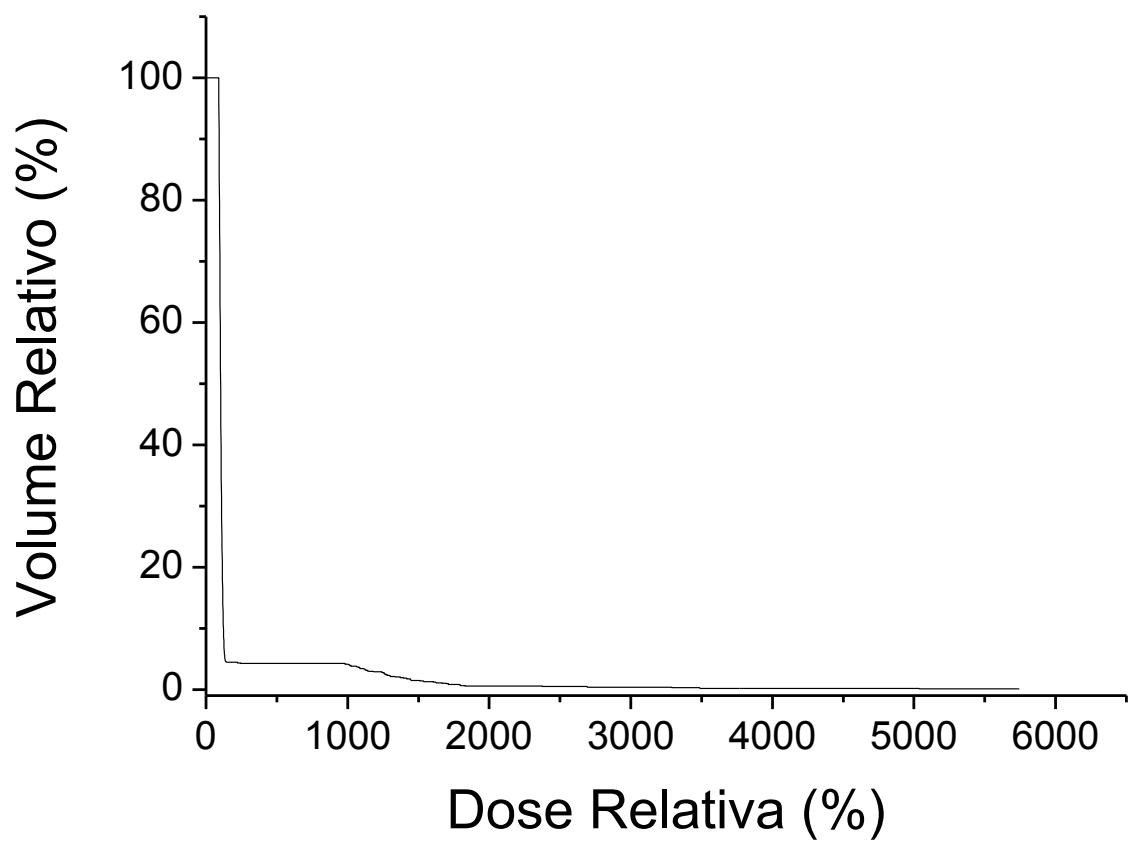

Figura 44: Histogramas dose-volume completo para IORT por elétrons de $7 \mathrm{MeV}$, para volume mamário pequeno (a), médio (b) e grande (c) (continua) 


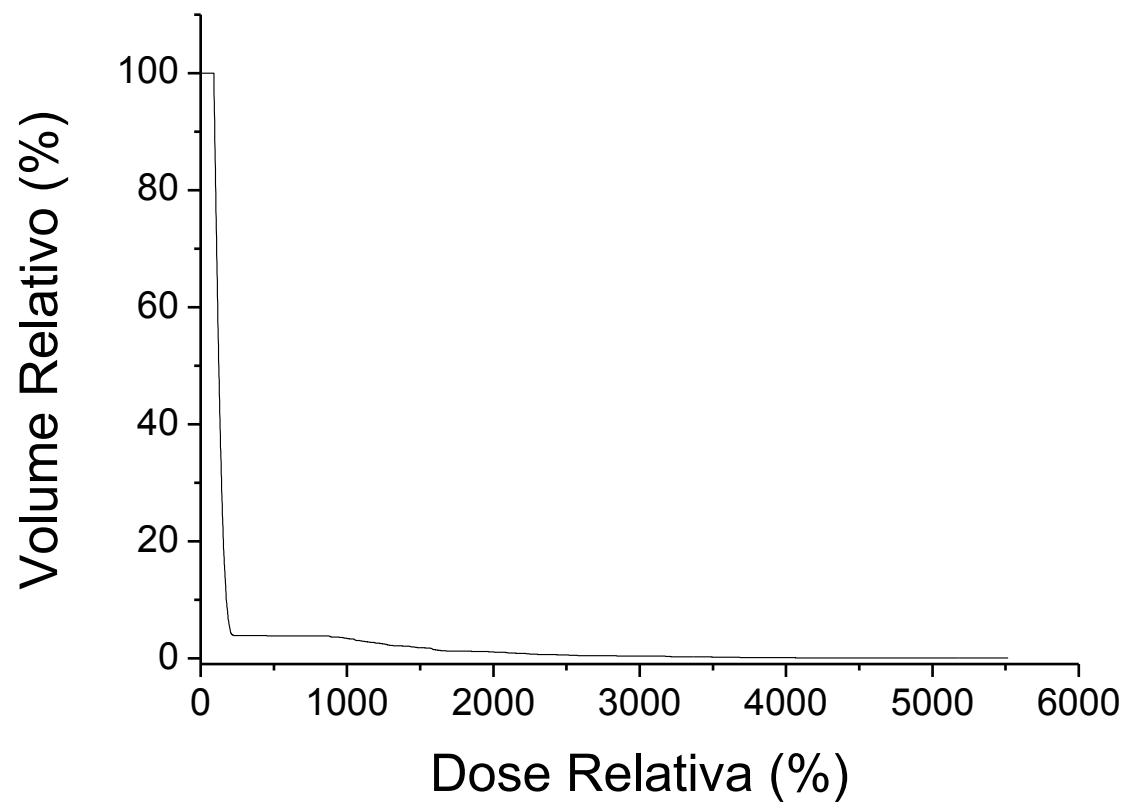

b

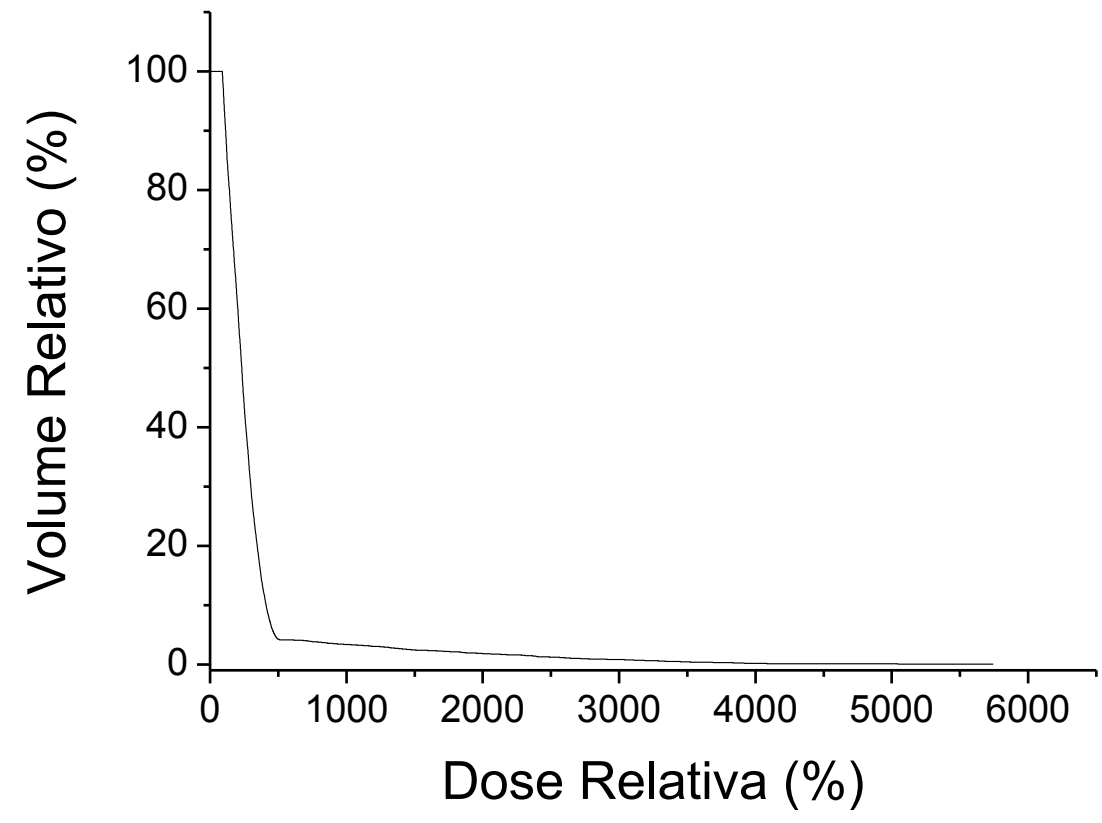

C

Figura 44: Histogramas dose-volume completo para IORT por elétrons de $7 \mathrm{MeV}$, para volume mamário pequeno (a), médio (b) e grande (c)

Como visto nas distribuições, uma pequena porcentagem do volume alvo recebe doses muito superiores a $100 \%$. Os histogramas indicam, para a energia de $7 \mathrm{MeV}$, uma mesma entrega de doses altas para todos os volumes mamários analisados, atingindo por volta de $5500 \%$ em todos os casos. É possível observar uma maior fração do volume recebendo doses de aproximadamente $1000 \%$, em todos os volumes mamários. Doses maiores são entregues em maiores frações do volume para o volume mamário grande. 
Apresentados na Tabela 10 estão os parâmetros de avaliação do plano para feixe de 7 MeV.

Tabela 10: parâmetros de avaliação da qualidade do plano para IORT por elétrons de $7 \mathrm{MeV}$

\begin{tabular}{|c|l|l|l|}
\hline Volume mamário & IC & HI & TCl \\
\hline Pequeno & 1 & 10,55 & 1,01 \\
\hline Médio & 1 & 9,80 & 1,00 \\
\hline Grande & 1 & 5,98 & 1,00 \\
\hline
\end{tabular}

Os índices foram calculados com base na isodose de prescrição de $90 \%$. Dada a definição adotada para volume alvo, baseada na isodose de $90 \%$, os IC obtidos para todos os volumes mamários perdem seu caráter comparativo, uma vez que volume alvo e volume coberto pela isodose de $90 \%$ são iguais. De modo geral, o $\mathrm{HI}$ indica uma distribuição heterogênea. Segundo o HI, a dose está mais homogeneamente depositada para o maior volume mamário quando comparada à dose entregue nos volumes mamário médio e pequeno, uma vez que o índice apresentou menor valor para o maior volume mamário. Para todos os volumes mamários estudados os $\mathrm{TCl}$ apresentaram valores próximos ou iguais a 1 , indicando que o volume coberto pela isodose de prescrição é equivalente ao volume coberto pela isodose de $95 \%$. Não houve diferença significativa entre os valores de $\mathrm{TCl}$ dos diferentes volumes mamários avaliados.

De modo geral, os índices indicam uma entrega de dose heterogênea. A maior homogeneidade ocorre para a mama de maior volume, indicando que a utilização de feixe de $7 \mathrm{MeV}$ poderia ser mais adequada para esses casos. Esses resultados, entretanto, referem-se ao posicionamento do aplicador utilizado neste trabalho.

\subsubsection{Feixe de elétrons de $9 \mathrm{MeV}$}

A Figura 45 apresenta as distribuições dentro do volume alvo para o feixe de elétrons de 9 MeV. 

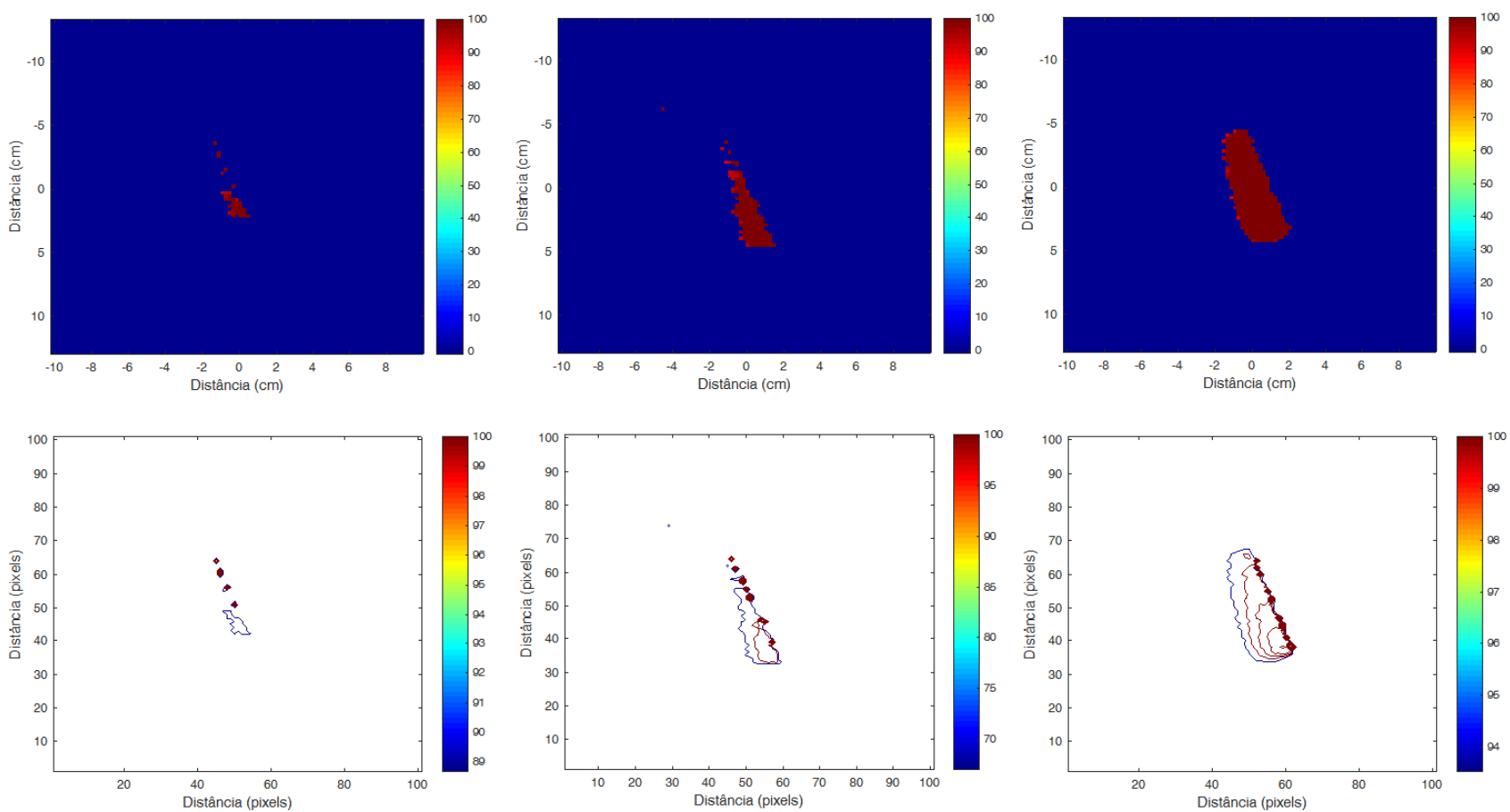

b

C

Figura 45: Uıstribuições de dose e curvas de isodose no volume alvo para IORT por elétrons de y MeV, para os volumes mamários pequeno (a), médio (b) e grande (c).

As curvas de isodose mostram que ocorrem, na região em contato com o ar que preenche o aplicador, doses elevadas. Devido à angulação do aplicador e ao plano onde foi cortado as distribuições não é possível avaliá-las qualitativamente, além da percepção que ocorrem, dentro do volume alvo, apenas doses maiores que $90 \%$, como de fato era esperado a partir de sua definição. A deposição de dose gerada no tratamento com IORT por feixe de elétrons de $9 \mathrm{MeV}$ foi avaliada através dos histogramas dose-volume e parâmetros de avaliação do plano.

Os histogramas dose-volume, para o feixe de $9 \mathrm{MeV}$ estão apresentados na Figura 46. São apresentados os histogramas até as doses de $100 \%$ da prescrição. 

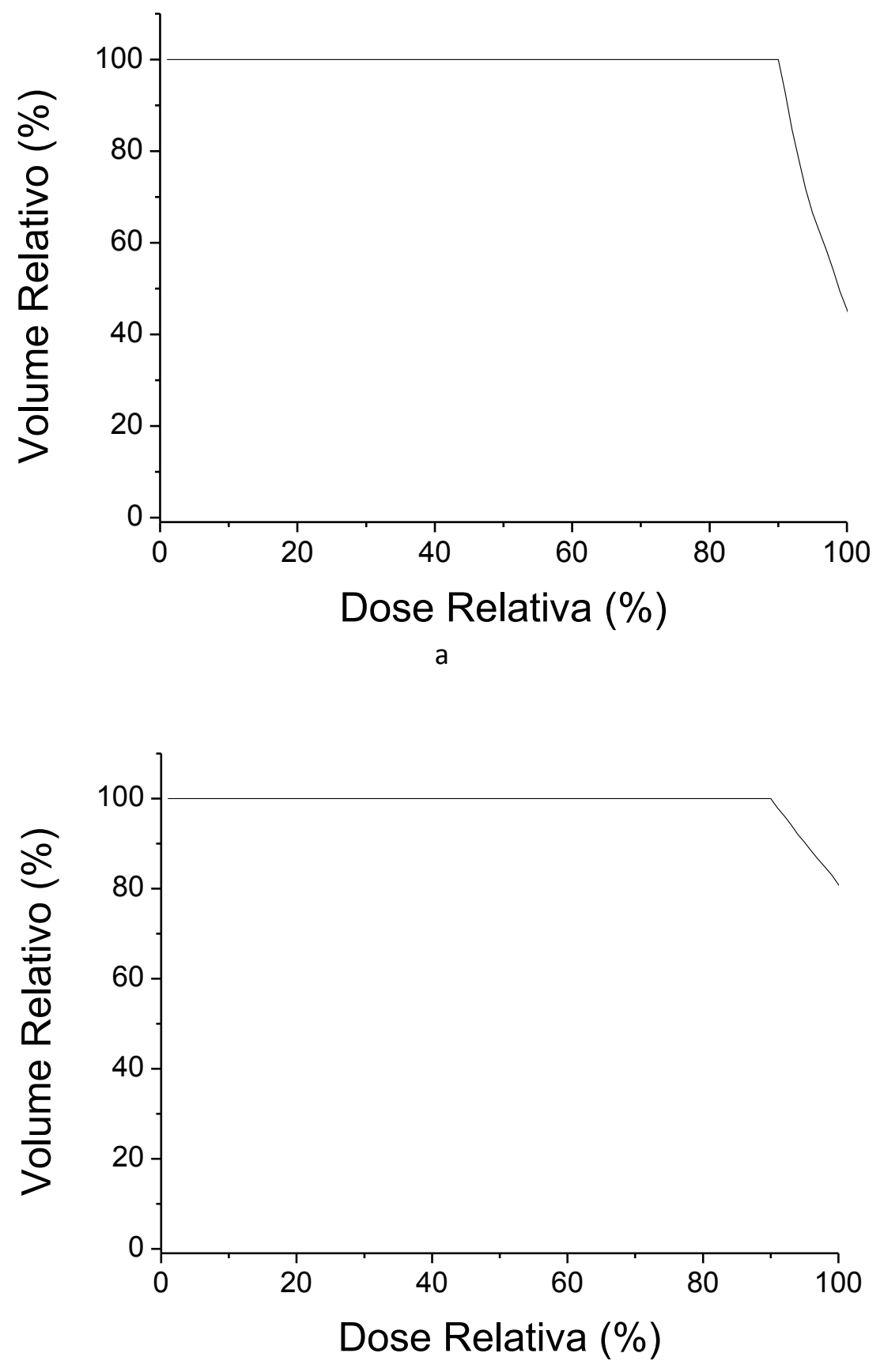

b

Figura 46: Histogramas dose-volume para IORT por elétrons de $9 \mathrm{MeV}$, para volume mamário pequeno (a), médio (b) e grande (c). (continua) 


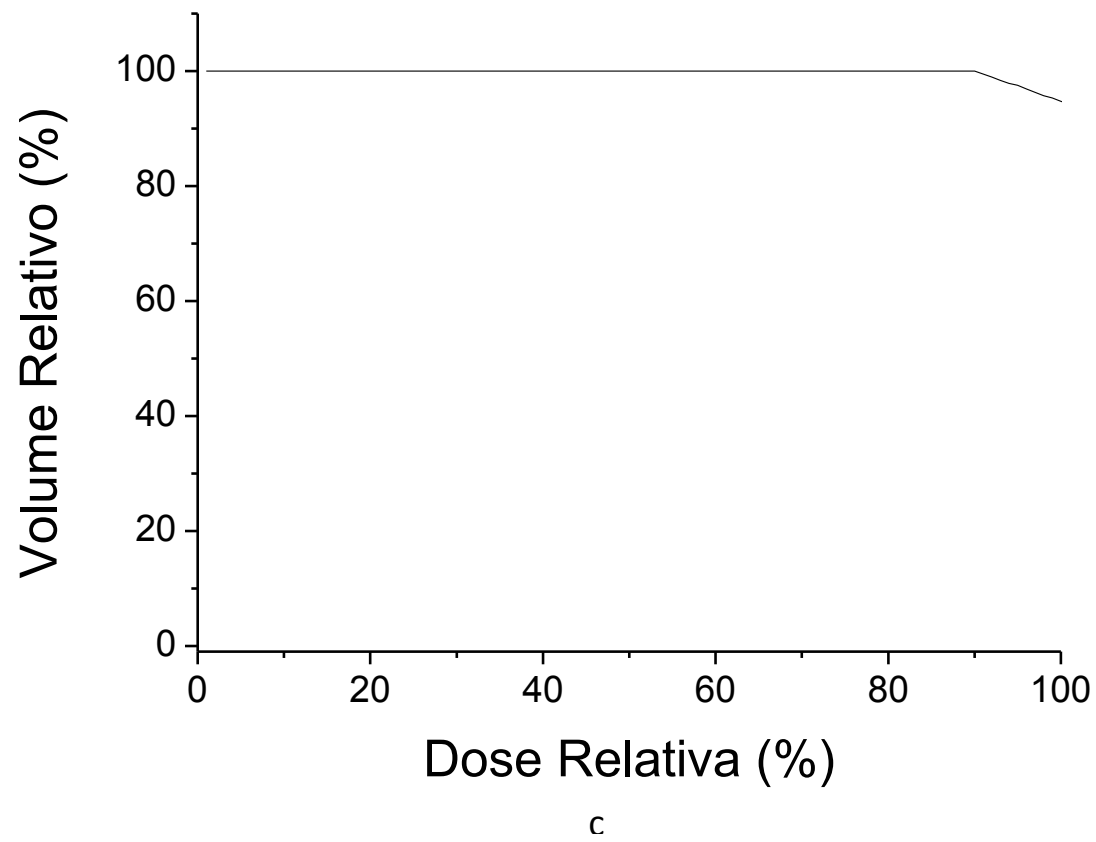

Figura 46: Histogramas dose-volume para IORT por elétrons de $9 \mathrm{MeV}$, para volume mamário pequeno (a), médio (b) e grande (c).

Os histogramas dose-volume apresentam, para todos os tamanhos de volume mamário avaliados, uma cobertura de $100 \%$ do volume pela isodose de $90 \%$, conforme esperado dada a definição do volume alvo. Para o menor volume mamário, $80 \%$ do volume alvo recebe doses pouco maiores que $90 \%$, enquanto que para as geometrias de volume mamário médio e grande doses de aproximadamente $100 \%$ da dose não normalizada são entregues em $80 \%$ do volume alvo.

A Figura 47 apresenta os histogramas dose-volume não limitados para o feixe de $9 \mathrm{MeV}$.

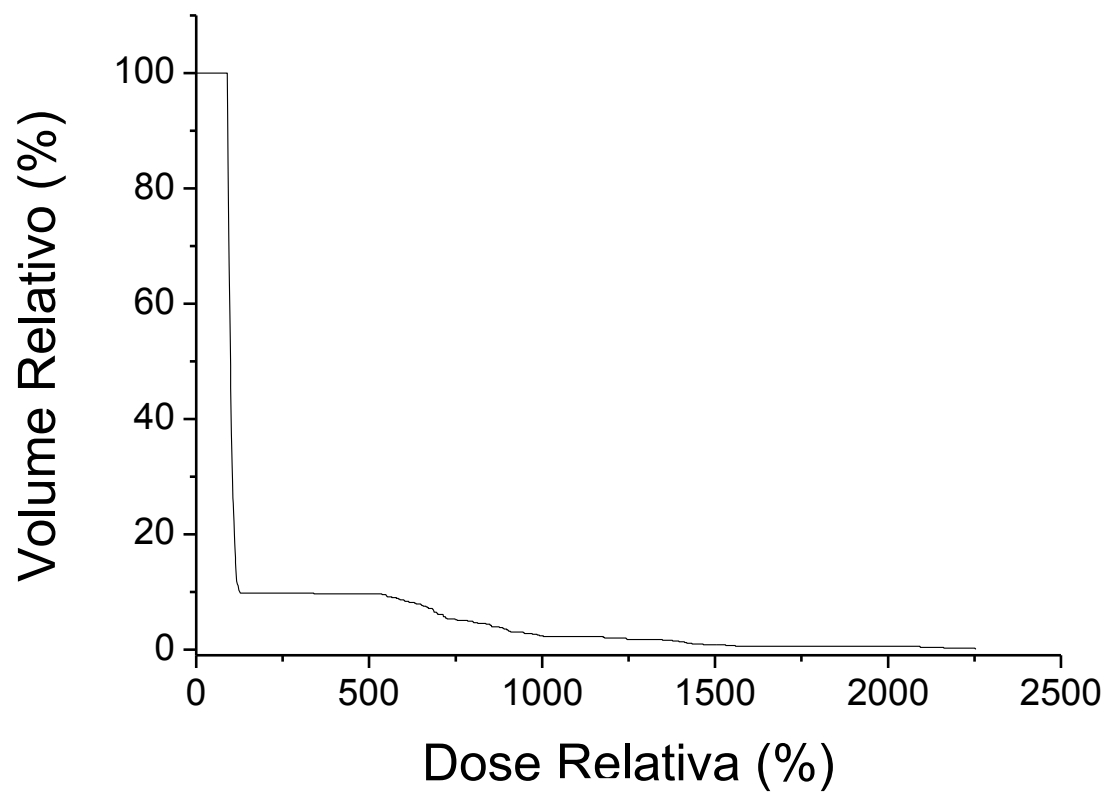

Figura 47: Histogramas dose-volume completo para IORT por elétrons de $9 \mathrm{MeV}$, para volume mamário pequeno (a), médio (b) e grande (c). (continua) 

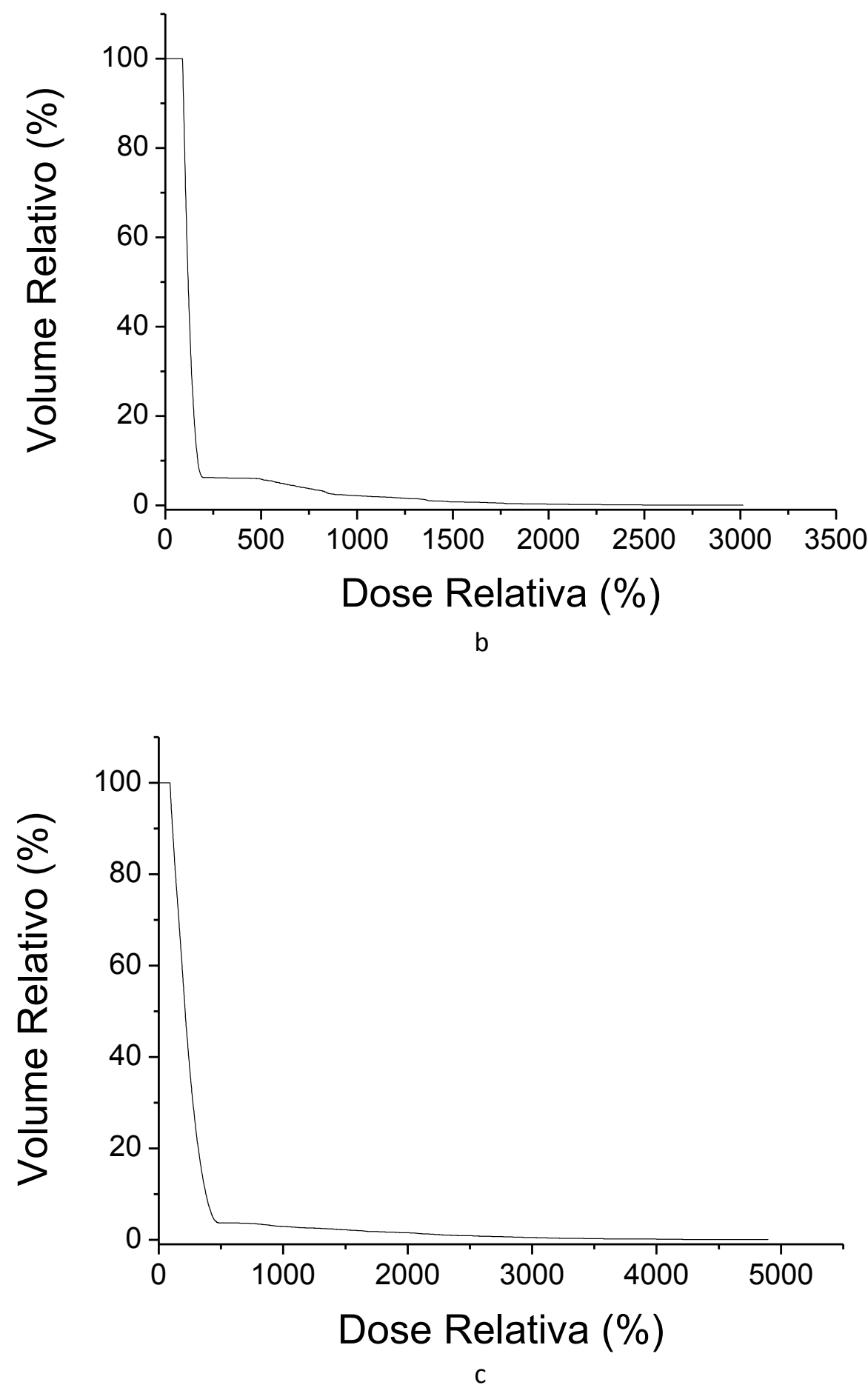

Figura 47: Histogramas dose-volume completo para IORT por elétrons de $9 \mathrm{MeV}$, para volume mamário pequeno (a), médio (b) e grande (c).

Conforme visto nas distribuições de dose, ocorrem doses bastante elevadas em porções pequenas do volume alvo. Os histogramas dose-volume mostram que as doses aumentam com o aumento do volume mamário. Ocorre um aumento na fração do volume alvo que recebe doses altas na região de doses de $500 \%$, em todos os volumes mamários analisados. 
O maior volume mamário apresenta doses altas em maior fração do volume alvo, quando comparado aos volumes mamários médio e pequeno.

Na tabela 11 estão apresentados os parâmetros de avaliação do plano para o feixe de 9 MeV.

Tabela 11: parâmetros de avaliação da qualidade do plano para IORT por elétrons de 9 MeV

\begin{tabular}{|c|l|l|l|}
\hline Volume mamário & IC & HI & TCI \\
\hline Pequeno & 1 & 10,75 & 1,01 \\
\hline Médio & 1 & 10,03 & 1,00 \\
\hline Grande & 1 & 6,97 & 1,00 \\
\hline
\end{tabular}

Os parâmetros de avaliação do plano foram obtidos para prescrição na isodose de $90 \%$. Os IC apresentam, para todos os tamanhos de mama estudados, valor 1, dado que ambos os volumes comparados, volume alvo e volume coberto pela isodose de prescrição, correspondem ao volume coberto pela isodose de $90 \%$ e, portanto, são iguais. No geral, os $\mathrm{HI}$ apresentaram valores elevados, indicando uma entrega de dose heterogênea. A maior heterogeneidade ocorre no volume mamário pequeno, apresentando o maior valor de $\mathrm{HI}$. Para o volume mamário médio a heterogeneidade está próxima à vista no menor volume mamário. A dose é mais homogeneamente entregue no volume mamário grande, cujo $\mathrm{HI}$ é o menor dentre os três volumes mamário analisados. Os valores de $\mathrm{TCl}$ são bastante próximos ou iguais a 1 , indicando que a isodose de $95 \%$ está muito próxima à isodose de prescrição. Não há diferença significativa entre os $\mathrm{TCl}$ obtidos para os diferentes volumes mamários.

Os parâmetros de avaliação do plano indicam, como um todo, distribuições de dose conformadas, heterogêneas e com áreas de doses elevadas dentro do volume alvo. Em conjunto, seus valores sugerem que a utilização do feixe de $9 \mathrm{MeV}$ traria melhores resultados em pacientes de maior volume mamário. Entretanto, é necessário ressaltar que a distribuição de doses é influenciada, ainda, pela posição do aplicador no momento da irradiação, e não apenas pelo volume nominal da mama.

\subsection{IORT por feixe de raios-X de baixa energia}

Para IORT por raios-X de baixa energia, o volume alvo pode ser definido como uma casca esférica ao redor do aplicador, conforme está descrito na literatura (Nairz et al, 2006).

Em IORT por raios-X de baixa energia o planejamento é prescrito geralmente na profundidade de $1,0 \mathrm{~cm}$ a partir do aplicador. Dessa forma, a espessura da casca esférica que define o volume alvo deve ser, também, de $1,0 \mathrm{~cm}$ e a dose nessa posição será de $100 \%$. 
As distribuições e curvas de isodose no volume alvo, para IORT por raios-X de baixa energia, estão apresentadas na Figura 48.
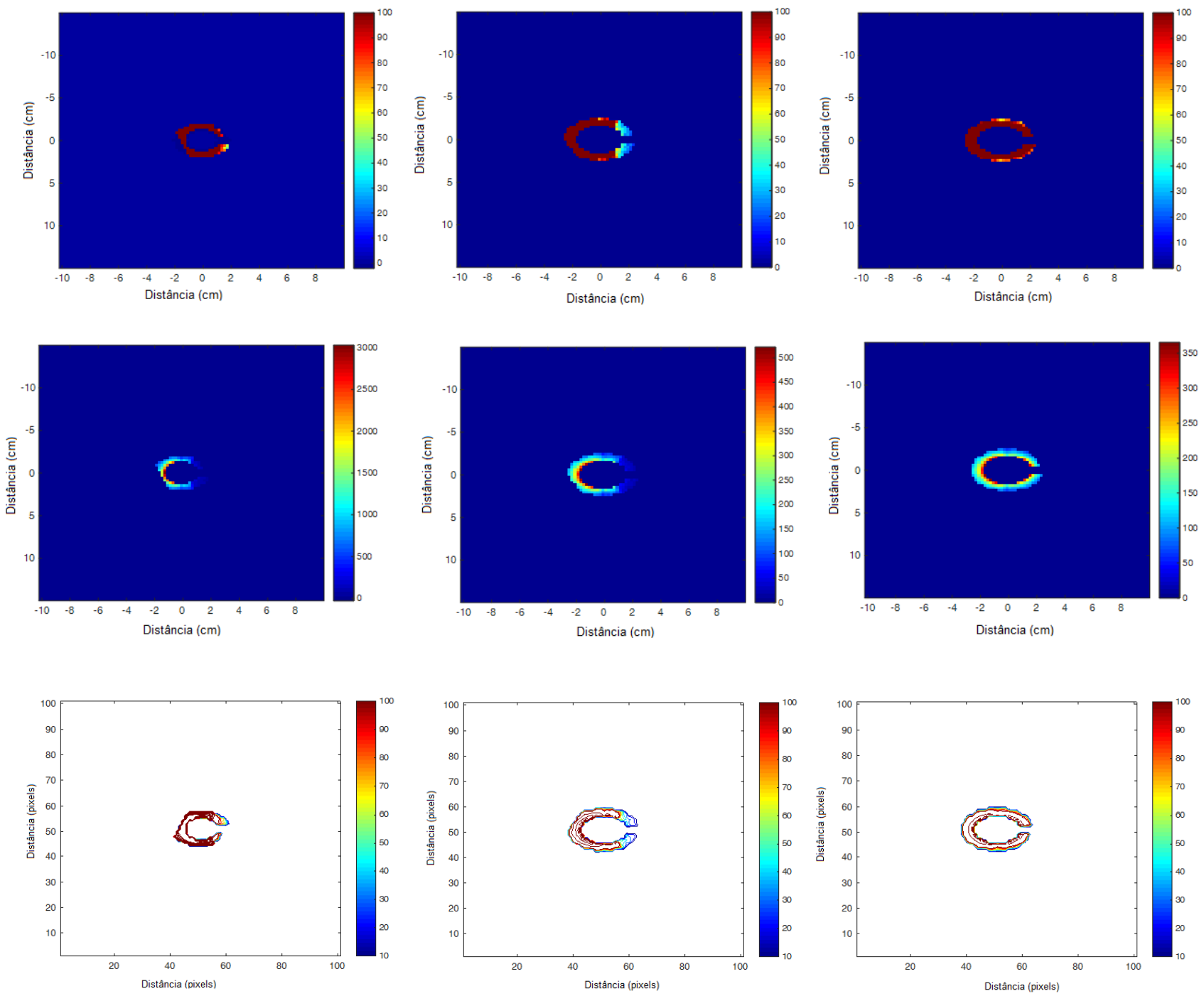

a

$b$

C

Figura 48: Volume alvo para IORT por raios- $X$ de baixa energia para geometria de volume mamario pequeno (a), médio (b) e grande (c). Na linha superior tem-se a escala de cores limitada para 100\%; na linha intermediária, a escala não está limitada; e na linha inferior tem-se as isodoses.

As distribuições de dose, normalizadas de forma que a isodose a 1,0 cm do aplicador seja de $100 \%$, mostram que, para todos os volumes mamários estudados, a prescrição em profundidade leva a uma superdosagem do volume alvo. A distribuição de dose para a mama de menor volume indica que doses até 30 vezes maiores que a dose de prescrição são entregues ao volume alvo.

Considerando-se que doses acima de $100 \%$ podem ser desejáveis dentro do volume alvo, as distribuições de dose apresentam-se, para todos os tamanhos de mama bastante homogêneas, uma vez que doses menores que $100 \%$ ocorrem em regiões pequenas do 
volume alvo. A maior heterogeneidade observada ocorre, nos estudos realizados, para o volume mamário médio.

Os histogramas dose-volume para IORT por raios-X de baixa energia estão apresentados na Figura 49, limitados para a dose de $100 \%$.

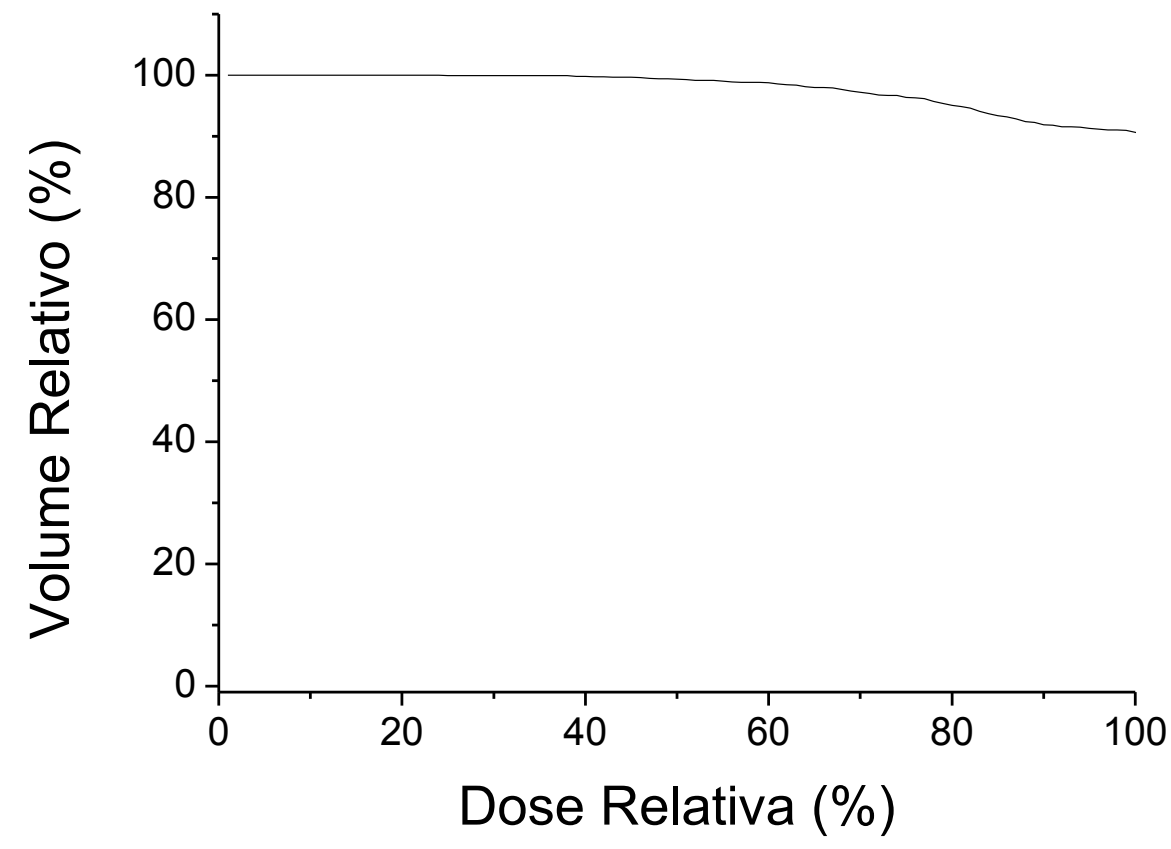

a

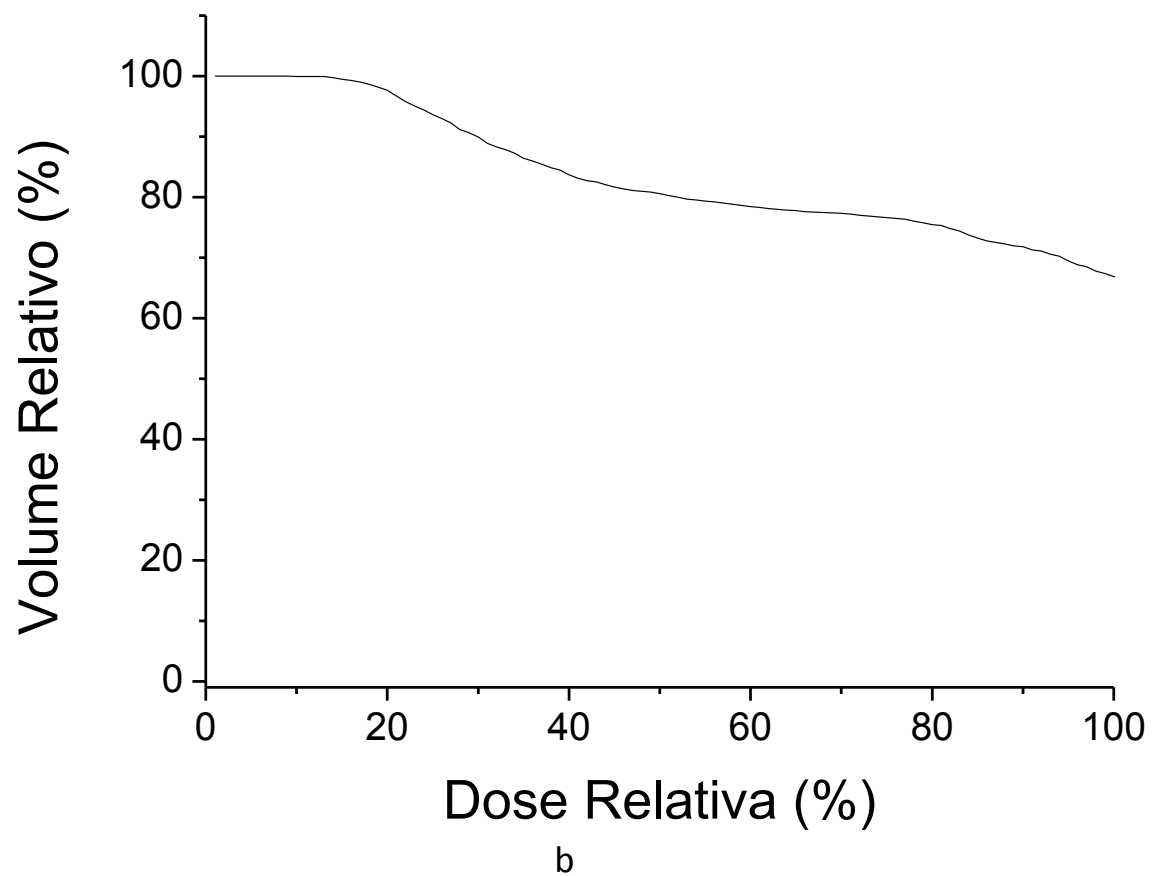

Figura 49: Histograma dose-volume para IORT por raıos-X de baixa energia, para volume mamário pequeno (a), médio (b) e grande (c) (continua) 


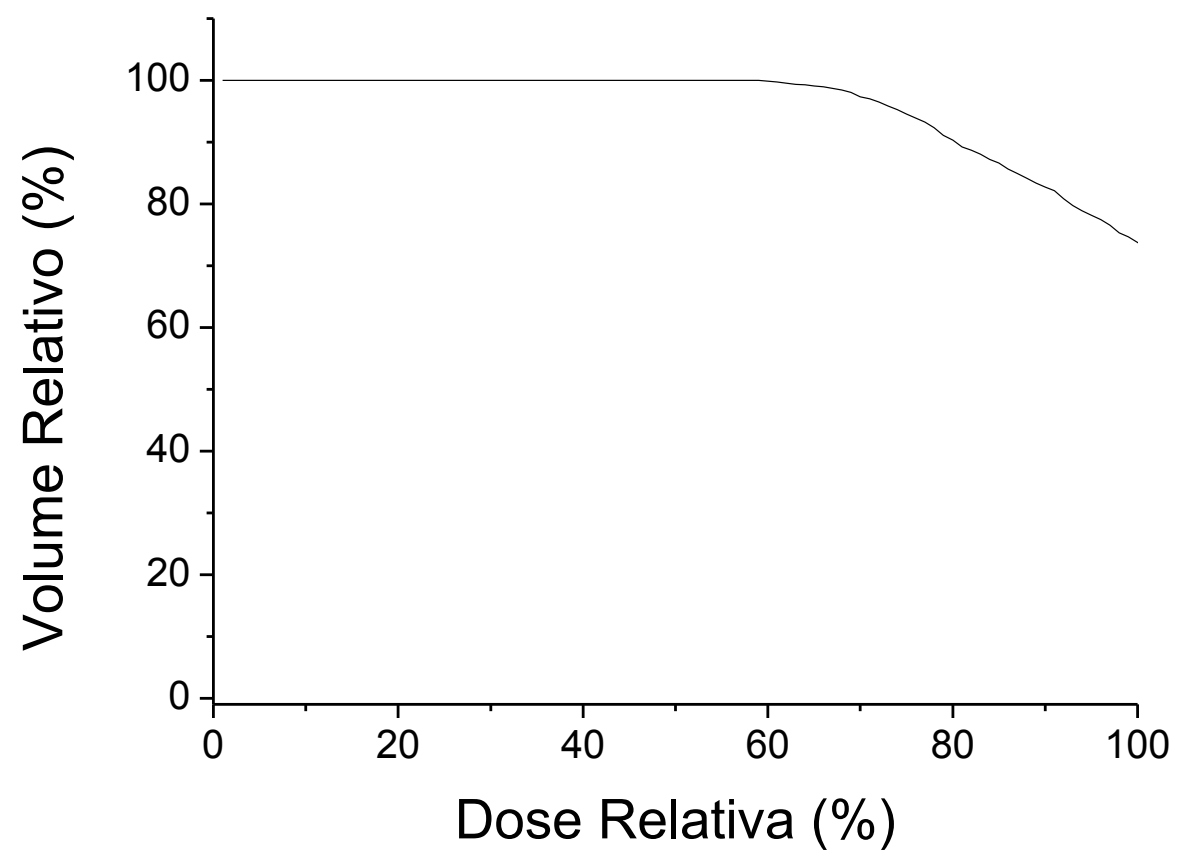

C

Figura 49: Histograma dose-volume para IORT por raios-X de baixa energia, para volume mamário pequeno (a), médio (b) e grande (c).

Pode-se perceber que, independentemente do tamanho de mama estudado, a dose de $100 \%$ não cobre todo o volume alvo, devido às doses menores que $100 \%$ que são entregues dentro do volume, na posição posterior do aplicador, conforme mostrado pelas distribuições de doses.

A melhor cobertura foi obtida para a mama de menor volume, onde $100 \%$ da dose foi entregue em $90 \%$ do volume. Nas geometrias de volume mamário médio e grande a dose de $100 \%$ cobriu, respectivamente, $67 \%$ e $73 \%$ do volume alvo, aproximadamente. Para a mama de menor volume, $80 \%$ do volume alvo recebem doses maiores ou iguais a $100 \%$, para o volume mamário médio, $80 \%$ do volume alvo recebe aproximadamente $50 \%$ da dose e para o maior volume de mama, $80 \%$ do volume alvo doses de aproximadamente $92 \%$. A queda da dose em $80 \%$ do volume observada para a mama de volume médio indica uma maior heterogeneidade na entrega da dose, conforme observado na distribuição de dose.

Na Figura 50 são mostrados os histogramas dose-volume sem limitação de dose. 


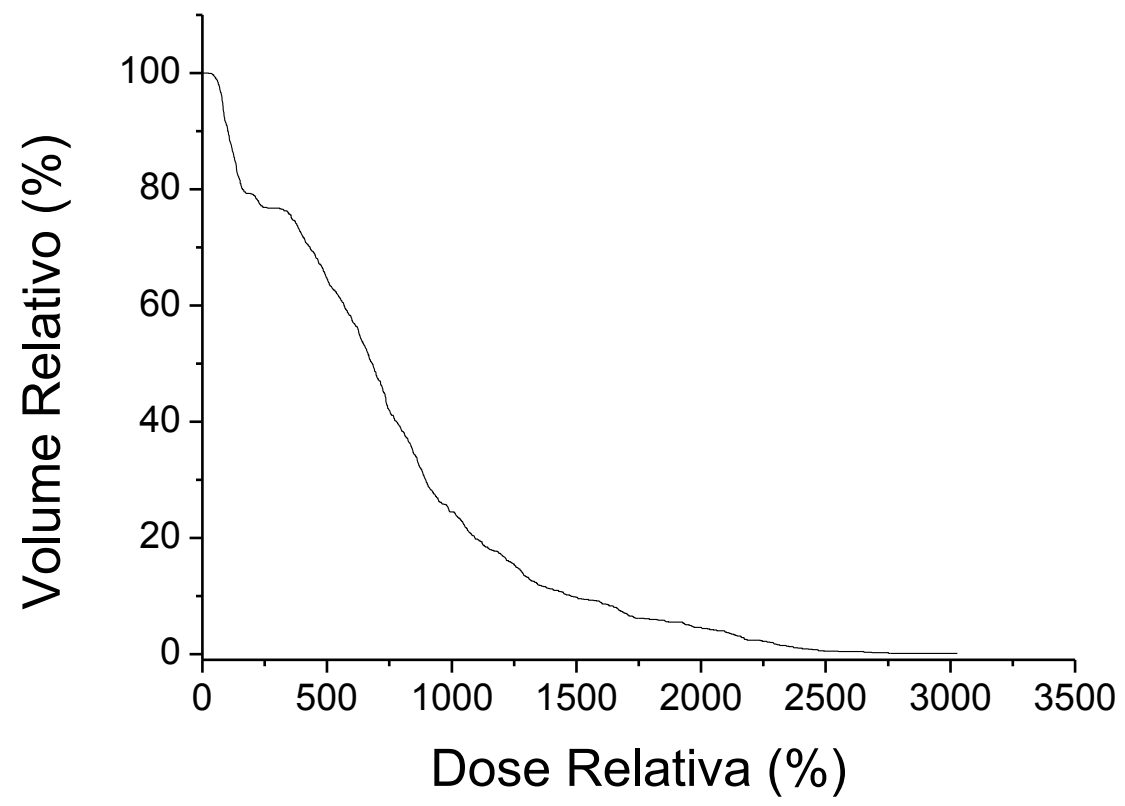

a

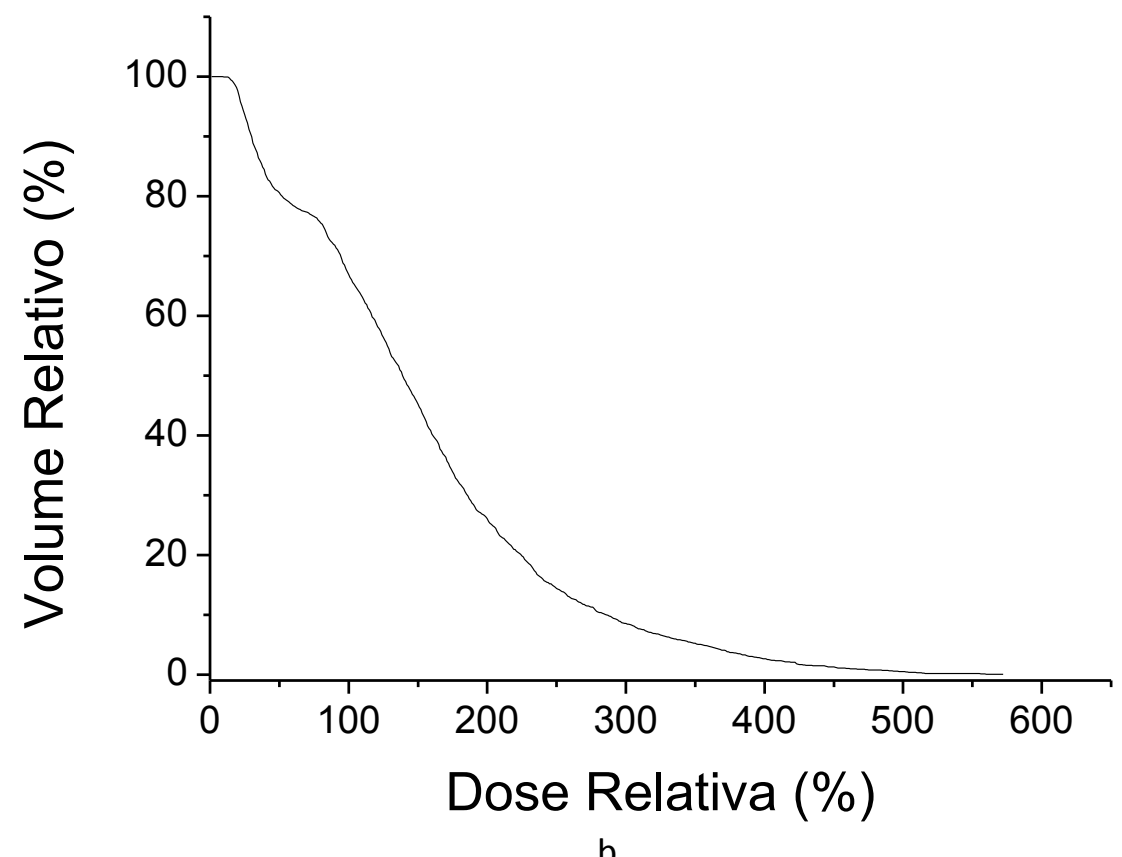

b

Figura 50: Histograma dose-volume completo para IORT por raios-X de baixa energia, para volume mamário pequeno (a), médio (b) e grande (c) (continua) 


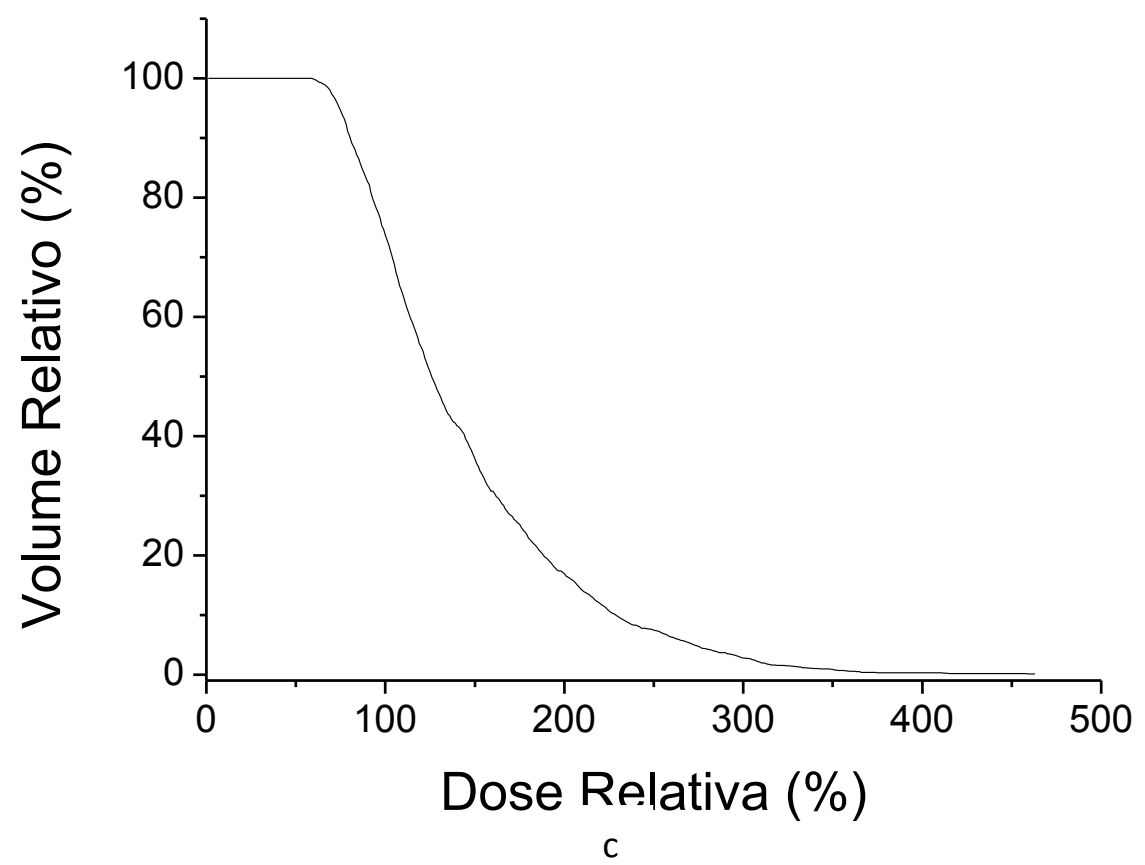

Figura 50: Histograma dose-volume completo para IORT por raios-X de baixa energia, para volume mamário pequeno (a), médio (b) e grande (c).

Os histogramas mostram, para todos os volumes mamários, uma superdosagem no volume alvo, como indicado pelas distribuições de dose. As maiores doses são entregues para a mama de menor volume, que contribuem para a melhor cobertura observada para esse volume mamário no histograma dose-volume limitado, apresentado na Figura 46. Analogamente as menores doses, ainda superiores a 100\%, são vistas para o volume mamário médio.

Os parâmetros de avaliação do plano estão apresentados na Tabela 12.

Tabela 12: parâmetros de avaliação da qualidade do plano para IORT por raios-X de baixa energia

\begin{tabular}{|c|l|l|l|}
\hline Volume mamário & IC & HI & TCl \\
\hline Pequeno & 0,91 & 33,84 & 0,99 \\
\hline Médio & 0,67 & 80,59 & 0,96 \\
\hline Grande & 0,74 & 30,94 & 0,94 \\
\hline
\end{tabular}

A isodose de prescrição adotada foi a isodose de $100 \%$, a $1,0 \mathrm{~cm}$ do aplicador. Os IC mostram que os diferentes volumes mamários apresentaram diferentes graus de conformação entre o volume coberto pela isodose de planejamento e o volume alvo total. A distribuição de dose não isotrópica gerada pelo aplicador leva a não conformidade entre os dois volumes. O volume alvo foi definido para a profundidade para a qual ocorre a dose de $100 \%$ diretamente abaixo do aplicador, no eixo da sonda. Entretanto, como visto nas distribuições de dose, a isodose de $100 \%$ não ocorre nessa mesma profundidade em todo o entorno do aplicador. Doses menores que 100\% ocorrem, em especial, em posições 
próximas à pele. O melhor IC ocorre para a geometria de menor volume mamário, indicando que nesse caso o volume coberto pela isodose de $100 \%$ está mais próximo do volume alvo total, quando comparado aos volumes de mama médio e grande estudados.

Os HI descrevem quão homogênea é a dose dentro do volume alvo. Dentre os valores de $\mathrm{HI}$ encontrados para os três volumes mamários estudados, pode-se perceber uma diferença significativa entre o valor de $\mathrm{HI}$ obtido para o volume mamário médio quando comparado aos valores obtidos para a mama de volume pequeno e grande. $\mathrm{O}$ valor de $\mathrm{HI}$ mostra-se significativamente mais alto para o volume mamário médio indicando uma grande heterogeneidade na entrega da dose para esse caso, corroborando o indicado na distribuição de dose e no histograma dose-volume para esse volume de mama. O HI mais baixo, indicativo de uma distribuição mais homogênea ocorre para a mama de maior volume. De acordo com o histograma dose-volume, a distribuição mais homogênea ocorre, no estudo realizado, para o menor volume mamário. Os dados do histograma e do $\mathrm{HI}$ se corroboram, $80 \%$ do volume alvo para o menor volume mamário é de fato coberto por doses maiores que $100 \%$, como indicado pelo histograma e desejável para o tratamento, porém essa região de superdosagem eleva o grau de heterogeneidade na entrega da dose medida através do HI.

Para todos os volumes mamários estudados, o $\mathrm{TCl}$ permaneceu menor que 1, indicando que a isodose de prescrição está mais interna à isodose de $95 \%$. O maior $\mathrm{TCl}$ ocorre para a mama de menor volume indicando uma menor região de doses menores que $100 \%$ dentro do volume alvo para esse tamanho de mama quando comparado aos volumes mamários médio e grande.

De forma geral, os parâmetros de avaliação do plano indicam uma entrega de dose mais homogênea e conformada à totalidade do volume alvo, para IORT por raios-X de baixa energia. Para mamas de volume médio a entrega de dose deve ser melhorada. $\mathrm{O}$ tamanho e posicionamento do aplicador são fatores que influenciam na distribuição de dose e sua adequação pode ser utilizada para melhora da distribuição.

\subsection{Comparação entre técnicas radioterápicas}

As diferentes técnicas de irradiação de mama estudadas foram avaliadas em função dos volumes mamários. Torna-se interessante a comparação das técnicas para cada um dos volumes de mama avaliados, tendo-se sempre em perspectiva que os resultados obtidos aplicam-se ao posicionamento do aplicador realizado neste trabalho; diferentes posicionamentos do aplicador no interior do volume mamário podem alterar os resultados em relação à técnica e energia do feixe utilizado. Deve-se ressaltar que os planos de 3DR apresentados nesse trabalho devem ser otimizados, de forma que a comparação das técnicas não apresenta resultados definitivos, apenas demonstra a tendência da IORT em comparação à 3DR. 


\subsubsection{Volume mamário pequeno}

Os histrogramas dose-volume de todas as técnicas estudadas para o volume mamário pequeno estão apresentados na Figura 51.

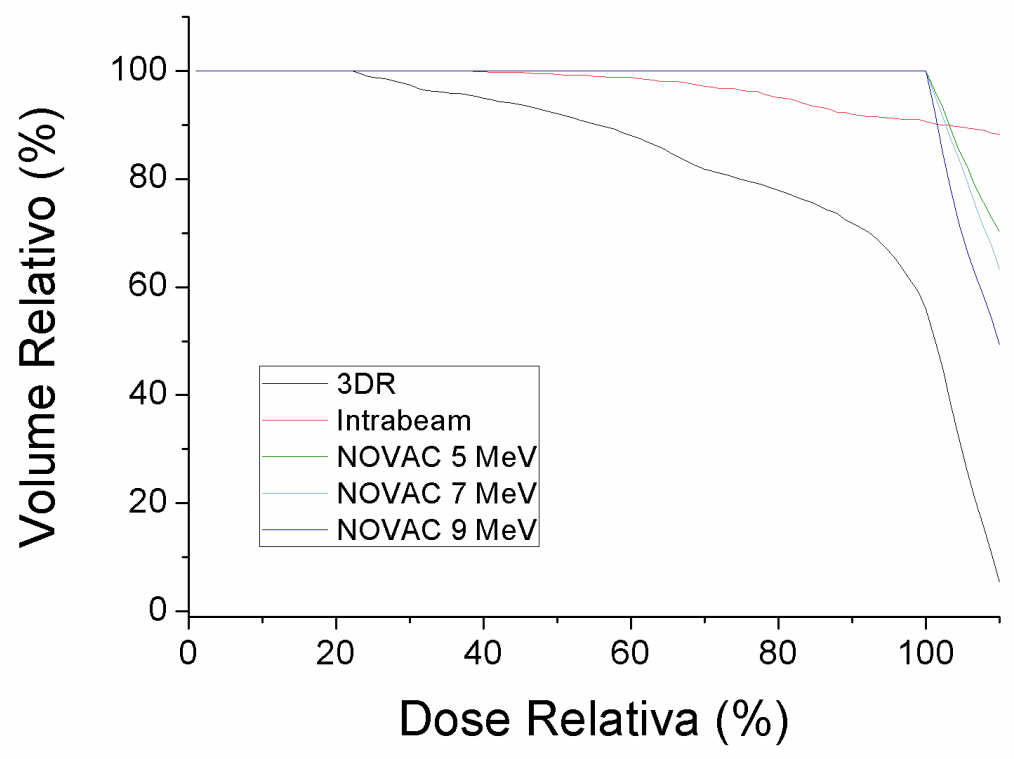

Figura 51: Histograma dose-volume para geometria de volume mamário pequeno.

Os histogramas foram normalizados para que a dose de prescrição correspondesse a dose de $100 \%$, e limitados para a maior dose existente no tratamento por 3DR. Dessa forma podese perceber que a melhor cobertura ocorre para o NOVAC7, onde $100 \%$ do volume recebe $100 \%$ da dose. Isso ocorre devido à definição de volume alvo adotada para essa técnica neste trabalho. Comparando-se a dose entregue em $80 \%$ do volume temos uma entrega de doses maiores que $100 \%$ para todas as técnicas de IORT. Para 3DR é entregue aproximadamente $72 \%$ da dose em $80 \%$ do volume. Embora a cobertura seja maior em IORT, sabe-se que a heterogeneidade de dose nessas técnicas pode ser relevante, com superdosagem em pequenos percentuais do volume alvo. Os parâmetros de avaliação do plano, para cada uma das técnicas estudas, estão apresentados, para o volume mamário pequeno, na Tabela 13.

Tabela 13: Parâmetro de avaliação da qualidade do plano para geometria de mama pequena.

\begin{tabular}{|l|l|l|l|}
\hline & IC & HI & TCl \\
\hline 3DR & 0,56 & 82,31 & 2,16 \\
\hline IORT Intrabeam & 0,90 & 33,84 & 0,99 \\
\hline IORT NOVAC 5 MeV & 1 & 10,44 & 1,00 \\
\hline IORT NOVAC 7 MeV & 1 & 10,55 & 1,00 \\
\hline IORT NOVAC 9 MeV & 1 & 10,75 & 1,01 \\
\hline
\end{tabular}


Os parâmetros foram calculados em função da dose de prescrição utilizada em cada uma das técnicas. Para IORT por feixe de elétrons o IC não tem caráter comparativo devido à definição do volume alvo, que equivale o volume alvo ao volume coberto pela isodose de prescrição. Dentre 3DR e IORT por raios-X de baixa energia o IC indica uma melhor conformidade entre volume alvo e volume coberto pela isodose de prescrição para a IORT, onde o valor aproxima-se de 1.

Todos os valores de $\mathrm{HI}$ encontrados são elevados, indicando certo grau de heterogeneidade de dose em todas as técnicas. Seu maior valor ocorre para 3DR, indicando maior heterogeneidade na entrega de dose dessa técnica. Isso pode ser explicado pelo tamanho e posicionamento dos campos, que deveriam ser melhorados, e levam à entrega de doses baixas nas extremidades do volume alvo. A heterogeneidade no tratamento através do Intrabeam também é elevada. Nesse caso, a heterogeneidade se deve a doses baixas depositadas na região superior do aplicador, próximo à pele. $\mathrm{O} \mathrm{HI}$ indica a melhor homogeneidade de dose para IORT por feixe de elétrons de $5 \mathrm{MeV}$.

Valores de $\mathrm{TCl}$ acima de 1 indicam que a isodose de 95\% está mais interna à isodose de planejamento e ocorrem em função da definição da mesma. A melhor cobertura, com homogeneidade, do PTV ocorre para IORT por feixe de elétrons, seguida por IORT por raios$X$, cujos valores de $\mathrm{TCl}$ aproximam-se de 1 . Valores maiores de $\mathrm{TCl}$ indicam áreas menores de doses elevadas, de forma que os valores obtidos para cada uma das técnicas confirma o indicado pelos histogramas dose-volume. As áreas de doses altas são menores em 3DR e maiores em IORT por raios-X de baixa energia, de forma que quando comparado um mesmo volume, doses mais altas serão entregues através de IORT, como visto nos histogramas.

Como um todo, os parâmetros de avaliação do plano indicam que, para volumes mamários pequenos, a utilização de IORT por feixe de elétrons pode gerar o melhor tratamento. Os índices, assim como os histogramas dose-volume, indicam que todas as energias de feixes de elétrons fornecem tratamentos comparáveis. O HI sugere um tratamento ligeiramente mais homogêneo para a energia de $5 \mathrm{MeV}$.

Deve-se ressaltar que o baixo desempenho observado para 3DR, observado tanto no histograma dose-volume quanto nos parâmetros de avaliação do plano, ocorre pois o tratamento não está otimizado, como seria na clínica, de forma que a comparação dos resultados de IORT com 3DR não é adequada.

\subsubsection{Volume mamário médio}

Para a geometria de volume mamário médio, os histogramas dose-volume de todas as técnicas estudadas estão apresentados na Figura 52. 


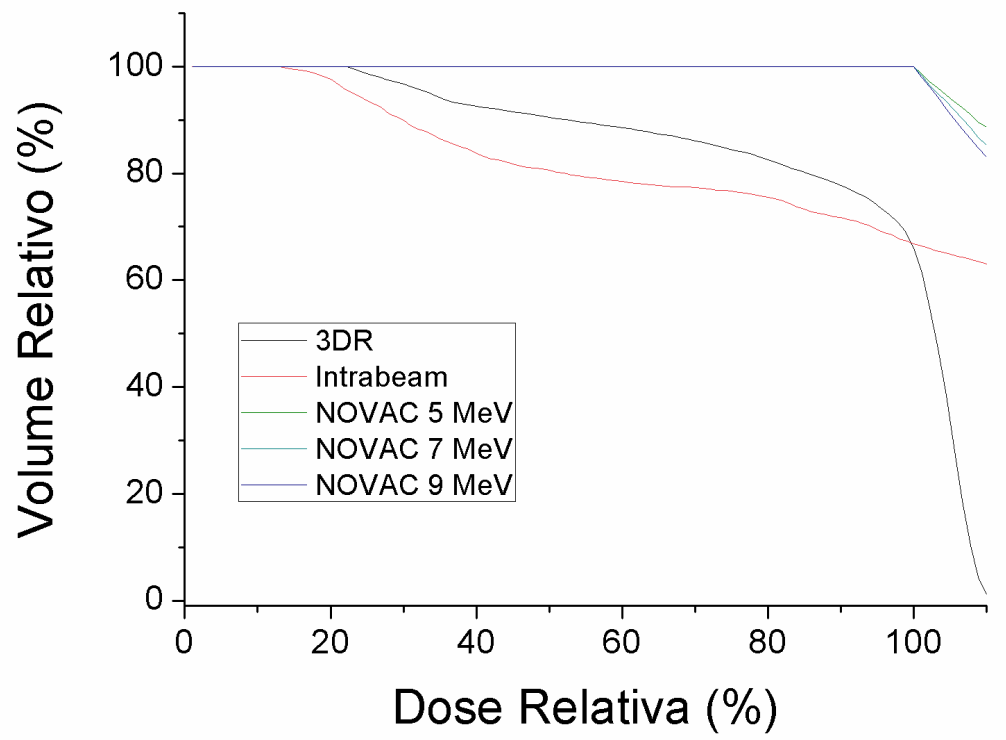

Figura 52: Histograma dose-volume para geometria de volume mamário médio.

Os histogramas dose-volume foram normalizados para que a dose de prescrição correspondesse a $100 \%$ em todas as técnicas. A melhor cobertura ocorre para IORT por feixe de elétrons, onde, devido a definição de volume alvo, $100 \%$ do volume recebe $100 \%$ da dose. A cobertura obtida para IORT por raios- $X$ de baixa energia e para 3DR foram equivalentes, em ambos os casos a dose de prescrição cobriu aproximadamente $67 \%$ do volume.

Em $80 \%$ do volume foram entregues doses maiores que $100 \%$, para IORT por feixe de elétrons, independente da energia analisada. Em 3DR apenas $85 \%$ da dose foi entregue em $80 \%$ do volume alvo, caindo para $50 \%$ em IORT por raios-X. Baixas doses entregues em grandes parcelas do volume alvo podem indicar que as áreas de doses altas são pequenas e/ou que existem áreas consideráveis de doses baixas dentro do volume alvo. Áreas de doses baixas podem ser observadas nas distribuições de dose de 3DR e de IORT, respectivamente, na extremidade do volume alvo e em regiões próximas à pele.

$\mathrm{Na}$ Tabela 14 estão apresentados os índices de avaliação do plano para o volume mamário médio.

Tabela 14: parâmetros de avaliação da qualidade do plano para geometria de mama média.

\begin{tabular}{|l|l|l|l|}
\hline & IC & HI & TCl \\
\hline 3DR & 0,66 & 83,01 & 2,29 \\
\hline IORT Intrabeam & 0,67 & 82,59 & 0,96 \\
\hline IORT NOVAC 5 MeV & 1 & 11,74 & 1,00 \\
\hline IORT NOVAC 7 MeV & 1 & 12,02 & 1,00 \\
\hline IORT NOVAC 9 MeV & 1 & 12,25 & 1,00 \\
\hline
\end{tabular}


Os índices foram calculados com base na isodose de prescrição definida para cada uma das técnicas. Os valores de IC são ideais para IORT por elétrons devido à definição de volume alvo para a técnica, perdendo sua capacidade comparativa. São comparáveis os IC obtidos para 3DR e para IORT por raios-X de baixa energia, indicando conformidades entre volume coberto pela isodose de prescrição e volume alvo total.

Os $\mathrm{HI}$ apresentam valores elevados independentemente da técnica observada, o que indica uma entrega de dose heterogênea para mamas de volume médio. A melhor homogeneidade da dose ocorre para o NOVAC7, cujos HI são os mais baixos dentre as técnicas analisadas. A entrega de dose é mais homogênea para a energia de $5 \mathrm{MeV}$, dentre os feixes de elétrons, apresentando valores comparáveis para as energias de 7 e $9 \mathrm{MeV}$. Os valores de $\mathrm{HI}$ indicam heterogeneidade elevada para 3DR e para IORT por raios-X. As duas técnicas apresentam valores comparáveis de $\mathrm{HI}$, explicados pela presença de doses baixas dentro do volume alvo, respectivamente nas extremidades do volume alvo e na região superior ao aplicador, como mostrado nas distribuições de dose.

Os valores de $\mathrm{TCl}$ próximos a 1 obtidos para todas as técnicas de IORT indicam que a isodose de prescrição cobre um volume semelhante ao volume coberto pela isodose de $95 \%$, indicando que as doses altas estão distribuídas por todo o volume alvo. O valor elevado de $\mathrm{HI}$ obtido para 3DR indica que as regiões de doses altas são pequenas relacionadas a totalidade do volume alvo.

Para volume mamário médio, a utilização de IORT através de elétrons apresenta o plano mais adequado, em relação à IORT por raios-X de baixa energia, comparáveis para todas as energias. A energia de $5 \mathrm{MeV}$ apresenta homogeneidade levemente maior em relação à 7 e $9 \mathrm{MeV}$. Os índices indicam tratamentos semelhantes para 3DR e IORT por raios-X para mamas de volume médio, entretanto essa comparação deve ser mais bem avaliada, uma vez que o tratamento através de 3DR apresentado nesse trabalho pode ser otimizado.

\subsubsection{Volume mamário grande}

Na Figura 53, estão apresentados os histogramas dose-volume referentes às técnicas estudas para a geometria de maior volume mamário. 


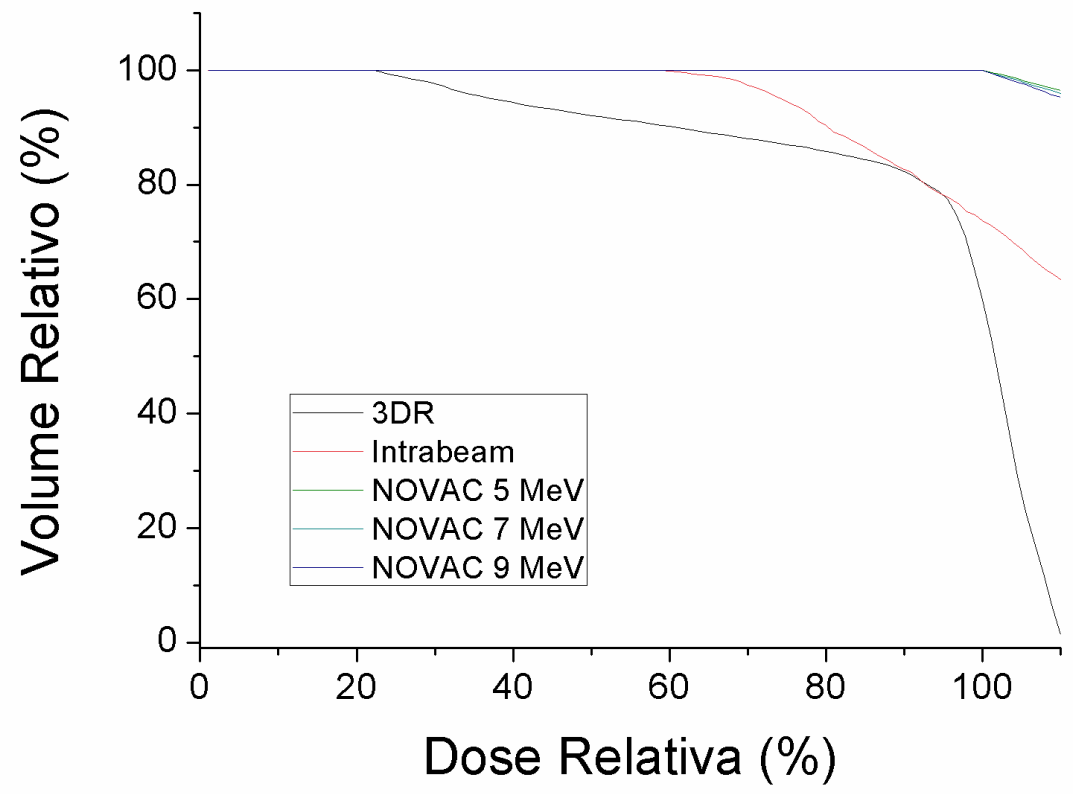

Figura 53: Histograma dose-volume para geometria de volume mamário grande.

Conforme apresentado nos histogramas dose-volume, normalizados para dose de $100 \%$, a melhor cobertura é dada por IORT por elétrons, onde, independentemente da energia, o volume alvo é completamente coberto pela dose de $100 \%$. Em seguida está IORT por raios-X de baixa energia, onde a dose de prescrição é entregue em $73 \%$ do volume alvo. Aproximadamente $60 \%$ do volume alvo é coberto pela isodose de prescrição para 3DR, indicando uma pior cobertura do volume alvo, ocasionada pelas regiões de baixa dose nas extremidades do volume alvo, mostradas nas distribuições de dose da técnica.

Tanto para IORT por raios-X de baixa energia quanto para 3DR, $80 \%$ do volume recebe doses de aproximadamente $92 \%$. Para IORT por feixe de elétrons ocorre um aumento na dose depositada em $80 \%$ do volume, em comparação com as outras técnicas, sendo que, independentemente da energia do feixe, doses maiores que $100 \%$ são depositadas nessa porção do volume alvo.

Os parâmetros de avaliação da qualidade do plano, para mama de volume grande, estão apresentados na Tabela 15.

Tabela 15: parâmetros de avaliação da qualidade do plano para geometria de mama grande.

\begin{tabular}{|l|l|l|l|}
\hline & IC & HI & TCl \\
\hline 3DR & 0,60 & 81,08 & 2,63 \\
\hline IORT Intrabeam & 0,74 & 32,94 & 0,94 \\
\hline IORT NOVAC 5 MeV & 1 & 7,54 & 1,00 \\
\hline IORT NOVAC 7 MeV & 1 & 8,20 & 1,00 \\
\hline IORT NOVAC 9 MeV & 1 & 9,19 & 1,00 \\
\hline
\end{tabular}


Os parâmetros de avaliação do plano foram calculados com base na isodose de prescrição determinada para cada uma das técnicas. Os IC obtidos para todas as energias dos feixes de elétron ocorrem em função da definição de volume alvo utilizada para a técnica, perdendo sua capacidade de comparação. Para 3DR e IORT por raios-X de baixa energia ocorre, em ambas as técnicas, uma baixa conformação entre os volumes alvo e coberto pela isodose de prescrição. Comparando-se as duas técnicas, 3DR e IORT, a melhor conformação entre volume coberto pela isodose de prescrição e volume de tratamento ocorre para IORT, cujo valor está mais próximo de 1.

Os HI apresentam diferenças consideráveis quando todas as técnicas estudadas são comparadas. Os $\mathrm{HI}$ apresentam valores bastante elevados para 3DR e IORT por raios-X de baixa energia. A homogeneidade no tratamento por 3DR é prejudicada devido as regiões de baixa dose nas extremidades da mama. Para IORT a heterogeneidade é causada pela anisotropia da distribuição, que leva à doses menores dentro do volume alvo em regiões acima do centro do aplicador, em direção à pele, e pela presença de doses muito altas na superfície do aplicador. Os feixes de elétrons de IORT apresentaram os menores valores de $\mathrm{HI}$, indicando a melhor homogeneidade entre todas as técnicas estudadas. Entre as diferentes energias dos feixes de elétrons, a distribuição mais homogênea é dada pelo feixe de $5 \mathrm{MeV}$, que apresenta menor valor de HI.

Devido à isodose definida para prescrição, o TCl apresenta valor menor que 1 para IORT por raios-X de baixa energia e maior ou igual a 1 para as outras técnicas. O melhor $\mathrm{TCl}$ deve ter valor próximo a 1, dessa forma, a melhor cobertura do volume alvo ocorre em IORT por feixe de elétrons. Não há diferença significativa entre as diferentes energias da técnica. O TCI encontrado para IORT por raios-X de baixa energia também se aproxima de 1 , indicando que altas doses são entregues em parte considerável do volume. $\mathrm{O}$ alto valor de $\mathrm{TCl}$ referente à 3DR indica que as regiões de altas doses são pequenas em relação ao volume alvo total, como mostrado pelas curvas de isodose da técnica e corroborado pelo histograma dosevolume, que indica menor dose em um mesmo volume quando comparado às outras técnicas.

Para volume mamário grande, os índices indicam um melhor tratamento através de IORT por feixe de elétrons. Não há grande diferenciação entre as energias, apresentando apenas diferenças em seus graus de heterogeneidade. Ao ser considerado o $\mathrm{HI}$ como fator de relevância para a decisão a energia de $5 \mathrm{MeV}$ parece proporcionar um melhor tratamento, dentre os feixes de elétrons. Deve-se ressaltar que os índices para 3DR foram obtidos para um tratamento não otimizado, de forma que a técnica não deve ser excluída como opção de tratamento. 


\section{Conclusões}

Nesse trabalho foram avaliadas as distribuições de dose geradas por feixes de radioterapia intraoperatória obtidas através do método Monte Carlo. Foram estudadas as características dosimétricas dos feixes em condições de referência e as distribuições de dose foram comparadas entre as diferentes técnicas e avaliadas através de parâmetros de avaliação do plano.

O estudo das características dosimétricas dos feixes foi realizado com o objetivo de validar a modelagem adotada no presente trabalho. A comparação dos dados simulados à dados da literatura mostrou, para radioterapia 3D, maiores diferenças na região da periferia dos campos, onde ocorre um aumento característico da dose, quando determinada na profundidade de máxima dose, que aparece subestimado nos dados simulados. Isso se deve à diferenças na fonte de radiação e, possivelmente, na modelagem dos filtros utilizados nos estudos utilizados para comparação. De forma geral, os feixes simulados apresentam perfil e entrega de dose em profundidade comparáveis aos dados da literatura. Para os feixes de radioterapia intraoperatória as maiores diferenças entre simulação e literatura ocorrem em baixas profundidades. Essas diferenças podem ser responsáveis pela área de superdosagem vista nas distribuições para IORT por elétrons, na transição entre tecido mole e ar.

As distribuições de dose demonstram que parte da dose pode ser entregue no tórax da paciente em todas as técnicas estudadas. A entrega de dose no tórax é influenciada pelo tamanho e posicionamento do campo, em radioterapia 3D. Em radioterapia intraoperatória, fatores como posicionamento do aplicador, energia do feixe e volume mamário influenciam na entrega de dose no tórax.

A comparação das diferentes técnicas estudadas mostra distribuições de dose bastante distintas entre as radioterapia intraoperatória com feixe de elétrons, em relação à radioterapia por raios- $X$ de baixa energia. $O$ feixe de elétrons de $5 \mathrm{MeV}$ apresenta resultados levemente melhores em relação às outras energias de feixe de elétrons. Sabe-se, entretanto, que a energia do feixe é escolhida de acordo com a extensão do volume alvo.

Para todas as técnicas de IORT ocorre a entrega de doses elevadas dentro do volume alvo. Essas regiões podem atingir frações consideráveis do volume alvo, em especial para IORT por raios-X de baixa energia, e deve ser cuidadosamente considerada no momento de escolha da técnica de tratamento a ser aplicada.

Os resultados obtidos não permitem afirmar em definitivo qual a melhor técnica para tratamento de tumores de mama, em nenhum dos volumes mamários avaliados. Para isso os tratamentos simulados, em especial através de radioterapia 3D, deveriam ser otimizados e um estudo caso a caso deve ser realizado. 
A importância de se conhecer as distribuições de doses nos volumes do tratamento reside na possibilidade de otimização e personalização do tratamento. Assim, a modelagem dos feixes de radioterapia intraoperatória realizada neste trabalho proporciona a possibilidade de desenvolvimentos de softwares de planejamento nessas técnicas. Além disso, a modelagem da interação desses feixes em geometrias realísticas pode fornecer as informações de distribuições de doses necessárias para que o tratamento seja planejado de forma mais adequada, podendo contribuir para o controle da doença e para a diminuição de efeitos colaterais do tratamento. 


\section{Referências bibliográficas}

Agostinelli, S., Allison, J., Amako, K. A., Apostolakis, J., Araujo, H., Arce, P., et al. (2003). GEANT4-a simulation toolkit. Nuclear instruments and methods in physics research section A: Accelerators, Spectrometers, Detectors and Associated Equipment, 506, pp. 250-306.

Allison, J., Allison, J., Amako, K., Apostolakis, J., Araujo, H. A., Dubois, P. A., et al. (2006). Allison, John, et al. "Geant4 developments and applications. IEEE Transactions on Nuclear Science, 53.1, pp. 270-278.

Baghani, H. R., Aghamiri, S. M., Mahdavi, S. R., Akbari, M. E., \& Mirzaei, H. R. (2015). Comparing the dosimetric characteristics of the electron beam from dedicated intraoperative and conventional radiotherapy accelerators. Journal of Applied Clinical Medical Physics, 16(2), pp. 62-72.

Beddar, A. S., Biggs, P. J., Chang, S., Ezzell, G. A., Faddegon, B. A., Hensley, F. W., et al. (2006). Intraoperative radiation therapy using mobile electron linear accelerators: Report of AAPM Radiation Therapy Committee Task Group No. 72. Medical Physics, 33(5), pp. 1476-1489.

Bielajew, A. F. (2013). History of Monte Carlo. In: J. Seco, \& F. Verhaegen, Monte Carlo Techniques in Radiation Therapy (pp. 3-16). Taylor \& Francis.

Björk, P., Knöös, T., \& Nilsson, P. (2002). Influence of initial electron beam characteristics on Monte Carlo calculated absorbed dose distributions for linear accelerator electron beams. Physics in Medicine and Biology, 47, pp. 4019-4041.

Blake, P. (2007). Clinical Introduction to Brachytherapy. In: P. Mayles, A. Nahum, \& J. C. Rosenwald, Handbook of Radiotherapy Physics Theory and Practice (pp. 1093-1100). Taylor \& Francis Group.

Borges, C., Cunha, G., \& Teixeira, N. (2013). Comparação de diferentes técnicas de irradiação de mama em radioterapia com recurso a acelerador linear em modo de fotões. Saúde $e$ Tecnologia, 9, pp. 33-39.

Bouzid, D., Bert, J., Dupre, P.-F., Benhalousche, S., Pradier, O., Boussion, N., et al. (2015). MonteCarlo dosimetry for intraoperative radiotherapy using a low energy x-ray source. Acta Oncologica, pp. 1-8.

Chen, W.-Z., Xiao, Y., \& Li, J. (2014). Impact of dose calculation algorithm on radiation therapy. World Journal of radiology, 6(11), pp. 874-880.

DRZYMALA, R. E., MOHAN, R., BREWSTER, L., CHU, J., GOITEIN, M., HARMS, W., et al. (1991). DoseVolume Histograms. International Journal of Radiation Oncology, 21, pp. 71-78.

Eaton, D. J., \& Duck, S. (2010). Dosimetry measurements with an intra-operative x-ray device. PHYSICS IN MEDICINE AND BIOLOGY, 55, pp. 359-369. 
Ebert, M. A., \& Carruthers, B. (2003). Dosimetric characteristics of a low-kv intra-operative x-ray source: implications for use in clinical trial for treatment of low-risk breast cancer. Medical Physics, 30(9), pp. 2424-2430.

Eisenhut, J. K. (2012). Comparação entre técnicas de planejamento de mama conformacional 3D, forward IMRT, IMRT híbrido de campos tangenciais e IMRT inverso. Monografia apresentada para Programa de Aprimoramento Profissional, 1-33.

Esposito, E., Anninga, B., Harris, S., Capasso, I., D'Aiuto, M., Rinaldo, M., et al. (2015). Intraoperative radiotherapy in early breast cancer. British Journal of Surgery, 102, pp. 599-610.

Esposito, E., Anninga, B., Honey, I., Ross, G., Rainsbury, D., Laws, S., et al. (2015). Is IORT ready to rollout? Ecancermedicalscience, 9, pp. 1-8.

Faddegon, B. (2005). Monte Carlo method of x-ray and electron beam simulation. In C. Ma, B. Faddegon, \& B. Curran, Monte Carlo for Radiotherapy I: Source Modelling and beam commissioning for Monte Carlo treatment planning (pp. 1-3). AAPM 2005 education Course.

Faddegon, B. A., Kawrakow, I., Kubyshin, Y., Perl, J., Sempau, J., \& Urban, L. (2009). The accuracy of egsnrc, Geant4 and PENELOPE Monte Carlo systems for simulation of electron scatter in external beam radiotherapy. Physics in Medicine and Biology, 54, pp. 6151-6163.

FEUVRET, L., NOËL, G., MAZERON, J.-J., \& BEY, P. (2006). CONFORMITY INDEX: A REVIEW. International Journal of Radiation Oncology, 64(2), pp. 333-342.

Fippel, M. (2013). Basics of Monte Carlo Simulations. In: J. Seco, \& F. Verhaegen, Monte Carlo Techniques in Radiation Therapy (pp. 17-28). Francis \& Taylor.

Fraass, B. A. (1995). The development of conformal radiation therapy. Medical Physics, 11(22), pp. 1911-1921.

Hill, R., Healy, B., Holloway, L., Kunic, Z., Thwaites, D., \& Baldock, C. (2014). Advances in kilovoltage xray beam dosimetry. Physics in Medicine and Biology, 59, pp. 183-231.

INCA. (2016). Estimativa 2016 - Incidência de Câncer no Brasil. Rio de Janeiro: Instituto Nacional de Câncer José Alencar Gomes da Silva.

INCA. (2017). Estimativa 2018 - Incidência de Câncer no Brasil. Rio de Janeiro: Ministério da Saúde Instituto Nacional do Câncer José Alencar Gomes da Silva.

Johnstone, P., Sindelar, W., \& Kinsella, T. (1994). Experimental and clinical studies of intraoperative radiation therapy. Current problems in cancer, 18.5, pp. 254-290.

Kawarow, I. (2000). Accurate condensed history Monte Carlo simulation of electron transport: 1. Egsnrc, the new EGS4 version. Medical Physics, 27, pp. 485-498.

Kawrakow, I. (2000). Accurate condensed history Monte Carlo simulation of electron transport: 2. Application to ion chamber response simulation. Medical Physics, 27, pp. 499-513. 
Lamanna, E., Gallo, A., Russo, F., Brancaccio, R., Soriani, A., \& Strigari, L. (2012). Intra-Operative Radiotherapy with Electron Beam. In: G. Natanasabapathi, Modern Practices in Radiation Therapy (pp. 145-168). Intech.

Lopes, J. M. (2013). Avaliação de filtros físicos modificadores de curvas de isodose usados em aceleradores radioterápicos. Dissertação de Mestrado, 101. Rio de Janeiro: UFRJ/COPPE.

Lowe, S. W., Cepero, E., \& G., E. (2004). Intrinsic tumour suppression. Nature, 432, pp. 307-315.

Malhotra, G. K., Zhao, X., Band, H., \& Band, V. (2010). Histological, molecular and functional subtypes of breast cancer. Cancer Biology \& Therapy, 10(10), pp. 955-960.

MARTA, G. N., HANNA, S. A., MARTELLA, E., SILVA, J. L., \& CARVALHO, H. A. (2011). Câncer de mama estádio inicial e radioterapia: atualização. Revista da Associação Médica Brasileira, 57(4).

Marta, G. N., Hanna, S. A., Martella, E., Silva, J. L., \& Carvalho, H. D. (2011). Câncer de mama estádio inicial e radioterapia: atualização. Revista da Associação Médica Brasileira, 57(4), pp. 468474.

Massagué, J. (2004). G1 cell-cycle control and cancer. Nature, 432, pp. 298-306.

Mcghee, D. E. (2011). Breast Volume and Bra Size. International Journal of Clothing Science and Technology, 23(5), pp. 351-360.

Mendes, B., \& Casarin, R. (Outubro de 2016). O doutor da mulher. Aventuras na História, pp. 33-39.

Mihailescu, D., \& Borcia, C. (2014). MONTE CARLO SIMULATION OF THE ELECTRON BEAMS. Romanian Reports in Physics, 66(1), pp. 61-74.

Nairz, O., Deutschmann, H., Kopp, M., Wurstbauer, K., Kametriser, G., Fastner, G., et al. (2006). A Dosimetric Comparison of IORT Techniques in Limited-Stage Breast Cancer. Strahlentherapie und Onkologie(108), pp. 342-348.

Njeh, C. F., Saunder, M. W., \& Langton, C. M. (2010). Accelerated Partial Breast Irradiation (APBI): a review of available techniques. Radiation Oncology, 90, pp. 1-28.

Nwankwo, O., Clausen, S., Schneider, F., \& Wenz, F. (2013). A virtual source model of a kilo-voltage radiotherapy device. Physics in Medicine and Biology, 58, pp. 2363-2375.

OPREA, M., CONSTANTIN, C., MIHAILESCU, D., \& Borcia, C. (2012). A MONTE CARLO INVESTIGATION OF THE INFLUENCE OF INITIAL ELECTRON BEAM CHARACTERISTICS ON THE ABSORBED DOSE DISTRIBUTIONS OBTAINED WITH A 9 MEV IORT ACCELERATOR. UPB Scientific Bulletin, 74(4), pp. 153-166.

Paddick, I. (2000). A simple scoring ratio to index the conformity of radiosurgical treatment plans. Journal of Neurosurgery, 93, pp. 219-222.

Park, M.-T., \& Lee, S.-J. (2003). Cell Cycle and Cancer. Journal of Biochemistry and Molecular Biology, $36(1)$, pp. $60-65$. 
Pedraza-Fariña, L. G. (2006). Mechanisms of Oncogenic Cooperation in Cancer Initiation and Metastasis. Yale Journal of Biology and Medicine, 79, pp. 95-103.

Pimpinella, M., Mihailescu, D., Guerra, A. S., \& Laitano, R. F. (2007). Dosimetric characteristics of electron beams produced. PHYSICS IN MEDICINE AND BIOLOGY, 52, pp. 6197-6214.

Polgár, C., Limbergen, E. V., Pötter, R., Kovács, G., Polo, A., Lyczek, J., et al. (2010). Patient selection for accelerated partial-breast irradiation (APBI) after breast-conserving surgery: Recommendations of the GEC-ESTRO breast cancer working group based on clinical evidence (2009). Radiotherapy and Oncology, 94, pp. 264-273.

Popolin, C. (2016). Efeitos antitumorais e antimetastáticos de novos complexos de rutênio em células de câncer de mama. Dissertação de Mestrado, 66. São Carlos: ufscar/UNESP.

Purdy, J. A., Poortmans, P., \& Perez, C. A. (2012). Three-Dimensional Treatment Planning and Conformal Therapy. In: S. H. Levitt, J. A. Purdy, P. Poortmans, \& C. A. Perez, Technical Basis of Radiation Therapy Practical Clinical Applications (pp. 253-274). Springer.

Rastogi, M., Revannasiddaiah, S., Gupta, M. K., Seam, R. K., Thakur, P., \& M., G. (2012). When Palliative Treatment Achieves More Than Palliation: Instances of Long-term Survival after Palliative Radiotherapy. Indian Journal of Palliative Care, 18(2), pp. 117-121.

Salvajoli, J. V., Souhami, L., \& Faria, S. L. (2013). Radioterapia em Oncologia (2 ed.). Atheneu.

Salvat, F., Fernandéz-Varea, J. M., \& Sempau, J. (2008). PENELOPE-2008: A Code System for Monte Carlo Simulation of Electron and Photon Transport. Barcelona.

Salvat, F., Fernandez-Varea, J., Sempau, J., \& Llovet, X. (2006). PENELOPE-2006, A code system for Monte Carlo simulation of electron and photon transport. Nuclear Energy Agency.

Schleger, W. (2006). New Technologies in 3D Conformal Radiation Therapy: Introduction and Overview. In: W. Schlegel, T. Bortfeld, \& A.-L. Grosu, New Technologies in Radiation Oncology (pp. 1-6). Springer.

Sempau, J., Fernandez-Varea, J. M., Acosta, E., \& Salvat, F. (2003). Experimental benchmarks of the Monte Carlo code PENELOPE. Nuclear Instruments and Methods in Physics Research, 207, pp. 107-123.

Sempau, J., Sánchez-Reyes, A., Salvat, F., Oulad ben Tahar, H., Jiang, S. B., \& Fernández-Varea, J. M. (2001). Monte Carlo simulation of electron beams from an accelerator head using PENELOPE. Physics in Medicine and Biology, 46, pp. 1163-1186.

Sheikh-Bagheri, D., \& Rogers, D. (2002). Monte Carlo calculation of nine megavoltage photon beam spectra using the BEAM code. Medical Physics, 29(3), pp. 391-402.

Urbach, D., Lupien, M., Karagas, M. R., \& Moore, J. H. (2012). Cancer heterogeneity: origins and implications for genetic association studies. Trends in Genetics, 28(11), pp. 538-543.

Vaidya, J., Tobias, J., Baum, M., Keshtgar, M., Joseph, D., Wenz, F., et al. (2004). Intraoperative radiotherapy for breast cancer. The Lancet Oncology, 5, pp. 165-173. 
Vaidya, J., Wenz, F., Bulsara, M., Tobias, J., Joseph, D., Keshtgar, M., et al. (2014). Risk-adapted targeted intraoperative radiotherapy versus whole-breast radiotherapy for breast cancer: 5year resultsnfor local control and overall survival from the TARGIT-A randomised trial. Lancet, 383, pp. 603-613.

Valdivieso-Casique, M., Rodríguez, R., Rodríguez-Bescós, S., Lardíes, D., Guerra, P., Ledesma, M., et al. (2015). RADIANCE-A planning software for intra-operative radiation therapy. Translational Cancer Research, 4(2), pp. 196-209.

Veronesi, U., Orecchia, R., Maisonneuve, P., Viale, G., Rotmensz, N., Sangali, C., et al. (2013). Intraoperative radiotherapy versus external radiotherapy for early breast cancer (ELIOT): a randomised controlled equivalence trial. The lancet oncology, 14(13), pp. 1269-1277.

Veronesi, U., Orecchia, R., Maisonneuve, P., Viale, G., Rotmensz, N., Sangalli, C., et al. (2013). Intraoperative radiotherapy versus external radiotherapy for early breast cancer (ELIOT): a randomised controlled equivalence trial. Lancet Oncology, 14, pp. 1269-1277.

Watson, P. G., \& Seuntjens, J. (2016). Technical Note: Effect of explicit M and N-shell atomic transitions. Medical Physics, 43(4), pp. 1760-1763.

White, J. (2016). APBI: History, Rationale, and Controversies. In: D. W. Arthur, F. A. Vicini, D. E. Wazer, \& A. J. Khan, Short Course Breast A Comprehensive Review of (pp. 3-22). Springer.

Yanch, J. C., \& Harte, K. J. (1996). Monte Carlo simulation of a miniature, radiosurgery x-ray tube using the ITS 3.0. Medical Physics, 23(9), pp. 1551-1558.

Yanch, J. C., \& Harte, K. J. (1996). Monte Carlo simulation of a miniature, radiosurgery x-ray tube using the ITS 3.0 coupled electron-photon transport code. Medical Physics, 23(9).

Yoder, B. J., Wilkinson, E. J., \& Massoll, N. A. (s.d.). Molecular and Morphologic Distinctions between Infiltrating Ductal and Lobular Carcinoma of the Breast. The Breast Journal, 13(2), pp. 172179.

Yoon, M., Park, S. Y., Shin, D., Lee, S. B., I Pyo, H. R., Kim, D. Y., et al. (2007). A new homogeneity index based on statistical analysis of the dose-volume histogram. JOURNAL OF APPLIED CLINICAL MEDICAL PHYSICS, 8, pp. 9-17.

Zhang, L., Zhou, Z., Mei, X., Yang, Z., Ma, J., Chen, X., et al. (2015). Intraoperative Radiotherapy Versus Whole-Breast External A Systematic Review and Meta-Analysis. Medicine, 94(27), pp. 1-8. 